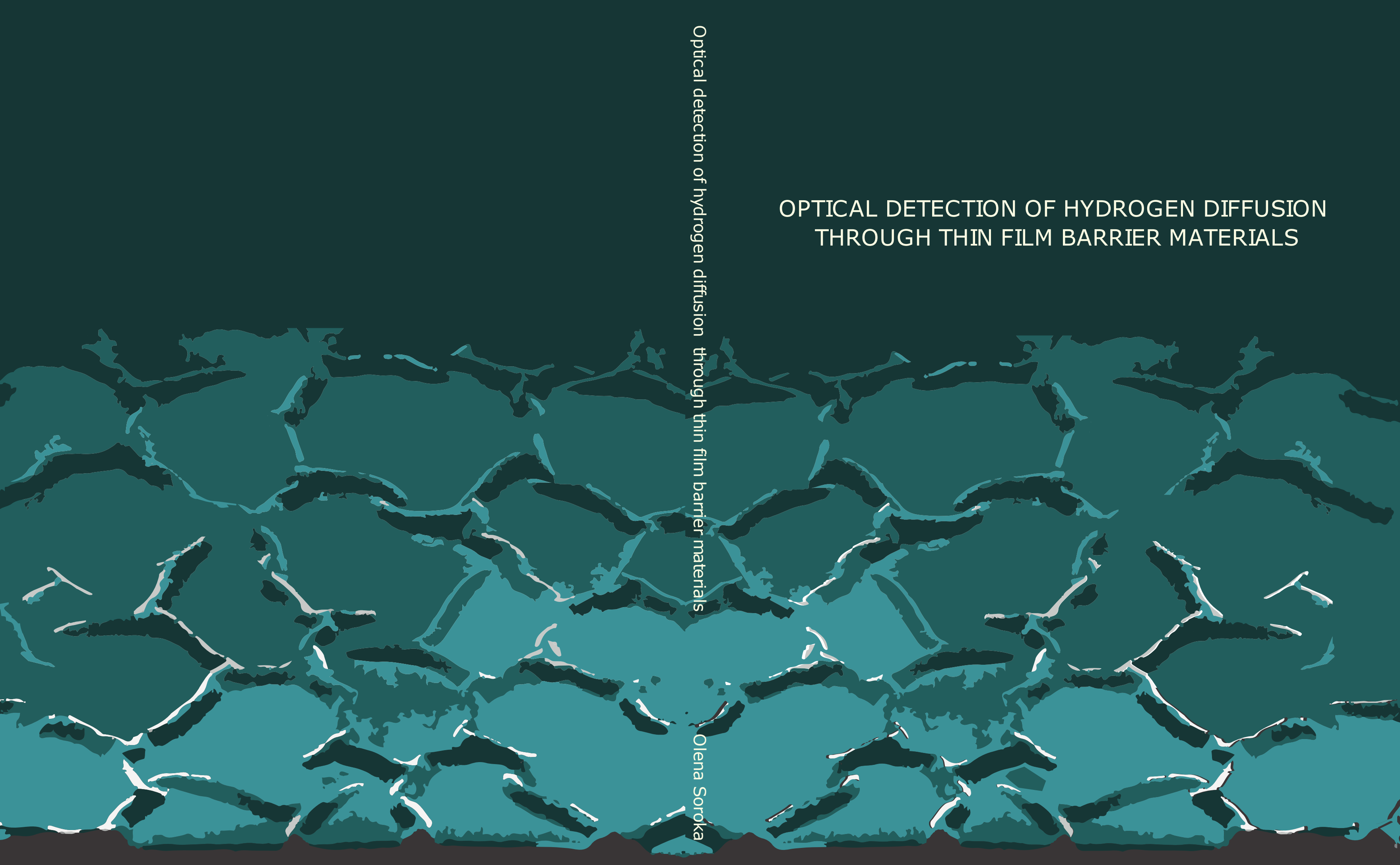

Olena Soroka 


\section{OPTICAL DETECTION OF HYDROGEN DIFFUSION THROUGH THIN FILM BARRIER MATERIALS}

Olena Soroka 



\title{
OPTICAL DETECTION \\ OF HYDROGEN DIFFUSION \\ THROUGH THIN FILM BARRIER MATERIALS
}

\section{DISSERTATION}

\author{
to obtain \\ the degree of doctor at the University of Twente, \\ on the authority of the rector magnificus, \\ prof. dr. T.T.M. Palstra, \\ on account of the decision of the Doctorate Board, \\ to be publicly defended \\ on Thursday the $26^{\text {th }}$ of November 2020 at 12.45 hours
}

by

\section{Olena Soroka}

born on the $30^{\text {th }}$ of June 1989 in Chernihiv, USSR 
This dissertation has been approved by:

Supervisor: $\quad$ Prof. dr. F. Bijkerk

Co-supervisor: $\quad$ Dr. ir. J.M. Sturm

Cover design: $\quad$ by Daria Sharykina

ISBN: $\quad$ 978-90-365-5078-9

DOI: $\quad 10.3990 / 1.9789036550789$

(C) 2020 Olena Soroka, The Netherlands.

All rights reserved. No parts of this thesis may be reproduced, stored in a retrieval system or transmitted in any form or by any means without permission of the author. Alle rechten voorbehouden. Niets uit deze uitgave mag worden vermenigvuldigd, in enige vorm of op enige wijze, zonder voorafgaande schriftelijke toestemming van de auteur. 


\section{Graduation Committee}

Chairman/secretary

Prof. dr. J.L. Herek

University of Twente

Supervisor

Prof. dr. F. Bijkerk

University of Twente

Co-supervisor

Dr. ir. J.M. Sturm

University of Twente

Committee Members:

Prof. dr. E. Brück

Delft University of Technology

Prof. dr. B. Dam

Delft University of Technology

Prof. dr. P.E. De Jongh

Utrecht University

Prof. dr. ir. M. Huijben

University of Twente

Prof. dr. ir. A. Nijmeijer

University of Twente 



\section{This thesis is based on the following publications:}

Chapter 2:

O. Soroka, J.M. Sturm, R.W.E. van de Kruijs, I.A. Makhotkin, K. Nikolaev, S.N. Yakunin, C.J. Lee, F. Bijkerk, "Hydrogenation dynamics of Ru capped Y thin films," J. Appl. Phys., vol. 126, no. 14, p. 145301, Oct. 2019.

Chapter 3:

O. Soroka, J. M. Sturm, R. W. E. van de Kruijs, C. J. Lee, and F. Bijkerk, "Control of $\mathrm{YH}_{3}$ formation and stability via hydrogen surface adsorption and desorption," Appl. Surf. Sci., vol. 455, pp. 70-74, Oct. 2018

Chapter 4:

O. Soroka, J. M. Sturm, C. J. Lee, H. Schreuders, B. Dam, and F. Bijkerk, "Hydrogen diffusion through Ru thin films," Int. J. Hydrogen Energy, vol 45, issue 29, pp. 15003-15010, May 2020.

Chapter 5:

O. Soroka, J. M. Sturm, C. J. Lee, and F. Bijkerk, "Comparative H diffusion measurement through metal and non-metal nano-layers using optical sensing," $J$. Phys. D: Appl. Phys., vol. 53, no 38, p. 385302, Sep 2020

\section{Patents:}

J.M. Sturm, O. Soroka, "Optisches Element mit einem Wasserstoff-Desorptionsmaterial", DE102017222690A1

D.H. Ehm, C.J. Lee, C. Nottbohm, O. Soroka, "Reflektives optisches Element fur die EUV-Lithographie, Wasserstoffplasma-Sensor und EUV-Lithographiesystem damit", DE102017205885A1

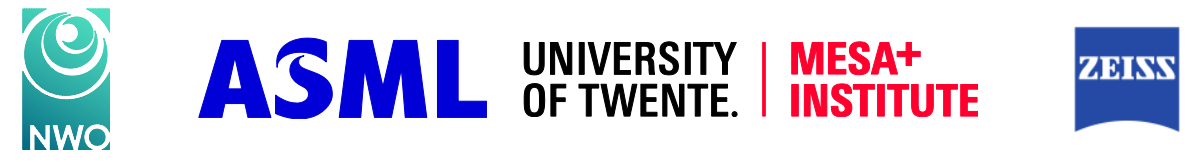

This work is part of the research programme with project number 13323, which is financed by the Netherlands Organisation for Scientific Research (NWO) and Carl Zeiss SMT. We acknowledge the support of the industrial partners ASML, Malvern Panalytical, and the Province of Overijssel through the Industrial Focus Group XUV Optics at the MESA+ Institute for Nanotechnology, University of Twente. 



\section{Contents}

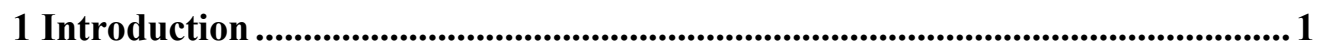

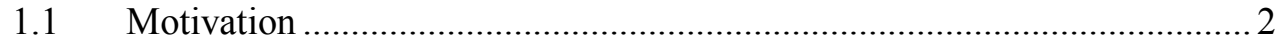

1.1.1 Techniques for measurement of hydrogen in solids ........................... 4

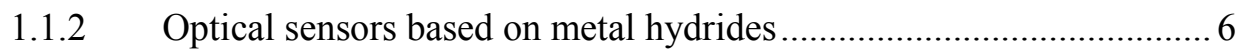

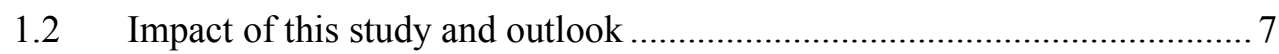

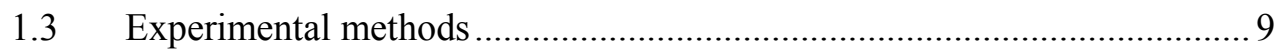

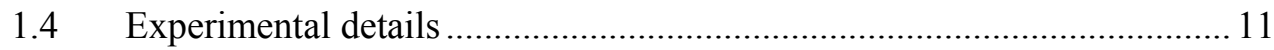

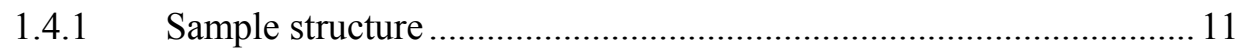

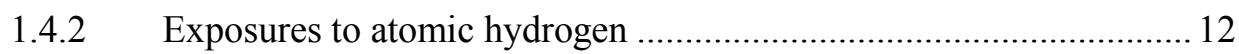

1.4.3 Transmission and ellipsometry measurements .................................. 13

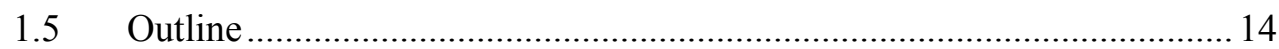

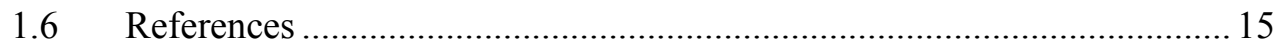

2 Hydrogenation dynamics of Ru capped $Y$ thin films ....................................... 19

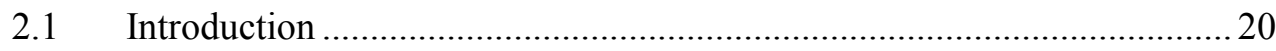

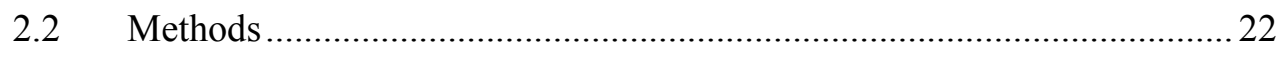

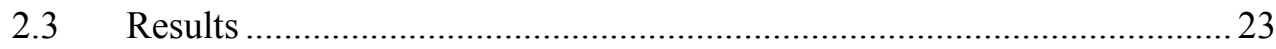

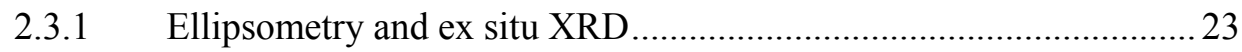

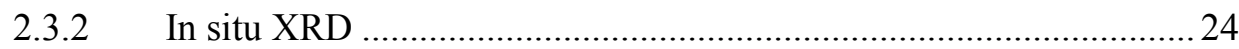

2.3.3 Ellipsometry modelling .............................................................. 28

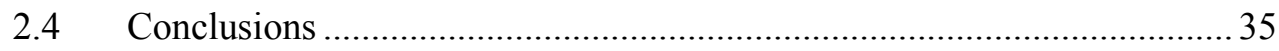

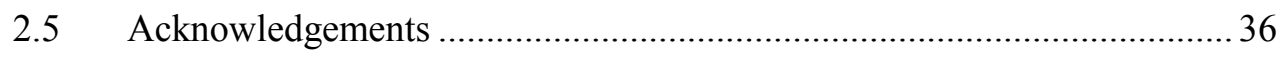

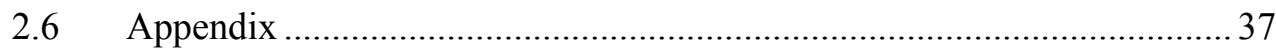

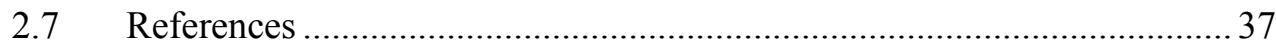

3 Control of YH3 formation and stability via hydrogen surface adsorption and

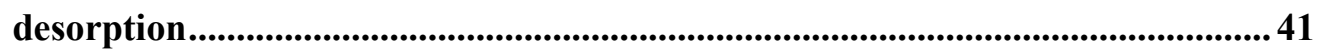




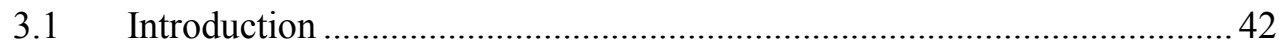

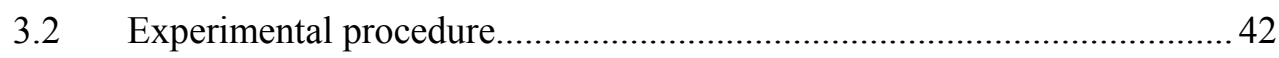

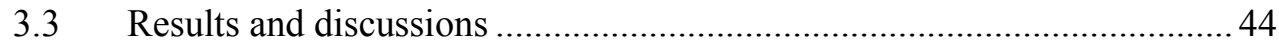

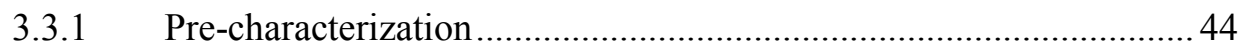

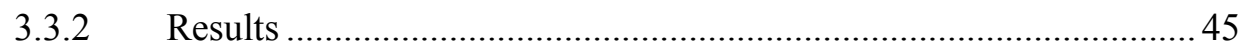

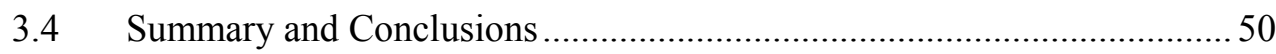

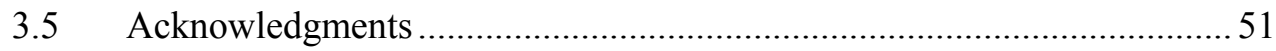

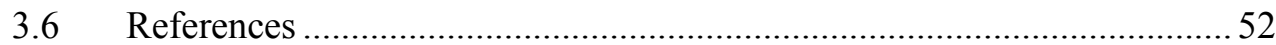

4 Hydrogen diffusion through Ru thin films..............................................................55

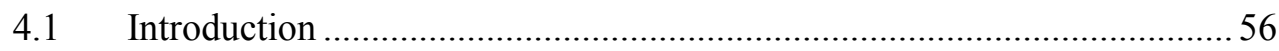

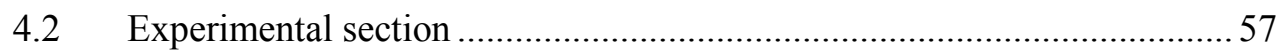

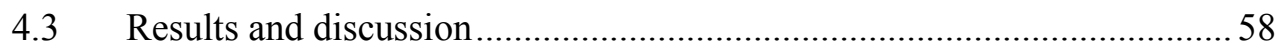

4.3.1 Limiting processes for the hydrogenation rate .................................5 58

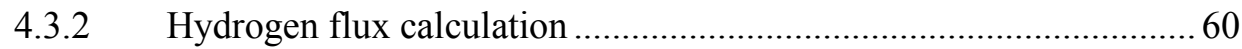

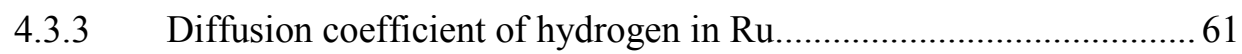

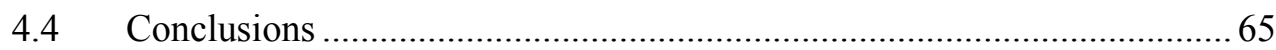

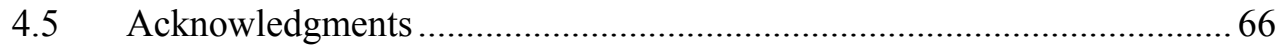

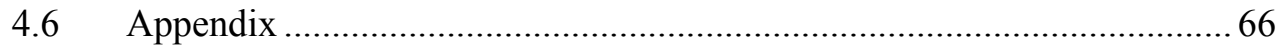

4.6.1 The initial loading of $\mathrm{Pd} / \mathrm{Ru} / \mathrm{Y}$ and $\mathrm{Pd} / \mathrm{Y}$ stacks.................................66

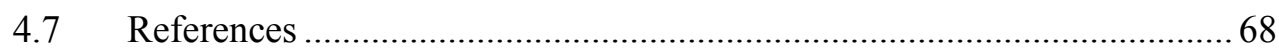

5 Comparative $H$ diffusion measurement through metal and non-metal nanolayers using optical sensing................................................................................................. 73

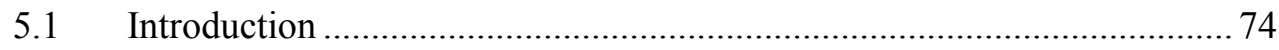

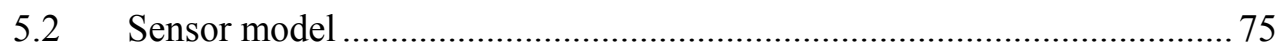

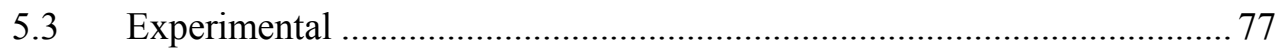

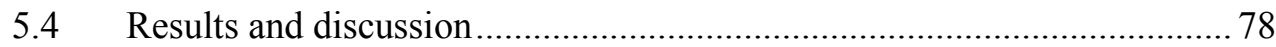

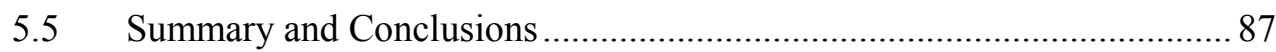

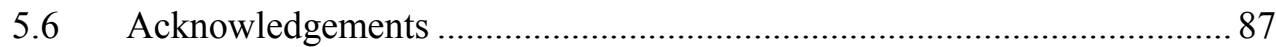

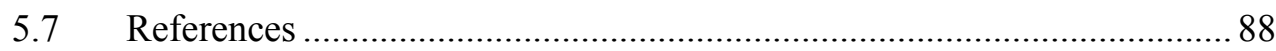

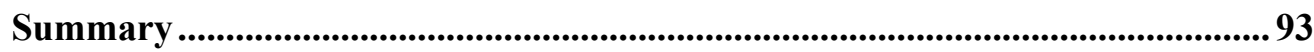

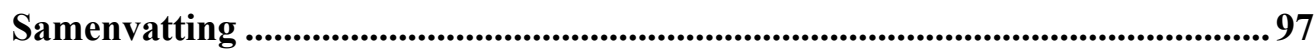


Acknowledgements.

About the author 

1

\section{Introduction}




\subsection{Motivation}

Diffusion processes are present in every field of nature, from the atmosphere of stars to the inside of cells. Diffusion happens when there is an excess of particles in one area compared to the immediate neighborhood. Despite the huge variety of diffusion processes, they are nearly universally described by either Fick's laws or a random walk of the diffusing particles, because of the similarity of the underlying physics.

Diffusion was found to play an important role in many industrial processes, and should be accounted for in, for example, transistor manufacturing [1], drug delivery optimization [2], and hydrogen storage cell designing [3]. Many studies confirmed that diffusion has a significant influence on processes where gases interact with other forms of matter, which can result in the aging of materials: rust and other forms of corrosion [4], for instance. In this thesis, we investigate hydrogen diffusion into solids, which has applications in the oil and gas industry, as well as space, fusion and photolithography. Hydrogen, as described below, may be especially problematic, because it can penetrate deeply into many solid materials, significantly altering their properties.

Hydrogen diffusivity and solubility in solids is the highest among gases and is comparable to ion diffusion in liquids. A comparison of the diffusion coefficient of $\mathrm{H}$ to that of other light elements in niobium is shown in Figure 1.1. Due to the small size of the $\mathrm{H}$ atom, it can travel via the interstitial sites, unlike other atoms that usually diffuse via lattice defects or vacancies. In addition, hydrogen has an intermediate value of electronegativity relative to other elements, which allows it to form chemical compounds with a wide range of elements [5].

Hydrogen can dissolve in metals and other materials exo- or endothermically. In the first case, a hydride is formed, which can be accompanied by various phase transitions, since properties, such as crystal structure and electric conductivity, depend on the chemical state of the hydride [6]. In the case of endothermal dissolution, bubbles of pressurized hydrogen can form in materials [6]. In both cases, high lattice strains can emerge in bulk materials, lowering the material's durability and mechanical resistance. This can lead to early failure of metal components that function under extremely demanding conditions, which is accompanied by crack formation and/or powderizing. Changes in material strength due to hydrogen absorption is known as hydrogen embrittlement [7]. It is, as the name suggests, generally unfavorable, and a lot of studies have been conducted 
to understand the embrittlement mechanism, aiming to mitigate or prevent it altogether $[3,4]$.

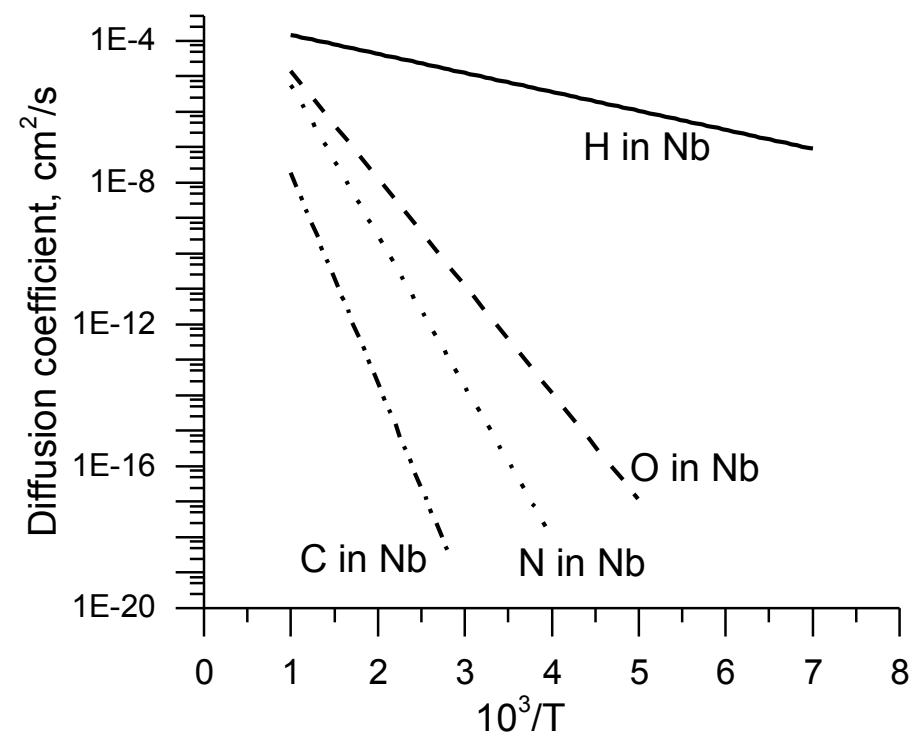

Figure 1.1. Comparison of temperature dependences of the diffusion coefficients of $H$, $O, N$ and $C$ in $\mathrm{Nb}$ (data for hydrogen is taken from Fukai [5] and for other elements from Ang [9]).

In 1996 Huiberts et al. [10] found that thin rare-earth metal films exhibit a metalto-dielectric transition upon hydrogenation without breaking or turning into a powder, contrary to the behavior of bulk materials. This finding made it simple to measure the electrical and optical properties of high stoichiometry hydrides in forms that were interesting for application. Such hydride films found application in hydrogen sensing [11]-[13]. Nowadays, many optical and electrochemical hydrogen sensors are based on thin films or nanostructures of $\mathrm{H}$ sensitive metals (Pd, Y, Mg) or metal alloys (for instance, Pd- [14] and Mg-based [15]). Thin films and nanostructures also found application in hydrogen storage, as the limited thickness of a metal film shortens the hydrogen loading/unloading times [7]. For this purpose the evaluation of hydrogen mobility in thin films should be accessible in both in-plane and normal directions to the film growth direction. Along with applications that promote hydrogen absorption and mobility in metals, shielding operational parts from $\mathrm{H}$ embrittlement is essential as well [16][18]. 
Numerous experimental and theoretical studies of metal hydrides demonstrate the possible applications in different fields. For instance, studies showed that high-hydrogen content hydrides are expected to exhibit novel superconductor properties [19]. Nonetheless, the most prominent application of metals and metal alloys with high $\mathrm{H}$ absorption is hydrogen storage for energy applications, since the hydrogen concentration in some metal hydrides may exceed the hydrogen concentration in liquid $\mathrm{H}_{2}$ : with about $150 \mathrm{~kg} \mathrm{H}_{2} / \mathrm{m}^{3}$ for metal hydrides compared to $71 \mathrm{~kg} \mathrm{H}_{2} / \mathrm{m}^{3}$ for liquid $\mathrm{H}_{2}$. A comparison of the hydrogen content in some of the material types used for hydrogen storage can be found, for example, in [3].

High hydrogen mobility in metals, while being highly favorable in the mentioned applications, is undesirable for materials that should be in long-time contact with hydrogen gas, especially at high pressures and/or temperatures. For example, nuclear fusion reactors contain a highly reactive hydrogen plasma at elevated temperatures. $\mathrm{H}$ isotopes tend to chemisorb, dissolve and react with the plasmafacing materials of the reactor, which leads to corrosion of the wall material. Codeposition of $\mathrm{H}$ isotopes with wall materials (especially $\mathrm{C}$ ) leads to $\mathrm{H}$ retention, which limits the operation time of the reactor due to safety considerations [20]. Another example of undesired hydrogen influence is extreme ultraviolet (XUV) lithography. Hydrogen is used as a buffer gas and cleaning agent in XUV lithography tools. The multilayer mirrors for XUV light may, in principle, degrade due to interaction with hydrogen ions and radicals formed in the XUV induced plasma $[9,10]$. To find a resistant material that can be used as a barrier, a number of studies focused on hydrogen solution and diffusion in bulk materials [11-13].

One of the ways to protect materials from hydrogen is to put a (thin) protective layer over the top surface to prevent hydrogen adsorption and diffusion into the material. This requires understanding the differences between hydrogen kinetics and thermodynamics in thin films and in bulk materials.

\subsubsection{Techniques for measurement of hydrogen in solids}

Due to high solubility of hydrogen in metals, hydrogen-metal systems have been consistently studied since the discovery of high $\mathrm{H}$ absorptive properties of $\mathrm{Pd}$ in 1866 by Graham [25]. His discovery triggered an avalanche of systematic investigation of hydrogen-metal interaction.

Depending on the specimen form, conditions of exposure to hydrogen (hydrogen source, temperature, pressure, and exposure time), and the parameters of interest 
(H diffusivity, solubility, enthalpy of absorption etc.), different techniques can be used for the assessment of hydrogen-solid systems. In this section, we describe some of the most used techniques that are currently available. As described here, these techniques have limitations and are not suitable for studying hydrogen diffusion across thin films with low hydrogen permeation, a case which is essential for hydrogen barrier applications.

Early studies used Sievert's method (so-called volumetry), in which H dissolution is measured by the change of $\mathrm{H}_{2}$ pressure over the sample's metal surface or the change of the sample mass. These types of experiments required high temperatures and/or high $\mathrm{H}_{2}$ pressures to reach measurable quantities of dissolved hydrogen, as well as macroscopic sample sizes. Most of the tabulated thermodynamic parameters (enthalpy and entropy) of formation of binary H-metal systems were measured using volumetry.

While Sievert's method measures hydrogen uptake under steady-state conditions, transport of hydrogen through materials is an important topic as well. One of the approaches to measure hydrogen transport through materials is the socalled membranes permeation technique. By measuring the pressure difference over the membrane and the hydrogen flux on the low pressure side of the membrane, the permeation of hydrogen in the membrane material can be determined. Pd-based membranes - used for hydrogen separation since the 1960s-have been well studied over the last decades [26]. The hydrogen permeation through a material depends on the kinetic processes that the $\mathrm{H}$ atom undergoes during transport (i.e. $\mathrm{H}_{2}$ dissociation, surface-to-bulk diffusion, diffusion and solution in the bulk of a membrane). As experiments show, $\mathrm{H}_{2}$ dissociation is often a limiting factor for permeation, as in the example of a Pd membrane at room temperature. When the purpose of an experiment is measurement of bulk diffusion properties, it is important to tune the membrane properties in such a way that the measured transport characteristics reflect bulk diffusion processes. For this, either the influence of dissociation on the overall kinetics is mitigated by increasing the temperature or the diffusion kinetics are slowed by choosing thicker (micrometer scale) films.

A thermal desorption spectroscopy technique, similar to volumetry, is also used for hydrogen diffusivity measurements [27]. It allows the binding energy of hydrogen to sample atoms to be measured by gradually heating up the hydrogenated sample. 
Ion-beam techniques, such as elastic recoil detection analysis (ERDA) and nuclear reaction analysis (NRA), are used for absolute hydrogen concentration measurements and hydrogen profiling in films [28]. Both techniques use the interaction between the ion beam and sample atoms to identify the sample atoms. A comparison of these techniques is given in [29]. ERDA, is similar to Rutherford back scattering spectroscopy, and was developed specifically for light element detection. An $\mathrm{MeV}$ range ion beam bombards the sample surface and sputters sample atoms towards a detector. The number and energy of detected atoms depends on the energy and mass of the incident ions, the angle of incidence, and the mass of removed (recoiled) atoms. In addition, ERDA allows the depth profile of several elements to be measured simultaneously with a precision down to approximately $10 \mathrm{~nm}$. NRA, uses a nuclear reaction between $\mathrm{N}$ (or F, or Li) ions with hydrogen ions (protons) and measures the yield of emitted $\gamma$-rays, which is proportional to the hydrogen concentration at the probed depth. The incoming ions lose energy as they traverse the sample, therefore, the reaction will only occur at a narrow depth range. By varying the incoming particle energy, a depth profile with high resolution can be constructed. The operational requirements of ERDA and NRA do not allow in situ measurements except under ultra-high vacuum conditions. Moreover, due to the high cost of the required equipment, access to ERDA and NRA techniques is limited.

The described techniques operate either at high pressures and/or temperatures or in high vacuum conditions, which are not compatible for applications such as XUV lithography or nuclear fusion. A technique that can be applied to materials with low hydrogen diffusivity at moderate hydrogen pressures is required. Furthermore, in situ measurements are highly desirable, since some hydrides are not stable, and post analysis would not detect their formation.

\subsubsection{Optical sensors based on metal hydrides}

The necessity to monitor hydrogen gas concentration as part of gas sensing or hydrogen safety systems resulted in scientific and technological interest in a wide variety of sensor designs, some of which can be transferred to sensing hydrogen in solids. For an overview of $\mathrm{H}_{2}$ sensing techniques, see Hübert et al. [30]. Here, the focus will be on optical sensors. Such sensors measure the change in optical reflectivity or absorbance of a sensing element when it reacts with hydrogen. Most optical sensors are based around a material, for which Pd is a common choice $[20,21]$, that changes its optical properties due to hydrogen absorption. 
After the discovery of metal-insulator switching in $\mathrm{Y}$ and La thin films upon hydrogen uptake [10], thin layers of rare earth metals have attracted attention. The optical changes, though all due to variation in electronic properties, can be based on different mechanisms. The dielectric function of some metals (for instance, $\mathrm{Pd}, \mathrm{Y}, \mathrm{La}, \mathrm{Mg}$ ) undergoes significant changes when metal hydrides form. This was employed in $\mathrm{Y}$ and $\mathrm{La}$ to create switchable mirrors. Plasmonic metals, such as $\mathrm{Pd}$ and $\mathrm{YH}_{2}$, enable a hydrogen induced shift of (local) surface plasmon resonance to be detected [22, 23]. Optical sensors for hydrogen have advantages over other types of sensors. They can be small in size, are unaffected by electromagnetic interference and require no electrical connections in potentially explosive hydrogen containing environments [30]. Moreover, they can easily operate in situ, which is beneficial for measurements of hydrogen kinetics.

\subsection{Impact of this study and outlook}

In this thesis, the lack of an adequate measurement technique of hydrogen transport in materials suited for $\mathrm{H}$ barrier applications is addressed. A hydrogen sensor, based on a Y sensing layer, is adopted for hydrogen diffusion measurements through thin films deposited on top of the Y film. This work discusses processes that impede hydrogen transport through nanometer-thick films and, therefore, control the kinetics of the hydrogenation. The results presented in this thesis show that, for thin films, the kinetics of hydrogen transport is often limited by surface processes, rather than by diffusion through the film. Surface processes limiting hydrogen uptake include dissociative adsorption (in case of molecular hydrogen exposure), recombinative desorption of hydrogen atoms adsorbed on the surface as molecular $\mathrm{H}_{2}$ and Eley-Rideal reactions of incoming $\mathrm{H}$ radical species with surface hydrogen, resulting in desorption of $\mathrm{H}_{2}$ (in the case of atomic $\mathrm{H}$ exposure) [34]. In addition, the presence of surface contamination may lead to changes in the kinetics of these processes and/or give rise to additional reactions of hydrogen species with contaminant species. This finding has two important implications for hydrogen barrier materials. First of all, the protective properties of a material applied as coating on the outermost surface of a material or layer stack to be protected against hydrogen, will not only depend on its bulk diffusion properties for hydrogen, but also on its surface properties. A stable $\mathrm{YH}_{3}$ phase was obtained due to the unique properties of the Ru surface, which allowed a Y-based $\mathrm{H}$ sensor to be characterized over the whole range of $\mathrm{H}$ concentrations, 
as described in chapter 2. In chapter 3, the impact of hydrogen desorption on hydrogenation is discussed. Secondly, when the in-depth diffusion properties of a thin film are to be measured, the hydrogenation conditions and/or layer stack should be chosen such that surface processes are not the limiting transport process. Taking into account these considerations, chapters 4 and 5 show studies of hydrogen diffusion through $\mathrm{Ru}$ and other potential barrier materials employing layer stacks and hydrogenation conditions that make sure that $\mathrm{H}$ diffusion through the test material is the limiting factor.

Optical sensing of hydrogen based on hydrogenation of transition metals is mostly employed in the form of transmission measurements, which require transparent substrates. Chapter 2 reports on the development of an ellipsometry model that allows the hydrogen concentration in $\mathrm{Y}$ to be estimated via reflection, eliminating the requirement for transparency.

In general, the proposed metrology technique based on a $\mathrm{Y}$ sensing layer opens the possibility for a direct measurement of hydrogen transport in any thin film made of materials having a relatively low degree of hydrogen diffusion. This method is especially valuable when the hydrogen transport in thin film specimens is in question, since some materials can drastically change their structure (or other properties) depending on their form, such that pre-existing knowledge from bulk materials is not applicable. The proposed method can still be improved. Several potential points of development are discussed further.

In this work, we tried to mitigate the influence of surface processes on the measured hydrogen flux. The samples were designed in such a way, that a high surface coverage of hydrogen was reached throughout the measurement and remained the same within an entire experiment. This way the $\mathrm{H}$ uptake was not limited by low surface saturation and could be approximated with a constant value. For certain applications, it may also be interesting to study the influence of surface processes on hydrogen uptake and transport. Further research is needed for finding a reliable way of measuring the $\mathrm{H}$ uptake in case surface processes are a limiting factor.

In the hydrogenography study (chapter 4), the possibility to vary the $\mathrm{H}_{2}$ pressure in a wide range allowed us to distinguish the limiting step of hydrogen uptake. If a similar variation of incoming hydrogen flux could be applied to an atomic hydrogen source, it may give a valuable insight into the limiting steps for uptake and diffusion of atomic hydrogen. However, such an experiment would require 
a method for measuring the dependence of the atomic hydrogen flux on the $\mathrm{H}_{2}$ pressure, which is currently not available.

Additionally, a deeper look into the dependence of hydrogen diffusion on film structure is of interest. The measurements and diffusion model proposed in chapter 5 could not predict the observed differences in hydrogen diffusion as function of film thickness for several materials, which may be caused by film structure changes depending on the film thickness. Therefore, it would be of interest to controllably vary the film structure and study the influence of structure on hydrogen diffusion.

Finally, a comparison between ellipsometry measurements and optical transmission measurements (hydrogenography) showed that the latter measurements are easier to interpret. For experiments where it is of interest to measure hydrogen diffusion during exposure to atomic hydrogen, it would be interesting to construct an exposure facility where exposure to atomic hydrogen and optical transmission measurements can be combined.

\subsection{Experimental methods}

A succinct description of experimental techniques that were used in this work is given in this section.

Spectroscopic ellipsometry (SE) is a thin film technique, which measures the change in polarization of the reflected light from a film surface [35]. When this method is applied in situ (usually without the ability to change the incidence angle), the film thickness and refractive index are coupled and, therefore, cannot be obtained simultaneously. An initial pre-characterization of one of these parameters is needed for reliable measurement of the other. Ellipsometry can reach atomic resolution in layer thickness measurements when provided with a reliable model of a sample's layered structure. SE is especially sensitive to the near-surface layers, with the probing depth depending on the light damping in the investigated material. All SE measurements in this study were conducted in situ during hydrogenation of samples. For that, an ellipsometer, operating in the spectral range of 245-1690 nm, was mounted to a vacuum chamber, which limited all measurements to one angle of incidence. Nonetheless, even with fixed geometry, SE is sensitive, not only to the slightest change in thickness, but also to structural changes in films that influence the refractive index. 
Hydrogenography (transmission measurements) is a technique that monitors the optical transmittance of thin films during exposure to $\mathrm{H}_{2}$ gas [36]. A supported thin film (or stack of thin-films), deposited on a transparent substrate, is homogeneously illuminated with a white light source and the transmitted light is measured with a CCD camera. A signal normalized to the initial transmittance is used to determine the concentration of absorbed hydrogen via the Lambert-Beer law. This makes data processing easier compared to SE. However, this method requires a transparent substrate, in contrast to SE, which can work with any substrate type. At the same time, it is less sensitive to the optical changes at the surface of the sample and, together with a high contrast in transmittance of a film before and after hydrogenation, this technique can reach high sensitivity to hydrogen absorption.

Atomic force microscopy (AFM) enables high resolution measurements of the topography of the film surface. It is based on the strong distance dependence of the repulsive forces between the surface atoms and the scanning tip. These forces are measured by changes in either the deflection (contact mode AFM) or nearresonant oscillation (dynamic AFM modes, as tapping mode or non-contact mode AFM) of a cantilever onto which the tip is mounted. Sub-nanometer precision can be reached with AFM.

$X$-ray diffraction $(X R D)$ is a technique that is based on Bragg diffraction of $\mathrm{X}$ rays from atomic planes (XRD). Being sensitive to interatomic distances, XRD can easily distinguish different crystal structures. With a proper analysis, the crystallite size and lattice strain can also be extracted from the XRD data.

$X$-ray reflectivity $(X R R)$, similarly to $\mathrm{XRD}$, measures $\mathrm{X}$-rays that are diffracted on thin layers of materials. XRR is a powerful technique that allows characterization of both thin film thickness and density. It can be applied to a single layer as well as to a multilayer stack, as long as the stack layers have optical contrast at the X-Ray wavelength. XRR is also sensitive to the interfaces between the layers and, using a realistic stack model, it is possible to obtain their thicknesses nondestructively.

Transmission electron microscopy (TEM) enables imaging a specimen structure on nanometer scale using a beam of transmitted electrons. Electrons, having a de Broglie wavelength smaller than that of light used in optical microscopes, allow a resolution of fractions of a nanometer to be reached. TEM is sensitive to dislocations and defects of the atomic lattice, can easily distinguish crystalline and 
amorphous phases, and shows the contrast between different materials in the specimen. For cross-sectional TEM the sample should undergo several preparation steps (for instance, grinding, etching, polishing) to reach a uniform thickness that is thin enough to be transparent for electrons. Depending on the material, the specimen thickness should be reduced down to $100 \mathrm{~nm}$.

\subsection{Experimental details}

In the following chapters, a range of experimental results are presented. Here, a short introduction to the sensor design, and the experimental exposure conditions is given.

\subsubsection{Sample structure}

To study hydrogen transport through thin films, a layer of a test material is deposited on a hydrogen sensitive material, called the sensor layer, using magnetron sputtering. The transport of hydrogen is then analyzed by studying the hydrogenation rate of the sensor layer.

Yttrium was chosen as the material for the sensor layer for this study for several reasons:

- $\mathrm{Y}$ has the lowest (most negative) enthalpy of solution for hydrogen among metals, meaning that it is most energetically favorable for hydrogen to dissolve and form a hydride with $\mathrm{Y}$.

- It forms $\mathrm{YH}_{2}$ and $\mathrm{YH}_{3}$ hydride phases that have different lattice structures, fcc and hcp, respectively, as well as different electrical and optical properties. Hydride formation can thus be monitored with various techniques, such as XRD, ellipsometry and optical transmission measurements.

- With fast $\mathrm{H}$ kinetics, $\mathrm{Y}$ can be used at room temperature, contrary to other promising materials like Hf [12].

$\mathrm{Y}$, however, is easily oxidized, forming a thin oxide layer (about $6 \mathrm{~nm}$ ) when exposed to air. A Y oxide layer hinders hydrogen uptake, which makes it important to perform the sample fabrication without breaking vacuum.

A protective cap layer with high hydrogen absorption rate and diffusivity is required for diffusion studies through test layers. In this work, Pd is used as a capping material. This makes the sample surface the same for different test layers, which is important for a reliable $\mathrm{H}$ diffusion study. The capping layer ensures 
that the impact of surface processes on the hydrogen uptake is the same for different test materials, as discussed in chapter 3 . The Pd layer makes it possible to compare hydrogen transport through test layers and evaluate the limiting step of Y hydrogenation. It should be noted, though, that the barrier properties of a test layer depend both on in-depth diffusion and hydrogen uptake (or release) at the surface. This work focuses on measuring diffusion through the film, independent of surface processes. All studies in this work are restricted to hydrogen uptake experiments, because hydrogen release into vacuum, when possible, appeared to be limited by the hydrogen desorption rate from the sample surface, or hydrogen release rate from the yttrium hydride layer.

\subsubsection{Exposures to atomic hydrogen}

The results described in chapters 2,3 , and 5 were obtained with a setup that enabled exposures of samples to atomic hydrogen and in situ measurements of $Y$ hydrogenation with SE (see Figure 1.2). In these experiments, atomic hydrogen was generated by passing an $\mathrm{H}_{2}$ flow past a hot tungsten filament. Since the flux of atomic hydrogen drops strongly with distance from the filament, due to recombination back to $\mathrm{H}_{2}$ [37], the sample should be placed in direct view of the filament. The vicinity of a hot filament heats the sample, which is mitigated by using a water-cooled sample holder.

With no dissociation barrier, atomic hydrogen has a higher sticking probability for sample surfaces compared to $\mathrm{H}_{2}$, which provides higher uptake rates. This enables the operating $\mathrm{H}_{2}$ pressures to be lowered to a level compatible with UHV chambers. Moreover, reactive atomic hydrogen can reduce native oxides that usually impede hydrogen uptake. On the other hand, atomic $\mathrm{H}$ interacts with contaminants in the surrounding of the sample surface due its high reactivity, which makes the experiment highly sensitive to contamination and complicates the measurement of the $\mathrm{H}$ flux that reaches the sample surface.

The hydrogenation experiment, monitored with optical transmission, described in chapter 4, uses molecular $\mathrm{H}_{2}$. An advantage of this method is that exposure to $\mathrm{H}_{2}$ is less likely to generate impurities (compared to atomic $\mathrm{H}$ ). In addition, the exposure of the sample to hydrogen can easily be related to the applied $\mathrm{H}_{2}$ pressure, since there is no need to take into account the efficiency of atomic $\mathrm{H}$ generation by a hot filament. Although this method requires a wide range of applied $\mathrm{H}_{2}$ pressures, as well as the use of a capping layer that catalytically dissociates $\mathrm{H}_{2}$, Y hydrogenation has been extensively studied in prior research $[29,30]$. 
Studying the hydrogenation rate over a wide $\mathrm{H}_{2}$ pressure range allows the limiting process of hydrogen uptake to be verified.

\subsubsection{Transmission and ellipsometry measurements}

The main difference between the transmission and ellipsometry techniques used in this work is the geometry of the measurement (transmission and reflection, respectively). Transmission measurements are easy to interpret, and they only require a transparent substrate. The thickness of a test layer should be small enough for it to remain transparent, no matter what the hydrogenation state is. This allows the sample thickness to be up to $100 \mathrm{~nm}$, whereas ellipsometry can only probe a signal from the sensor layer under metal test layers with thicknesses up to about $15 \mathrm{~nm}$. However, a lack of contrast between the dielectric $\mathrm{YH}_{3}$ film and the substrate brings higher uncertainty in determination of the $\mathrm{H}$ content in transparent hydrides for transmission measurements. Ellipsometry can be applied to non-transparent substrates, in addition it can show the change in optical properties in more detail. However, the coupling between optical properties and layer thickness can make observed changes difficult to interpret.

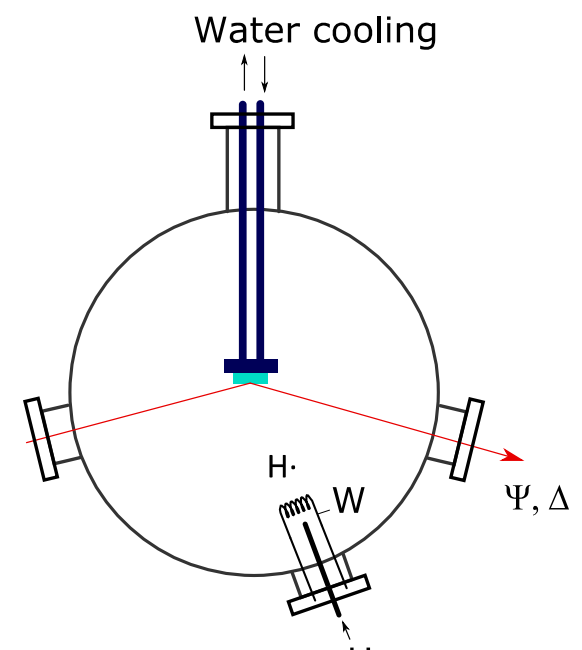

$\mathrm{H}_{2}$

Figure 1.2. A sketch of the setup used for exposures to atomic hydrogen. A water-cooled sample holder can be translated for adjustment of the reflected light beam used for ellipsometry. The angle of incidence is around $75^{\circ}$. A W filament for hydrogen radical generation is placed in between the hydrogen gas inlet and the sample. 


\subsection{Outline}

This thesis aims to experimentally verify the use of a $\mathrm{Y}$ indicator for the measurement of hydrogen transport through thin films and find the optimal design of the structure for a hydrogen sensor. First, for a reliable measurement of the hydrogen content in $\mathrm{Y}$ with optical techniques, a calibration of the optical signal should be done. In chapter 2 , the hydrogenation of a Y film capped with a $\mathrm{Ru}$ layer is studied with both ellipsometry and XRD for better understanding of the structural transformations in $\mathrm{Y}$ during hydrogen uptake and their impact on the dielectric function of the film. The transition from $\mathrm{Y}$ to $\mathrm{YH}_{2}$ was found to be reliable for hydrogen concentration measurements, from the perspective of optical monitoring.

Next to the aspect of optical sensing, the different processes that contribute to hydrogen transport through a test layer should be accounted for. In the case of thin films, the measured time of $Y$ hydride formation is often mainly determined by surface processes and hydrogen diffusivity and solubility of $\mathrm{H}$ in the test material. Chapter 3 shows how the variation in the desorption energy of $\mathrm{H}$ from the test material surface can affect the uptake of $\mathrm{H}$ by a $\mathrm{Y}$ sensing layer. Because of the low energy barrier for desorption, it is not possible to reach the $\mathrm{YH}_{2}$ and/or $\mathrm{YH}_{3}$ phase for some materials. Therefore, an additional cap layer is needed to be able to reach the same hydrogenation state of Y. A Pd layer has been used for this purpose in the further work presented here.

Hereafter, to measure the hydrogen diffusion through a test layer, a layered structure of $\mathrm{Pd} /$ Test layer/Y was constructed. In chapter 4 , the diffusion coefficient for hydrogen in $\mathrm{Ru}$ films was derived from hydrogenography measurements (with molecular $\mathrm{H}_{2}$ ) of such a layered structure. Low hydrogen solubility and diffusivity in $\mathrm{Ru}$, compared to both $\mathrm{Y}$ and $\mathrm{Pd}$, ensures that the kinetics of the hydrogenation process is limited by permeation through the Ru layer. The influence of the film polycrystalline structure on the obtained diffusion coefficient is also discussed.

In chapter 5 , hydrogen transport in a set of test layers, which included metals, oxides and $\mathrm{Si}$, was measured using ellipsometry and atomic hydrogen. The oxides were found to be the most impermeable to hydrogen and, therefore, the best candidates for a barrier application. The mechanisms of hydrogen transport in the tested materials differ from material to material. However, despite these differences, it could be shown that the hydrogenation rate correlates with hydrogen solubility in the material rather than with its diffusivity. 


\subsection{References}

[1] W. B. Jackson, N. M. Johnson, C. C. Tsai, I. W. Wu, A. Chiang, and D. Smith, "Hydrogen diffusion in polycrystalline silicon thin films," Appl. Phys. Lett., vol. 61, no. 14, pp. 1670-1672, Oct. 1992.

[2] J. Siepmann and F. Siepmann, "Mathematical modeling of drug delivery," International Journal of Pharmaceutics, vol. 364, no. 2. pp. 328-343, Dec-2008.

[3] A. Züttel, "Hydrogen storage methods," Naturwissenschaften, vol. 91, no. 4. pp. 157-172, 2004.

[4] C. Andrade, M. Castellote, and R. D'Andrea, "Measurement of ageing effect on chloride diffusion coefficients in cementitious matrices," Journal of Nuclear Materials, vol. 412, no. 1. pp. 209-216, May-2011.

[5] Y. Fukai, The Metal-Hydrogen System, vol. 21. Berlin/Heidelberg: Springer-Verlag, 2005.

[6] H. Wipf, "Solubility and Diffusion of Hydrogen in Pure Metals and Alloys," Phys. Scr., vol. T94, no. 1, p. 43, 2003.

[7] R. Kirchheim and A. Pundt, "Hydrogen in Metals," in Physical Metallurgy, vol. 1, Elsevier, 2014, pp. 2597-2705.

[8] M. Dornheim et al., "Stress development in thin yttrium films on hard substrates during hydrogen loading," J. Appl. Phys., vol. 93, no. 11, pp. 8958-8965, May 2003.

[9] C. Y. Ang, "Activation energies and diffusion coefficients of oxygen and nitrogen in niobium and tantalum," Acta Metall., vol. 1, no. 2, pp. 123125, Mar. 1953.

[10] J. N. Huiberts et al., "Yttrium and lanthanum hydride films with switchable optical properties," Nature, vol. 380, no. 6571, pp. 231-234, Mar. 1996.

[11] C. Wadell, S. Syrenova, and C. Langhammer, "Plasmonic hydrogen sensing with nanostructured metal hydrides," ACS Nano, vol. 8, no. 12. pp. 11925-11940, 2014.

[12] C. Boelsma, L. J. Bannenberg, M. J. Van Setten, N. J. Steinke, A. A. Van Well, and B. Dam, "Hafnium - An optical hydrogen sensor spanning six orders in pressure," Nat. Commun., vol. 8, no. 1, p. 15718, Aug. 2017.

[13] F. Sterl, N. Strohfeldt, R. Walter, R. Griessen, A. Tittl, and H. Giessen, "Magnesium as Novel Material for Active Plasmonics in the Visible Wavelength Range," Nano Lett., vol. 15, no. 12, pp. 7949-7955, Dec. 
2015.

[14] R. J. Westerwaal et al., "The hydrogen permeability of Pd-Cu based thin film membranes in relation to their structure: A combinatorial approach," Int. J. Hydrogen Energy, vol. 40, no. 10, pp. 3932-3943, 2015.

[15] T. Radeva, P. Ngene, M. Slaman, R. Westerwaal, H. Schreuders, and B. Dam, "Highly sensitive and selective visual hydrogen detectors based on Y xMg1-x thin films," Sensors Actuators, B Chem., vol. 203, pp. 745751, Nov. 2014.

[16] V. Nemanič, "Hydrogen permeation barriers: Basic requirements, materials selection, deposition methods, and quality evaluation," Nuclear Materials and Energy, vol. 19. pp. 451-457, 2019.

[17] X. Xiang, X. Wang, G. Zhang, T. Tang, and X. Lai, "Preparation technique and alloying effect of aluminide coatings as tritium permeation barriers: A review," International Journal of Hydrogen Energy, vol. 40, no. 9. pp. 3697-3707, 2015.

[18] M. Tamura and T. Eguchi, "Nanostructured thin films for hydrogenpermeation barrier," J. Vac. Sci. Technol. A Vacuum, Surfaces, Film., vol. 33, no. 4, p. 041503, 2015.

[19] Y. Sun, J. Lv, Y. Xie, H. Liu, and Y. Ma, "Route to a Superconducting Phase above Room Temperature in Electron-Doped Hydride Compounds under High Pressure," Phys. Rev. Lett., vol. 123, no. 9, p. 097001, Aug. 2019.

[20] G. Federici et al., "In-vessel tritium retention and removal in ITER," $J$. Nucl. Mater., vol. 266, pp. 14-29, 1999.

[21] A. S. Kuznetsov, Hydrogen particle and plasma interactions with heterogeneous structures. Enschede: Universiteit Twente, 2013.

[22] R. A. J. M. Van Den Bos, Hydrogen infuced blister formation in Mo/Si multilayer structures. Enschede, The Netherlands: University of Twente, 2018.

[23] A. Perujo and K. S. Forcey, "Tritium permeation barriers for fusion technology," Fusion Eng. Des., vol. 28, no. C, pp. 252-257, 1995.

[24] C. H. Henager, "Hydrogen permeation barrier coatings," in Materials for the Hydrogen Economy, CRC Press, 2007, pp. 181-190.

[25] T. Graham, "On the absorption and dialytic separation of gases by colloid septa," J. Franklin Inst., vol. 83, no. 1, pp. 39-41, Jan. 1867.

[26] T. L. Ward and T. Dao, "Model of hydrogen permeation behavior in palladium membranes," J. Memb. Sci., vol. 153, no. 2, pp. 211-231, Feb. 
1999.

[27] G. A. Young and J. R. Scully, "The diffusion and trapping of hydrogen in high purity aluminum," Acta Mater., vol. 46, no. 18, pp. 6337-6349, Nov. 1998.

[28] B. L. Doyle, P. S. Peercy, T. J. Gray, C. L. Cocke, and E. Justiniano, "Surface spectroscopy using high energy heavy ions," IEEE Trans. Nucl. Sci., vol. 30, no. 2, pp. 1252-1254, 1983.

[29] W. A. Lanford, "Analysis for hydrogen by nuclear reaction and energy recoil detection," Nucl. Instruments Methods Phys. Res. Sect. B Beam Interact. with Mater. Atoms, vol. 66, no. 1-2, pp. 65-82, Mar. 1992.

[30] T. Hübert, L. Boon-Brett, G. Black, and U. Banach, "Hydrogen sensors A review," Sensors Actuators, B Chem., vol. 157, no. 2, pp. 329-352, Oct. 2011.

[31] Y. Yamada, K. Tajima, S. Bao, M. Okada, and K. Yoshimura, "Hydrogenation and dehydrogenation processes of palladium thin films measured in situ by spectroscopic ellipsometry," Sol. Energy Mater. Sol. Cells, vol. 93, no. 12, pp. 2143-2147, 2009.

[32] Y. Pivak et al., "Effect of the substrate on the thermodynamic properties of PdH x films studied by hydrogenography," Scr. Mater., vol. 60, no. 5, pp. 348-351, Mar. 2009.

[33] N. Strohfeldt et al., "Yttrium hydride nanoantennas for active plasmonics," Nano Lett., vol. 14, no. 3, pp. 1140-1147, 2014.

[34] A. Kutana, T. Ito, I. L. Bolotin, B. Makarenko, and J. W. Rabalais, "TOFSARS study of hydrogen adsorption and desorption kinetics on $\operatorname{Si}(10$ 0)," in Vacuum, 2004, vol. 73, no. 1, pp. 73-78.

[35] R. M. A. Azzam and N. M. Bashara, Ellipsometry and polarized light. North-Holland Pub. Co., 1977.

[36] R. Gremaud et al., "Hydrogenography: An optical combinatorial method to find new light-weight hydrogen-storage materials," Adv. Mater., vol. 19, no. 19, pp. 2813-2817, Oct. 2007.

[37] M. S. Hofman, D. Z. Wang, Y. Yang, and B. E. Koel, "Interactions of incident H atoms with metal surfaces," Surf. Sci. Rep., vol. 73, no. 4, pp. 153-189, 2018.

[38] Y. Pivak, H. Schreuders, and B. Dam, "Effect of the structure transformation on the (de-)hydrogenation hysteresis of La1-zYzHx films as studied by hydrogenography," J. Mater. Chem., vol. 22, no. 46, pp. 24453-24462, Nov. 2012. 
[39] R. Griessen et al., "Yttrium and lanthanum hydride films with switchable optical properties," J. Alloys Compd., vol. 253-254, pp. 44-50, May 1997. 


\section{2 \\ Hydrogenation dynamics of Ru capped $Y$ thin films}

The structural changes in Ru-coated $\mathrm{Y}$ films during hydrogenation were studied for the first time. In situ XRD data was used to show that the $\mathrm{Y}$ to $\mathrm{YH}_{2}$ transition requires significant hydrogen loading of the $\mathrm{Y}$ lattice. By comparing the XRD data with in situ spectroscopic ellipsometry data, an effective medium model for the transition was obtained. This model describes the $\mathrm{Y}$ to $\mathrm{YH}_{2}$ transition well. The $\mathrm{YH}_{2}$ to $\mathrm{YH}_{3}$ transition is also described by an effective medium model, however, with reduced accuracy around the mid-point of the transition. By comparing the $\mathrm{YH}_{2}$ and $\mathrm{YH}_{3}$ crystal sizes, we show that these deviations may be due to a surface plasmon resonance. The improved understanding of the ellipsometry measurements is important for optical hydrogen sensing applications. 


\subsection{Introduction}

When hydrogenation of thin layers of $\mathrm{Y}$ was studied for the first time, metalinsulator switching during the transition of $\mathrm{YH}_{2}$ to $\mathrm{YH}_{3}$ was discovered [1]. This optical change upon hydrogenation found application in many fields, particularly in hydrogen sensing. Many Y-based sensors were developed for hydrogen gas detection [2-4] and measurement of hydrogen diffusion in metals [5]. These sensors have the advantage of using optical techniques to monitor the change in the hydrogen concentration, such that electrical connections to the sensor and associated safety risks in the presence of oxygen-hydrogen mixtures can be avoided $[6,7]$.

A common feature of yttrium-based H-sensors is the presence of a Pd protective layer. In addition to protecting the yttrium from oxidation, the Pd coating adsorbs and dissociates molecular hydrogen, which is then released as atomic hydrogen into the $\mathrm{Y}$ film. It is possible to reach the $\mathrm{YH}_{3}$ phase in a $\mathrm{Pd} / \mathrm{Y}$ stack by varying the applied hydrogen pressure, though it dissociates back to a stable $\mathrm{YH}_{2}$ phase when the hydrogen supply is switched off [8]. This happens, because (i) the $\mathrm{YH}_{2}$ phase is thermodynamically more stable than $\mathrm{YH}_{3}$ [9] and (ii) the desorption temperature of hydrogen from the Pd surface is close to room temperature [10]. In a previous study, we demonstrated that a Ru protective layer, with a higher hydrogen desorption temperature, can stabilize $\mathrm{YH}_{3}$ at lower applied hydrogen flux and/or pressure. In order to exploit both the $\mathrm{Y}$ to $\mathrm{YH}_{2}$ and $\mathrm{YH}_{2}$ to $\mathrm{YH}_{3}$ transitions for sensing hydrogen at lower pressures, it therefore can be an advantage to use $\mathrm{Ru}$ as protective material. In addition, it is also desirable to study hydrogen diffusion through layers of other materials. In case of a $\mathrm{Ru}$ protective cap layer, however, an atomic hydrogen source is needed to achieve hydrogenation of the $\mathrm{Y}$. Only atomic $\mathrm{H}$ can reduce the native $\mathrm{RuO}_{2}$ from the $\mathrm{Ru}$ surface, which otherwise would inhibit hydrogen diffusion. In this article, we analyze the hydrogenation with atomic hydrogen of a Y film covered by a Ru layer.

Ruthenium coated yttrium films are used to understand the optical properties of $\mathrm{Y}$ as function of hydrogen loading, structural changes during the hydrogenation and de-hydrogenation processes, and thermodynamics and kinetics of $\mathrm{Y}$ hydrogenation. In previous work [10], it was shown that the $\mathrm{YH}_{3}-\mathrm{YH}_{2}$ transition is strongly influenced by the surface binding energy of hydrogen on the surface of the protective material on top of the Y film. The optical properties of the sensor 
may also be influenced by, for instance, the crystallinity of the different $\mathrm{Y}$ (hydride) phases, and lattice expansion.

In most cases, the hydrogen concentration in a Y film is obtained by measuring its transparency $[11,12]$. However, this requires a transparent substrate, reducing the optical contrast between the $\mathrm{YH}_{3}$ film and the substrate near saturation. The lack of contrast between the film and its substrate complicates extracting the film's dielectric constants, which leads to increased uncertainty in the hydrogen concentration. To resolve these difficulties, spectroscopic ellipsometry (SE) could be used, which is known to be highly sensitive to the optical properties of both dielectric and metallic films. Therefore, SE is an ideal candidate to increase the sensitivity to hydrogen diffusion for hydrogenation states up to $\mathrm{YH}_{2}$ (where the yttrium hydride is metallic), as well as to increase the accuracy of quantification during the $\mathrm{YH}_{2}$ to $\mathrm{YH}_{3}$ transition. Furthermore, by using a high-contrast substrate such as silicon, the optical properties of $\mathrm{YH}_{3}$ near saturation are easier to obtain.

Though there are numerous works on $\mathrm{Y}$ hydrogenation $[8,13-16]$ only few of them used ellipsometry to monitor the process $[8,16]$. To our knowledge, none of the published data include the dynamics of the phase transition, but instead focus on the beginning and end points of hydrogenation. For a sensor application, however, it is important to understand the structural changes in the $\mathrm{Y}$ film during the hydrogenation process and their impact on the ellipsometry signal.

One possible reason for the lack of dynamic ellipsometry data is that analysis is complicated by multiple processes occurring in parallel. It is difficult to obtain a realistic solution to the inverse problem without a reliable model containing film thicknesses and dielectric constants of the layers in the sample. To address this challenge, we combine in situ SE with ex and in situ X-ray diffraction (XRD) and ex situ X-ray reflectivity (XRR) to obtain a detailed picture of the film's structural changes during hydrogen in-diffusion and during the phase transformations from $\mathrm{Y}$ to $\mathrm{YH}_{2}$ and $\mathrm{YH}_{2}$ to $\mathrm{YH}_{3}$.

In this work, an ellipsometric model is developed for the entire $\mathrm{Y}$ hydrogenation process for the first time. Based on the XRD and XRR data, the optical signature of $\mathrm{YH}_{2}$ and $\mathrm{YH}_{3}$ formation was identified in the ellipsometry measurements. This allows for the construction of an accurate ellipsometric model for the transition from $\mathrm{Y}$ to $\mathrm{YH}_{2}$, and a qualitatively accurate model for the $\mathrm{YH}_{2}$ to $\mathrm{YH}_{3}$ transition. The combination of methods reveals insight into why the $\mathrm{Y}-\mathrm{YH}_{2}$ phase transition 
is delayed with respect to the start of hydrogen exposure. In addition, a possible local surface plasmon resonance in the $\mathrm{YH}_{2}-\mathrm{YH}_{3}$ transition is revealed, which limits the accuracy of our present model to describe the $\mathrm{YH}_{2}-\mathrm{YH}_{3}$ transition.

\subsection{Methods}

To study Y hydrogenation, a series of samples were prepared using DC magnetron sputtering in a vacuum chamber with a base pressure of $10^{-8} \mathrm{mbar}$. Si (100) single crystal substrates of $15 \times 15 \mathrm{~mm}$ size were coated with $70 \mathrm{~nm}$ of $Y$ and 3 $\mathrm{nm} \mathrm{Ru}$ using $\mathrm{Ru}$ and $\mathrm{Y}$ targets with a purity of $99.95 \%$. The surface roughness and sample structure were characterized using atomic force microscopy (AFM) (Bruker, Dimension Edge) and XRR (Malvern PANalytical Empyrean).

Hydrogenation of $\mathrm{Y}$ was monitored using in situ spectroscopic ellipsometry (Woollam M-2000XI) at an angle of incidence of about $75^{\circ}$ and a spectral range of 240-1600 nm. Samples were exposed to atomic hydrogen in a vacuum chamber with a base pressure of $2 \cdot 10^{-8}$ mbar. Hydrogen species were generated by passing $100 \mathrm{sccm}$ of $\mathrm{H}_{2}$ over a W filament heated to $2000{ }^{\circ} \mathrm{C}$, which was placed at $4 \mathrm{~cm}$ from the sample surface. The temperature of the filament was measured using an infrared temperature sensor (Raytek, RayMR1SCCF). The sample temperature was maintained below $40{ }^{\circ} \mathrm{C}$ with a water cooled sample holder. The hydrogen flux increased the chamber pressure to $2 \cdot 10^{-2}$ mbar. The flux to the sample surface was calculated to be $10^{18}$ at $/ \mathrm{cm}^{2} / \mathrm{s}$ after measuring the etch rate of a carbon layer (following the method of Braginsky et al. [17]). Atomic hydrogen exposure efficiently reduces the native oxide of the Ru cap of the Y film [18]. Therefore, it is expected that the Ru oxide film is fully reduced during measurements of the hydrogenation of Y. Maximum hydrogenation was assumed to be achieved when the ellipsometric angles $\Psi$ and $\Delta$ re-stabilized after a rapid and large change.

For the first set of ellipsometry measurements, exposure to atomic hydrogen was stopped at various moments during hydrogenation (28, 53, and 59 minutes). The exposed samples were removed from the vacuum and XRD (Malvern PANalytical Empyrean) was used to obtain the crystalline structure of the yttrium/yttrium hydride layer. XRD measurements were performed in a $\theta-2 \theta$ geometry using $\mathrm{Cu}-$ $\mathrm{K} \alpha$ radiation $(0.154 \mathrm{~nm})$. Since the $\mathrm{Ru}$ capping layer stabilizes the $\mathrm{YH}_{3}$ phase, it is possible to perform ex situ XRD on partially and fully saturated samples. 
In situ XRD measurements during hydrogenation and dehydrogenation were performed using the BM 25 (SpLine) beamline at the European Synchrotron Radiation Facility (ESRF) in Grenoble. A small vacuum chamber (base pressure 6.10${ }^{6}$ mbar) was installed at the first focus point of branch B [19]. XRD was performed using a photon energy of $20 \mathrm{keV}$. In situ measurements were made in $\theta$ $2 \theta$ geometry, using a scan range that encompassed the $\mathrm{Y}(100), \mathrm{Y}(002), \mathrm{YH}_{2}$ (111), and $\mathrm{YH}_{3}(002)$ peaks. Each scan took approximately 3 minutes. Also, inplane Grazing Incidence x-ray Diffraction (GIXRD) measurements with a fixed incident angle (higher than the critical angle) were performed in the same $2 \theta$ range. Similar to the ellipsometry measurements, hydrogen exposures were performed by flowing molecular hydrogen past a $\mathrm{W}$ filament, placed at $4 \mathrm{~cm}$ from the sample surface. To ensure that hydrogenation was slow compared to the scan time, the chamber pressure during exposure was limited to $5 \cdot 10^{-3} \mathrm{mbar}$ by reducing the hydrogen flow. The filament temperature was set to $1850^{\circ} \mathrm{C}$ using a pyrometer (MAURER, KTR 1075-1-L). De-hydrogenation of $\mathrm{YH}_{3}$ was achieved by switching off the hydrogen supply and heating the sample with a heater that was built into the sample holder.

\subsection{Results}

\subsubsection{Ellipsometry and ex situ XRD}

The typical time evolution of ellipsometric angle $\Psi$ for a $\mathrm{Ru} / \mathrm{Y}$ sample is shown in Figure 2.1a. A set of identical samples was used to determine the intermediate states of $\mathrm{Y}$ hydrogenation. The exposure times indicated by lines marked 1 through 5 correspond to the times when the exposure to hydrogen of the different samples in the set was interrupted. The as-deposited sample corresponds to state 1 , and state 5 is the maximally hydrogenated sample. The XRD spectra show that the observed changes in $\Psi$ are indeed caused by the formation of $\mathrm{YH}_{2}$ and $\mathrm{YH}_{3}$ (Figure 2.1b). The fully hydrogenated sample still has a small fraction of the $\mathrm{YH}_{2}$ phase (subplot 5 of Figure 2.1b, note the logarithmic scale), which was observed in prior research [20]. The integrated intensity of the $\mathrm{YH}_{2}$ (111) peak for a maximally hydrogenated sample is only $7 \%$ of the maximum integrated intensity of the $\mathrm{YH}_{2}$ (111) and $\mathrm{YH}_{3}$ (002) peaks, which corresponds to $\mathrm{YH}_{2.9}$. This estimate is somewhat higher than values reported elsewhere, possibly due to the stabilizing effect of the $\mathrm{Ru}$ layer [10]. Once formed, the $\mathrm{YH}_{3}$ phase stays 
stable under the Ru cap at the room temperature. Note that the location of the $\mathrm{Y}$ peaks of the as-deposited sample are shifted, which is a result of the film stress.

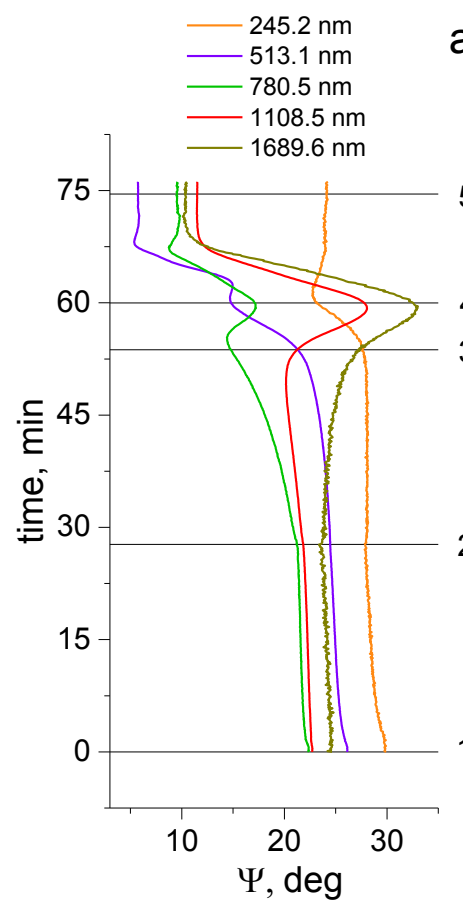

a)

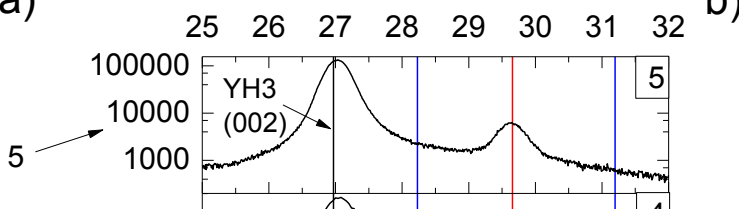

b)

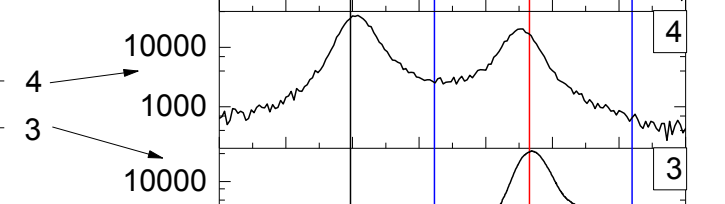

2

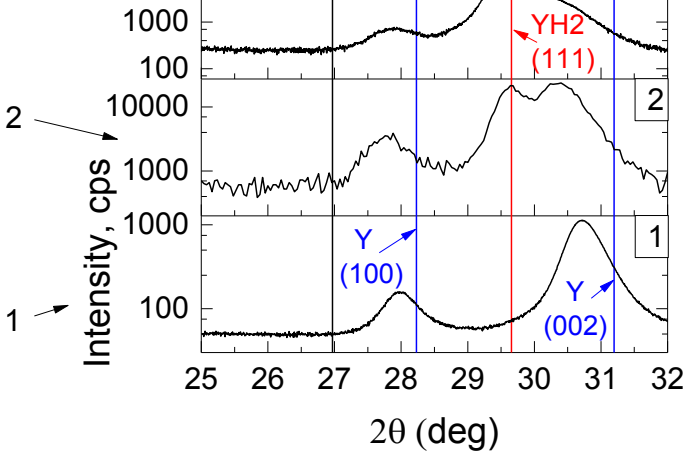

Figure 2.1. Time evolution of ellipsometric angle $\Psi$ for a $70 \mathrm{~nm}$ Y film, coated with $3 \mathrm{~nm}$ of $R u$, during exposure to atomic $H$ (time axis is vertical for ease of comparison to subfigure (b)). The five displayed wavelengths are evenly distributed over the detected spectrum. Five identical samples were exposed to hydrogen until the indicated times in graph (a). The ex situ XRD spectrum for each sample is shown in graph (b), starting with an unexposed sample (1) and finishing with a maximally saturated sample (5).

\subsubsection{In situ XRD}

In order to understand the formation and dissociation of the $\mathrm{YH}_{3}$ phase, $\mathrm{Ru}$ capped samples were investigated in situ with XRD at SpLine, ESRF. The evolution of the X-ray diffraction pattern during hydrogenation (Figure 2.2a) and de-hydrogenation (Figure 2.2b) was recorded. Hydrogenation is started by switching the $\mathrm{W}$ filament on. Due to vicinity to the $\mathrm{W}$ filament, the sample was also heated to about $340 \mathrm{~K}$ during hydrogenation, which is indicated below the $2 \theta$ plot of Figure 2.2a. Regardless of the different temperatures and hydrogen pressures, the $\mathrm{Y}$ hydrogenation recorded with in situ XRD (Figure 2.2a) and SE 
(Figure 2.1a) have similar trends in $2 \theta$ peaks shifts and SE angle evolution, respectively. The ex situ XRD measurements show that there is some remaining $\mathrm{YH}_{2}$ in the end of the transition (Figure 2.1b, subplot 5), while a complete transition to $\mathrm{YH}_{3}$ is seen in the in situ experiment. This is caused by some release of hydrogen during transportation of samples in air from the $\mathrm{H}$ exposure chamber to the diffractometer.

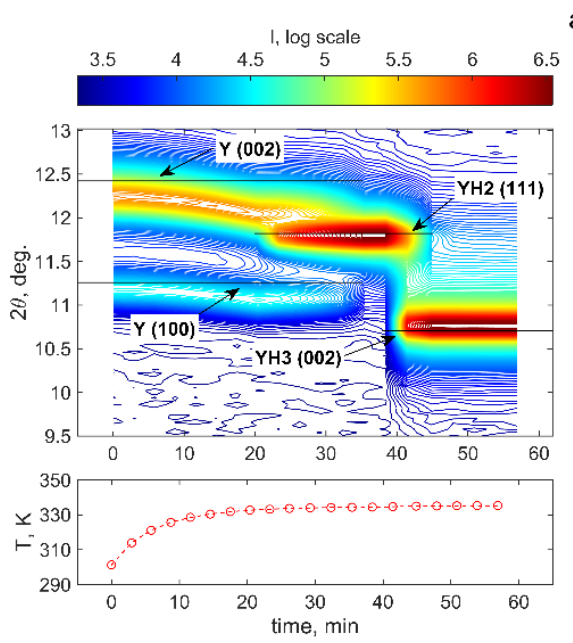

a)

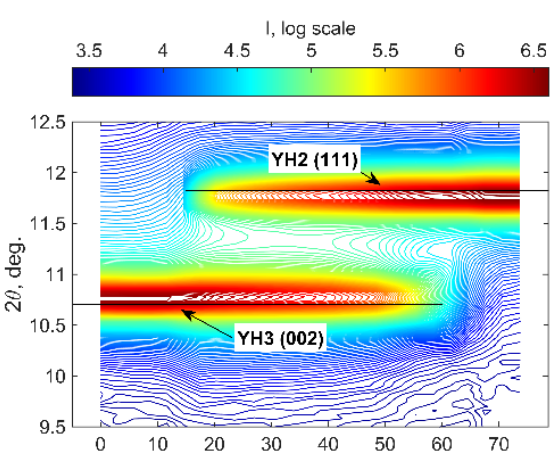

b)

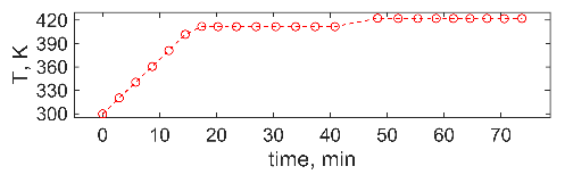

Figure 2.2. Time evolution of in situ XRD spectra for a $70 \mathrm{~nm}$ Y film, coated with $3 \mathrm{~nm}$ of $R u$, during hydrogenation (a) and de-hydrogenation (b). Horizontal lines indicate the tabulated diffraction angles for a Y powder. The lower subplots show the sample temperature during (de)hydrogenation.

Following saturation, the temperature was gradually increased from $300 \mathrm{~K}$ until de-hydrogenation started, which corresponded to $410 \mathrm{~K}$ (see Figure 2.2b). As discussed previously [10], this temperature is an activation temperature for the desorption of hydrogen from the Ru surface. Note that the phase transition from $\mathrm{YH}_{2}-\mathrm{YH}_{3}$ occurs faster than the reverse transition (5 minutes for hydrogenation (Figure 2.2a), compared to 20 minutes for dehydrogenation (Figure 2.2b)), even when the temperature is above the threshold temperature. A similar slower speed of dehydrogenation compared to hydrogenation has been observed in Pd-capped Y systems and was attributed to stress in the film and the kinetics of structure transformations [15]. However, in this study, the lower rate of hydrogenation is 
not only due to film stress, but also due to the higher surface desorption temperature of hydrogen from ruthenium $[10,21]$.

As hydrogenation begins, the lattice slowly expands, but there is no evidence of $\mathrm{YH}_{2}$ formation. This is clearly visible in Figure 2.2a where from 0 to 20 minutes the Y (002) XRD peak shifts from $12.26^{\circ}$ to $12.05^{\circ}$. Such a shift is significantly larger than expected from thermal expansion (heating by $40 \mathrm{~K}$ would results in a $2 \theta$ shift of $0.005^{\circ}$ ), and is most likely caused by the presence of interstitial hydrogen expanding the $\mathrm{Y}$ lattice. Thus, crystalline $\mathrm{YH}_{2}$ formation takes place after the $\mathrm{Y}$ lattice is at least partially loaded with hydrogen. However, the enthalpy of formation for $\mathrm{YH}_{2}$ is negative and the applied hydrogen pressure and flux of atomic $\mathrm{H}$ are sufficient to be above the plateau pressure for saturating the $\mathrm{Y}$ film to $\mathrm{YH}_{3}$ in equilibrium conditions, implying that $\mathrm{YH}_{2}$ should form continuously.
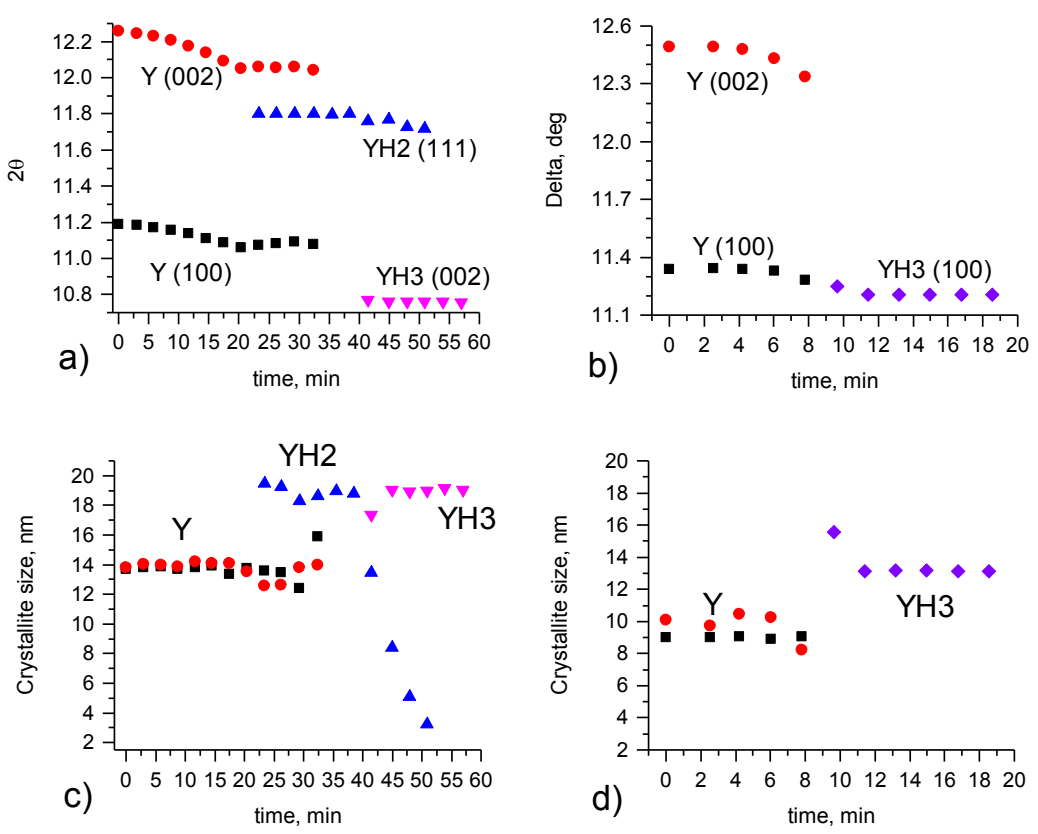

Figure 2.3. Time evolution of XRD peak positions for a $70 \mathrm{~nm}$ Y film, coated with $3 \mathrm{~nm}$ of $R u$, during hydrogenation in $\theta-2 \theta$ (a) and in in-plane grazing incidence geometry (b). The time evolution of the crystallite size, calculated from the peak width, is shown in (c) and $(d)$. The time of hydrogenation is different due to the different hydrogen pressures: (a, c) $3 \cdot 10^{-3}$ mbar and $(b, d) 1.6 \cdot 10^{-2}$ mbar. 
It is likely, however, that the formation of isolated $\mathrm{YH}_{2}$ in a $\mathrm{Y}$ crystal structure is energetically unfavorable, due to the increase in the surface energy of both $\mathrm{Y}$ and $\mathrm{YH}_{2}$ at the interface formed between the two. On the other hand, the energy in the film increases due to the strain imposed by lattice expansion. Hence, the transition from $\mathrm{Y}$ to $\mathrm{YH}_{2}$ only begins when the increase in energy due to elastic strain exceeds the increase in energy due to the interface formed between $\mathrm{Y}$ and $\mathrm{YH}_{2}$. From that, we can estimate a pseudo-activation energy of formation of the $\mathrm{Y} / \mathrm{YH}_{2}$ interface from the elastic energy stored in the $\mathrm{Y}$ lattice. The elastic energy equals: $U=\frac{1}{2} E\left(\frac{\Delta d}{d}\right)^{2}$, where $\mathrm{E}$ is Young's modulus, $\mathrm{E}=63.5 \mathrm{GPa}$ [22], $d$ is the initial lattice constant of $\mathrm{Y}, \Delta d$ is a difference in the $\mathrm{Y}$ lattice constants at the beginning of exposure and before the $\mathrm{YH}_{2}$ formation. A calculation yields an elastic energy of $2.1 \mathrm{eV} / \mathrm{at}$. $\mathrm{Y}$ along the (002) diffraction plane. This implies 2.1 $\mathrm{eV}$ for the interface formation between $\mathrm{Y}$ and $\mathrm{YH}_{2}$.

Since the enthalpy of $\mathrm{YH}_{2}$ formation is $-2.25 \mathrm{eV} /$ at. $\mathrm{H}$ [23], the phase transition proceeds rapidly once the energy stored in the lattice is sufficient to initiate the transition. The enthalpy of $\mathrm{YH}_{3}$ formation is only slightly lower, at $-2.54 \mathrm{eV} /$ at. $\mathrm{H}$ [23]. The formation of the $\mathrm{YH}_{3}$ phase is twice as fast as for $\mathrm{YH}_{2}$ with no evidence of lattice expansion: it only takes about 6 minutes, compared to 12 minutes for the $\mathrm{Y}$ to $\mathrm{YH}_{2}$ transition (not including the time of $\mathrm{Y}$ lattice expansion). This can be expected when both transitions are limited by $\mathrm{H}$ flux diffusing through $\mathrm{Ru}$ (since half of the hydrogen is required for the $\mathrm{YH}_{2}$ to $\mathrm{YH}_{3}$ transition in comparison to $\mathrm{Y}$ to $\mathrm{YH}_{2}$ ). Hence, it can be concluded that diffusion through $\mathrm{Y}, \mathrm{YH}_{2}$ and $\mathrm{YH}_{3}$ are not rate-limiting steps.

It should also be noted that XRD measurements are only sensitive to the presence of crystalline phases. Hence, from XRD alone we cannot exclude the formation of intermediate amorphous $\mathrm{YH}_{2}$ and $\mathrm{YH}_{3}$ phases. Ellipsometry is sensitive to the formation of amorphous phases, because the optical properties of amorphous materials are different from the crystalline polymorphs of the same chemical composition. We discuss the possibility of the existence of amorphous $\mathrm{YH}_{2}$ and $\mathrm{YH}_{3}$ phases in section 3.3.

To better understand the growth and decay of the crystallites in the film, $\theta-2 \theta$ XRD measurements were complemented with in-plane $2 \theta$ GIXRD, the combination of which allowed probing the atomic planes in two orthogonal directions, in-plane and normal to the sample surface. To obtain the crystallite size, the XRD peaks were fitted with a pseudo-Voigt function. The extracted parameters, such 
as the peak position and FWHM, are plotted as a function of time in Figure 2.3ab. Since the crystallites in (a) and (b) are probed in perpendicular directions, $\mathrm{YH}_{3}$ peaks that are produced by mutually perpendicular atomic planes, (002) and (100), are observed. It should be noted that, due to the (111) preferred orientation (normal to the sample surface) of the $\mathrm{YH}_{2}$ phase, the $\mathrm{YH}_{2}$ peak is not present in the in-plane GIXRD measurement. Both $\theta-2 \theta$ (a) and GIXRD (b) measurements confirm that the lattice expands in the (002) direction to a greater extent (see Figure 2.3a-b), which is in line with earlier neutron scattering experiments $[24,25]$. Using the Scherrer equation [26], the crystal sizes were calculated from the FWHM values and are shown in Figure 2.3c-d. The crystal sizes rapidly increase after the transition from $\mathrm{Y}$ to a hydride phase.

The XRD data reveals several necessary elements required for an ellipsometry model. The hydrogen loading before the $\mathrm{YH}_{2}$ transition will cause a minor modification in the $\mathrm{Y}$ optical properties. The lack of $\mathrm{YH}_{2}$ lattice expansion indicates that no significant hydrogen loading is required for the $\mathrm{YH}_{3}$ transition. However, it is known that the optical properties of the $\mathrm{Y}-\mathrm{H}$ system strongly change with hydrogenation state between $\mathrm{YH}_{1.9}$ and $\mathrm{YH}_{2.1}$. Thereby, we take the $\mathrm{YH}_{1.9}$ state as end point of the $\mathrm{Y}-\mathrm{YH}_{2}$ transition as observed by XRD and verify that the ellipsometry spectra can be fitted with literature data of the dielectric function of $\mathrm{YH}_{1.9}$, as will be further detailed in section 3.3. We will still refer to this phase as $\mathrm{YH}_{2}$ for simplicity.

\subsubsection{Ellipsometry modelling}

Let us now focus on the interpretation of the ellipsometry data obtained during hydrogenation. Figure 2.4 shows the time evolution of ellipsometric angles of the $\mathrm{Ru}$ capped $\mathrm{Y}$ film during the loading with atomic hydrogen. When considering the entire hydrogenation process, we take into account only two processes that lead to the change of the reflectance, namely the removal of a native ruthenium oxide [27] and formation of yttrium hydrides. The large optical contrast between $\mathrm{Y}, \mathrm{YH}_{2}$ and $\mathrm{YH}_{3}$ dominates the reflectance change and, once the $\mathrm{Y}$ to $\mathrm{YH}_{2}$ transitions begin, we attribute all changes in the reflectance solely to transformations of the yttrium (hydride) layer. However, the initial small changes of reflectance (first $30 \mathrm{~min}$ in Figure 2.4) happen before $\mathrm{YH}_{2}$ starts to form and are the result of ruthenium oxide removal and $\mathrm{Y}$ lattice expansion. Since ellipsometry is most sensitive to the topmost layer of metal-coated samples, even small changes on the surface of a Ru cap will affect the reflectance. Therefore, the 
initial removal of $\mathrm{RuO}_{2}$ should not be neglected. The observed $\mathrm{Y}$ lattice expansion is assumed to have smaller impact on the reflectance and, therefore, is not taken into account by the model.

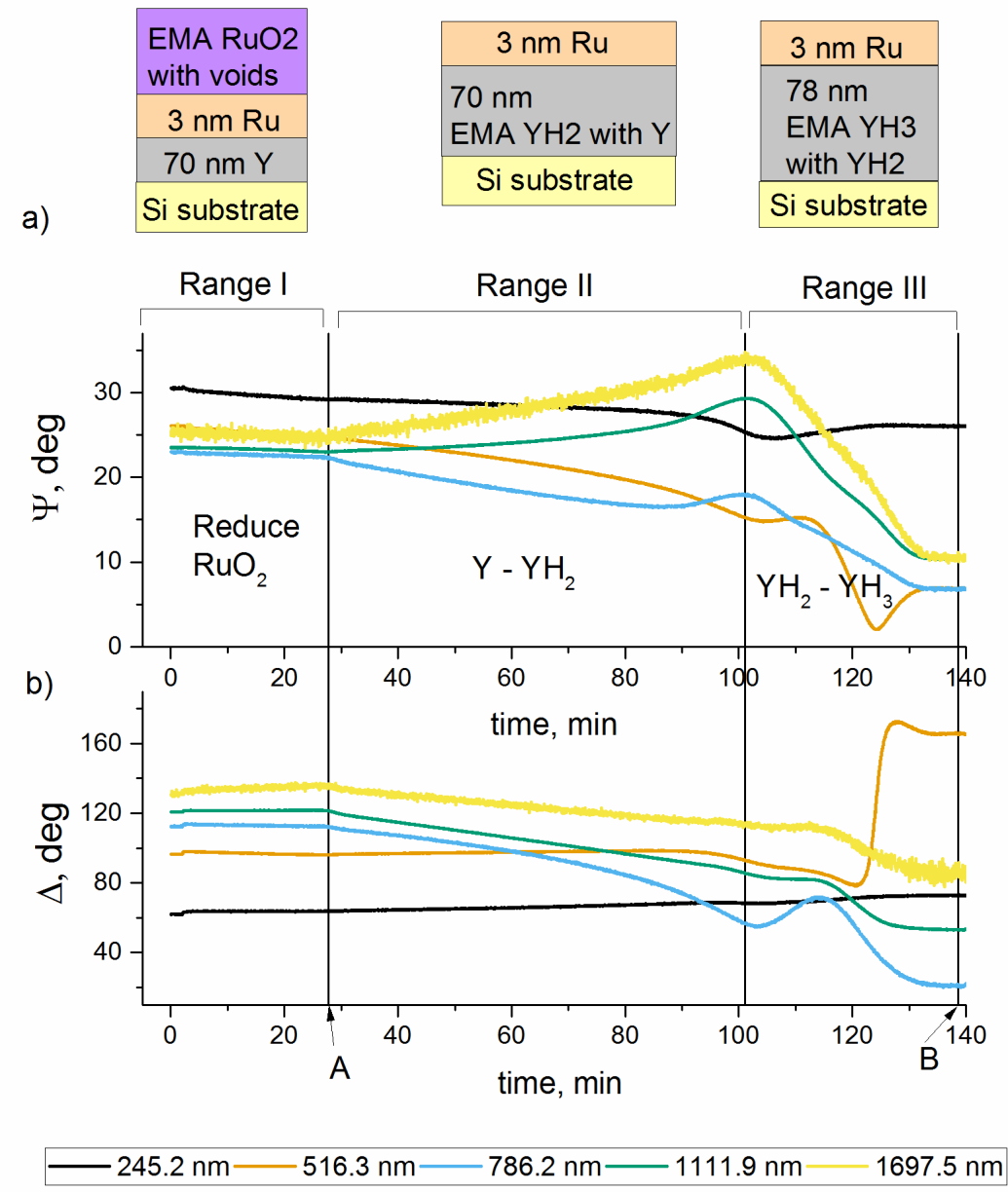

Figure 2.4. Ellipsometric angles $\Psi$ (a) and $\Delta$ (b) for a $70 \mathrm{~nm}$ Y film, coated with $3 \mathrm{~nm}$ of $R u$, during hydrogenation. The whole hydrogenation process is divided into three ranges: I-reduction of ruthenium oxide, II-the transition from $Y$ to $\mathrm{YH}_{2}, I I I$-transition from $\mathrm{YH}_{2}$ to $\mathrm{YH}_{3}$. The fit of the Ru optical constants is done at the time labelled with A. Time $B$ corresponds to the point when the dielectric constants of the $\mathrm{YH}_{3}$ phase are extracted from the fit (see the text for further explanation). A schematic of the layered model used for fitting within each range is shown above the corresponding range. 
To successfully model the hydrogenation of $Y$, we divide the process into three ranges (Figure 2.4). The thicknesses of Ru and $\mathrm{Y}$ layers were obtained from XRR to be 3 and $68 \mathrm{~nm}$, respectively, and assumed constant throughout first two ranges. The $\mathrm{Y}$ thickness was set as a free parameter for the $\mathrm{YH}_{2}$ to $\mathrm{YH}_{3}$ transition (the $3^{\text {rd }}$ range). When representing a layer as a mixture of phases/materials in each range, an effective medium approximation (EMA) is used in a Bruggeman analysis mode. Optical constants for $\mathrm{RuO}_{2}, \mathrm{Y}$, and $\mathrm{YH}_{2}$ were obtained from prior studies [28, 29]. Van Gogh et al. [28] has published optical constants for $\mathrm{YH}_{3}$. But, due to the lack of contrast between $\mathrm{YH}_{3}$ and the glass substrate in Van Gogh's experiment, the dielectric constants (even when including a non-zero fraction of $\mathrm{YH}_{2}$ ) could not reproduce the SE measurements in this work. Indeed, the variation in maximum hydrogenation between different published results makes it difficult to obtain a reliable optical model for $\mathrm{YH}_{3}$. Hence, we chose not to use published optical models for $\mathrm{YH}_{3}$.

The effective optical constants for $\mathrm{Ru}$ and $\mathrm{YH}_{3}$ were obtained using $\mathrm{b}$-spline fits. It is known that $\mathrm{RuO}_{2}$ is reduced under atomic hydrogen flux [27], and we assume that range $\mathrm{I}$ in Figure 2.4 corresponds mainly to $\mathrm{RuO}_{2}$ reduction. Thus, the end of range I corresponds to a metallic Ru layer.

A b-spline fit to the ellipsometry spectrum, using the model shown in the first row of Table 2.1, yields effective optical constants for $\mathrm{Ru}$. These constants and the thickness of the Ru layer are not changed for the remainder of the modeling procedure. After the optical constants for Ru are obtained, the optical constants for $\mathrm{YH}_{3}$ are obtained by performing the same fitting procedure at the end of the hydrogenation procedure. In this case we use the model from the second row of Table 2.1. The best fit is obtained for a $\mathrm{YH}_{3}$ thickness of $78 \mathrm{~nm}$, which is consistent with the calculated volumetric lattice expansion of $12 \%$ [10]. To investigate the reliability of the obtained dielectric function, the b-spline dielectric function for $\mathrm{YH}_{3}$ was then parametrized with the sum of two Tauc-Lorentz oscillators (see Figure 2.5). The Tauc-Lorentz oscillator is given by [30]:

$$
\varepsilon_{2}=\left\{\begin{array}{cl}
\frac{\mathrm{AE}_{0} \mathrm{~B}\left(\mathrm{E}-\mathrm{E}_{\mathrm{g}}\right)^{2}}{\left(E^{2}-\mathrm{E}_{0}^{2}\right)^{2}+B^{2} E^{2}} \cdot \frac{1}{E}, & \text { where } E>\mathrm{E}_{\mathrm{g}} \\
0, & \text { where } E \leq \mathrm{E}_{g}
\end{array}\right.
$$




$$
\varepsilon_{1}=\frac{2}{\pi} P \int_{E_{g}}^{\infty} \frac{\xi \varepsilon_{n 2}(\xi)}{\xi^{2}-E^{2}} d \xi
$$

where $\varepsilon_{1}$ and $\varepsilon_{2}$ are real and imaginary parts of a dielectric function, respectively. $A$ is the amplitude, $B$ is the broadening term of the peak, $\mathrm{E}_{0}$ is the peak central energy of an oscillator, $E_{g}$ is the band gap, and $E$ is the photon energy. All parameters are in $\mathrm{eV}$. P denotes the Cauchy principal value of the integral (over the photon energy). We obtained a band gap of $2.5 \mathrm{eV}$, which is consistent with values reported elsewhere [8].

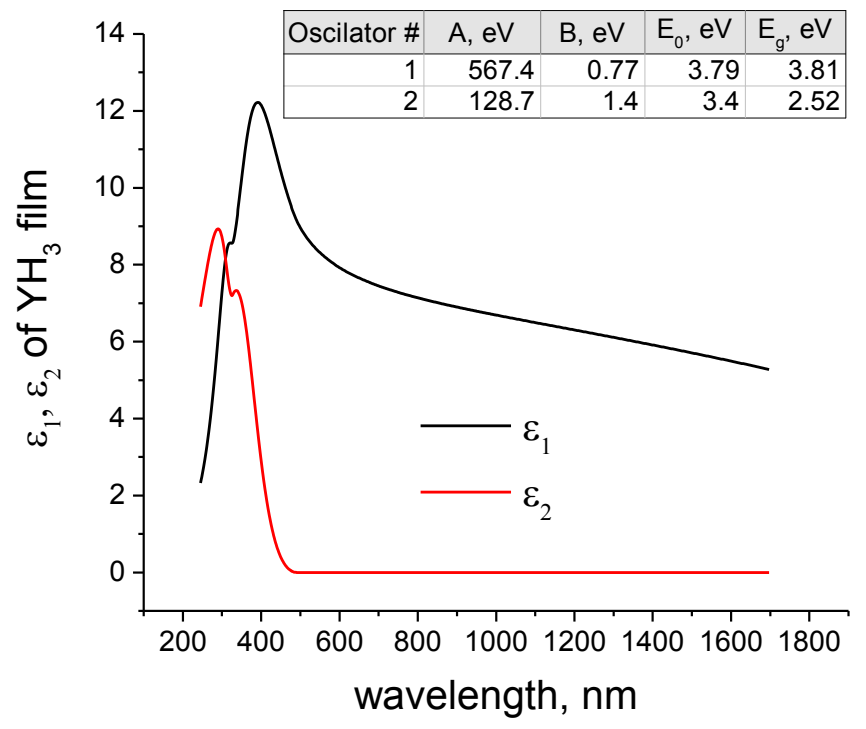

Figure 2.5. Parametrized dielectric function for $\mathrm{YH}_{3}$, extracted from the model (see Table 2.1) and parametrized with two Tauc-Lorentz functions.

With optical models for the individual components in place, the ellipsometry data is analyzed using EMA models for the full temporal range. The schematics of the layered models are shown in Figure 2.4. In range I, where the ruthenium oxide is removed, an EMA model of $\mathrm{RuO}_{2}$ and voids is used. In range II, where the $\mathrm{Y}$ to $\mathrm{YH}_{2}$ phase transition takes place, an EMA of $\mathrm{Y}$ and $\mathrm{YH}_{2}$ is used. And, finally, in range III an EMA of $\mathrm{YH}_{2}$ and $\mathrm{YH}_{3}$ is used. In the first two ranges, only one parameter is fit: the ratio of the two relevant constituents (see Table 2.2). 
The angle offset (the offset of the incident angle) and the thickness of the $\mathrm{YH}_{2} / \mathrm{YH}_{3}$ film are also set as free parameters in the III range. The thickness of the film is expected to expand during the phase transition, so must be fit. The thermal expansion of mounting system also causes a small variation in the angle of incidence, so this was allowed to vary as well.

Table 2.1. Sources of the optical constants of all materials used in the fitting procedure.

\begin{tabular}{|c|l|}
\hline Material & \multicolumn{1}{|c|}{ Source/model } \\
\hline $\mathrm{Ru}$ & $\begin{array}{l}\text { b-spline fit of } \mathrm{Ru} \text { dielectric constants at point A } \\
\text { (see Figure 2.4) }\end{array}$ \\
\hline $\mathrm{YH}_{3}$ & $\begin{array}{l}\text { b-spline fit of } \mathrm{YH}_{3} \text { optical constants at point } \mathrm{B} \text { in } \\
\text { Figure 2.4 }\end{array}$ \\
\hline $\mathrm{Y}$ & Ref [28] \\
\hline $\mathrm{YH}_{2}$ & Ref [28], dielectric function for $\mathrm{YH}_{1.9}$ \\
\hline $\mathrm{RuO}_{2}$ & Ref [29] \\
\hline
\end{tabular}

Table 2.2. The free parameters of each model that were used for fitting ellipsometric data (see Figure 2.4).

\begin{tabular}{|l|l|}
\hline Fit range & Free parameters \\
\hline I & Fraction of voids in $\mathrm{RuO}_{2}$ layer \\
\hline II & Fraction of $\mathrm{Y}$ in $\mathrm{YH}_{2}$ \\
\hline III & $\begin{array}{l}\text { Fraction of } \mathrm{YH}_{3} \text { in } \mathrm{YH}_{2} \text { mixture; } \\
\text { Angle offset; layer thickness }\end{array}$ \\
\hline
\end{tabular}

Figure 2.6a shows the results of fitting the entire hydrogenation process in the manner described above. More detail regarding ellipsometry measurements and fitting results are provided in Appendix (section 2.6). In range I, the fraction of voids in $\mathrm{RuO}_{2}$, which represents the fraction of pinholes in the oxide, rapidly increases when the $\mathrm{W}$ filament is switched on and stays constant thereafter. A void fraction of $100 \%$, which corresponds to an oxide-free surface, was never reached, similar to the data from Ugur et al. [18]. However, an XPS study on reduction of $\mathrm{RuO}_{2}$ by atomic hydrogen showed that nearly complete reduction 
can be achieved [31]. This probably implies that the model does not fully describe the $\mathrm{RuO}_{2}$ reduction process. We speculate that this may be partially caused by sub-stoichiometry of the initial $\mathrm{RuO}_{2}$ film. In addition, simultaneous with the reduction of $\mathrm{RuO}_{2}$, expansion of the $\mathrm{Y}$ lattice due to hydrogen loading starts, which was omitted in the model used here. Nevertheless, the model consistently shows that the void fraction in $\mathrm{RuO}_{2}$ increases rapidly after atomic hydrogen is supplied, suggesting that oxide reduction happens much faster than $\mathrm{H}$ permeation through the Ru capping layer. Previous research on Ru-capped thin films indicates that the surface roughness of Ru layers does not increase due to atomic hydrogen exposure [31]. Therefore, we do not consider porosity of the Ru layer in our model.
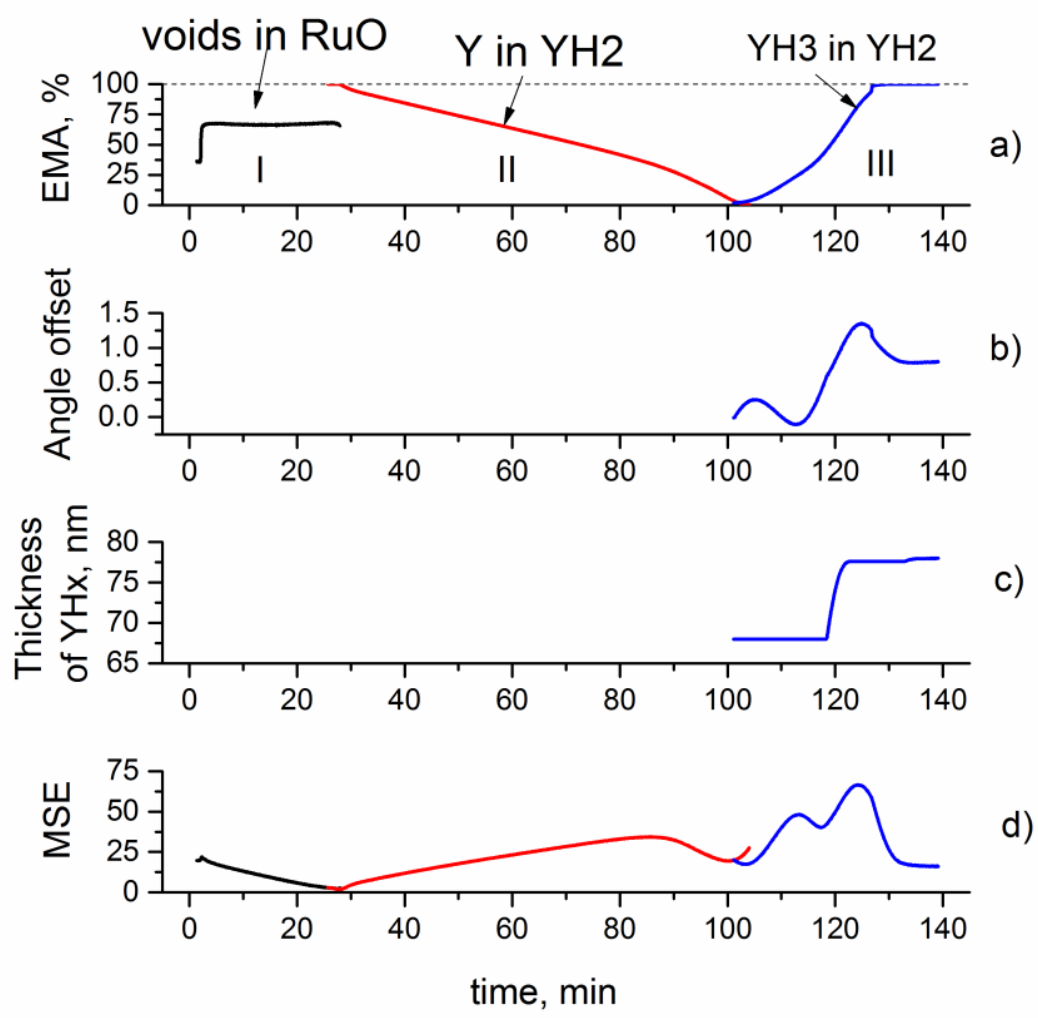

Figure 2.6. The fitted fractions (a) and mean square error (MSE) (d) of the fit as a function of time: range I-fraction of voids in $\mathrm{RuO}_{2}$ layer, range II - fraction of $\mathrm{Y}$ in $\mathrm{YH}_{2}$ phase, and range III - fraction of $\mathrm{YH}_{3}$ in $\mathrm{YH}_{2}$. The angle offset (b) and the $\mathrm{YH}_{3}$ thickness (c) were also fit parameters in range III. 
The hydrogenation trend in range II and range III agree well with the observations from in situ XRD (Figure 2.2). The time of $\mathrm{YH}_{2}$ phase formation (the border of ranges II and III in Figure 2.4) was reliably determined from the fitting of ranges II and III. Since range II excludes the sudden change in optical properties between hydrogenation states $\mathrm{YH}_{1.9}$ and $\mathrm{YH}_{2.1}$, a smooth concentration change in range II is obtained. Thus, we conclude that the model, in general, shows the degree of hydrogenation relatively well. The fit of $\mathrm{YH}_{2}$ to $\mathrm{YH}_{3}$ transition was improved to some extent by setting the angle offset and the thickness of $\mathrm{YH}_{\mathrm{x}}$ as free parameters (Figure 2.6b and Figure 2.6c). A high mean square error in the range III (Figure 2.6d) suggests that the optical properties of the film are not well described by the model over the entire phase transition.

It is clear from the XRD data that there may be some $\mathrm{YH}_{2}$ still present at saturation, which may introduce some minor additional error. However, including $\mathrm{YH}_{2}$ at $7-10 \%$ concentration in the construction of the optical model does not improve the fit. Therefore, it is most likely that a physical process has not been included in the model. It should be noted that an initial bad fit in range III (Figure 2.6d) may be due to the change of optical properties between $\mathrm{YH}_{1.9}$ and $\mathrm{YH}_{2.1}$, which was not accounted for in the ellipsometric model.

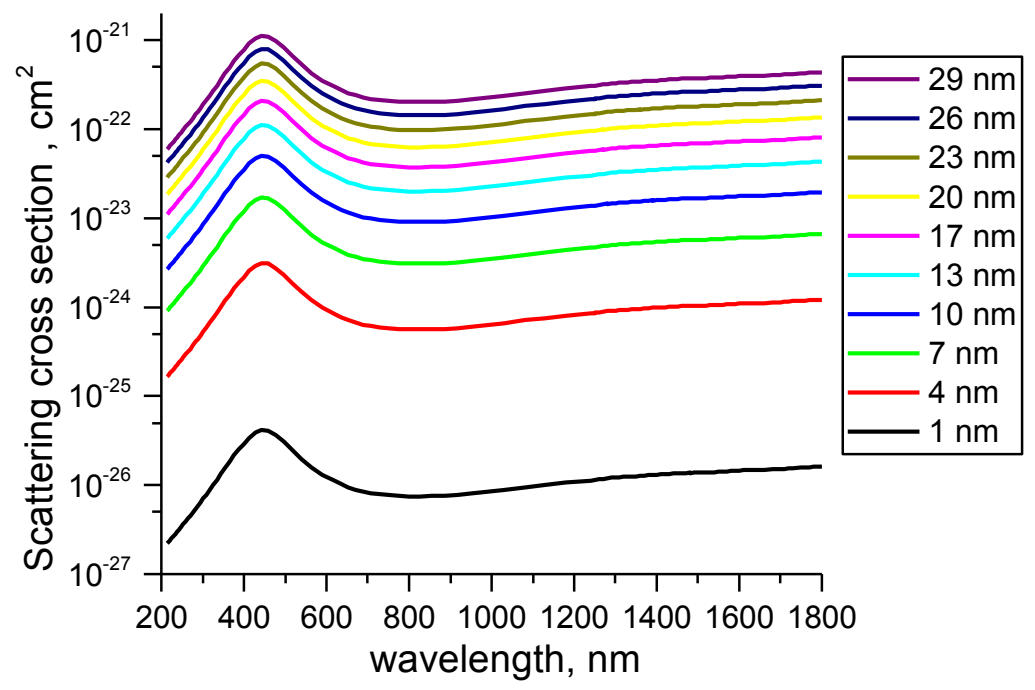

Figure 2.7. The scattering cross section of a single isolated $\mathrm{YH}_{2}$ sphere in a $\mathrm{YH}_{3}$ medium, calculated from Mie scattering theory [32]. 
Wang et al. [13] have shown that reconstruction of bcc $\mathrm{YH}_{2}$ into hcp $\mathrm{YH}_{3}$ creates voids in the film due to shrinkage of the crystal lattice in the plane perpendicular to the c-axis of the $\mathrm{YH}_{3}$ lattice. However, adding voids as a third constituent to the $\mathrm{YH}_{2}-\mathrm{YH}_{3}$ mixture did not improve the fit. Another possibility is the presence of amorphous material. It is possible that there is an unknown fraction of amorphous $\mathrm{YH}_{2}$ or $\mathrm{YH}_{3}$ in the sample during the phase transition, but that the end point is highly crystalline. For the case of the $\mathrm{YH}_{2}$ to $\mathrm{YH}_{3}$ phase transition, we attempted to include a third material in the EMA model (with optical properties obtained from a b-spline fit at the point where the MSE was maximum. However, this was not observed to improve the fit substantially. Although not conclusive, the failure to obtain an improved fit suggests that it is unlikely that a significant amorphous phase forms.

The formation of a metal-dielectric nanostructure is known to modify the optical properties of thin-films in ways that are not well-described by common effective medium theories [33]. Mie theory describes how the growth of isolated nanocrystals may give rise to plasmonic effects that make an EMA model invalid $[33,34]$. When comparing the time at which the maxima in the MSE occur (Figure 2.6d) with the mean crystal size estimation of $\mathrm{YH}_{2}$ and $\mathrm{YH}_{3}$ by XRD (Figure $2.3 \mathrm{c}$ ), it is observed that peaks in the MSE correspond to small isolated $\mathrm{YH}_{3}$ crystallites in a $\mathrm{YH}_{2}$ matrix (in the beginning of range III) and, later, to isolated $\mathrm{YH}_{2}$ crystals in $\mathrm{YH}_{3}$. Mie scattering theory calculations [32] of $\mathrm{YH}_{2}$ spheres, embedded in a $\mathrm{YH}_{3}$ matrix, reveal that $\mathrm{YH}_{2}$ has a local surface plasmon resonance at $450 \mathrm{~nm}$ (see Figure 2.7). This resonance may become significant during $\mathrm{YH}_{3}$ formation at two points during the transition. The resonance may be excited near the beginning of the transition, when small crystallites of $\mathrm{YH}_{3}$ are isolated in $\mathrm{YH}_{2}$. Near the end of the transition, when there are isolated crystallites of $\mathrm{YH}_{2}$ in a $\mathrm{YH}_{3}$ matrix, the resonance may also be excited. In between these two points, the increased connectivity between isolated crystallites will broaden the surface plasmon resonance peak and reduce its influence. Although neither the crystal growth data nor the MSE provide direct evidence for a surface plasmon resonance, the combined data of Figure 2.3 and 6 support its existence and effect on the ellipsometry spectrum.

\subsection{Conclusions}

In this work, the structural changes of Ru coated $\mathrm{Y}$ films during hydrogenation are characterized for the first time. An ellipsometric model was developed to 
quantify the ratio of hydride phases $\mathrm{YH}_{2}$ and $\mathrm{YH}_{3}$ in a $\mathrm{Y}$ film, from which the absorbed amount of hydrogen can be determined. The proposed model encompasses the entire hydrogenation process, which, in combination with other structure analysis, allowed a consistent study of hydride formation. The results suggest that $\mathrm{RuO}_{2}$ is reduced to $\mathrm{Ru}$ by atomic hydrogen in the first seconds, well before any phase transformation occurs. We show that the delayed onset of the $\mathrm{Y}$ to $\mathrm{YH}_{2}$ transition is not due to the lack of hydrogen in the $\mathrm{Y}$ lattice. Instead, the lattice first loads with hydrogen, followed by a rapid phase transition. We speculate that the delayed onset is because the $\mathrm{Y}-\mathrm{YH}_{2}$ interface energy is rather large at approximately $2.1 \mathrm{eV}$.

Once the transition begins, it is described well by an effective medium approximation using pre-existing optical models for $\mathrm{Y}$ and $\mathrm{YH}_{2}$. The time of $\mathrm{YH}_{2}$ formation was reliably determined from the model, which is an important step for sensor development. The hydrogenation time can be used to estimate the hydrogen flux through the capping layer.

To describe the $\mathrm{YH}_{2}$ to $\mathrm{YH}_{3}$ transition, we obtained an optical model for the $\mathrm{YH}_{3}$ phase, with parameters, such as the band gap, that are broadly in agreement with previous models. In this case, however, the transition deviates from an EMA model. These deviations occur at stages in the transition when isolated crystallites are present, for which calculations show a significant plasmonic resonance. This can be interesting for future applications of active plasmonics with a tunable size of plasmonic $\mathrm{YH}_{2}$ crystallites. For highly accurate hydrogen sensors, a model that includes plasmonic effects may be necessary. For that, additional experiments for isolating the plasmonic effect are desirable.

\subsection{Acknowledgements}

The authors would like to thank Dr. German R. Castro and Dr. Juan Rubio-Zuazo for technical support at ESRF and Mr. Cedric Hendrikx for help in conducting the experiments at ESRF. We also thank Mr. Theo van Oijen for depositing samples, and Mr. Goran Milinkovic and Mr. John de Kuster for the technical support. This work is part of the research programme of the Netherlands Organization for Scientific Research (NWO), Domain Applied and Engineering Sciences (AES, previously Technology Foundation STW). The work is additionally supported by ZEISS. We also acknowledge the support of the Industrial Focus Group XUV 
Optics at the MESA+ Institute at the University of Twente, notably the industrial partners ASML, ZEISS, Malvern Panalytical, and the Province of Overijssel.

\subsection{Appendix}

For a direct comparison, a fit of ellipsometry data with EMA models described in this chapter is presented at several intermediate points of the hydrogenation process. The time points correspond to the start, middle and finish of each range. In range III, the data for two maximal values of MSE are also shown (subplots 8 and 6).
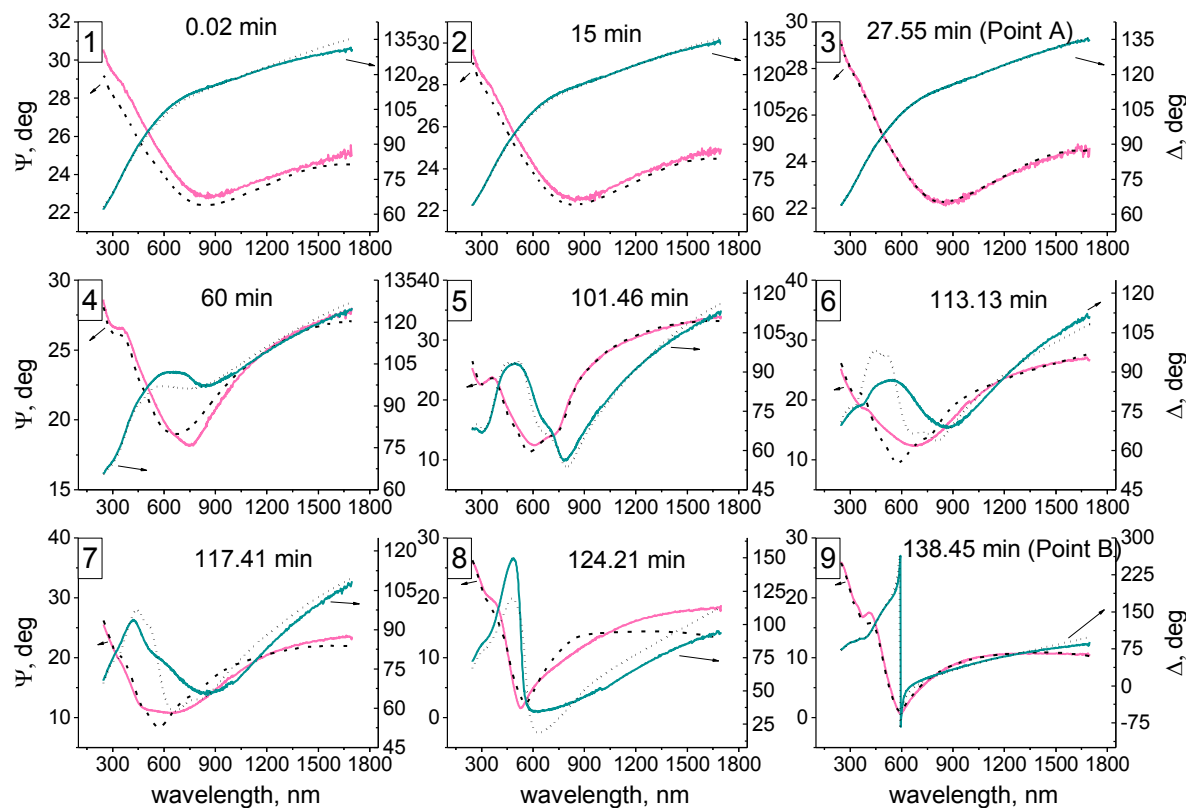

Figure 2.8. Ellipsometric angles $\Psi$ and $\Delta$ as a function of wavelength for different time points of the hydrogenation process, as indicated on each graph. The fit with the described EMA models (see Figure 2.4) is shown with black lines. The subplots are shown chronologically, with subplot 1 corresponding to the start of the hydrogenation and subplot 9 being in the end of the process (point B in Figure 2.4).

\subsection{References}

[1] J. N. Huiberts et al., "Yttrium and lanthanum hydride films with 
switchable optical properties," Nature, vol. 380, no. 6571, pp. 231-234, Mar. 1996.

[2] N. Strohfeldt et al., "Yttrium hydride nanoantennas for active plasmonics," Nano Lett., vol. 14, no. 3, pp. 1140-1147, 2014.

[3] P. Ngene, T. Radeva, M. Slaman, R. J. Westerwaal, H. Schreuders, and B. Dam, "Seeing hydrogen in colors: Low-cost and highly sensitive eye readable hydrogen detectors," Adv. Funct. Mater., vol. 24, no. 16, pp. 2374-2382, Apr. 2014.

[4] F. J. A. Den Broeder et al., "Visualization of hydrogen migration in solids using switchable mirrors," Nature, vol. 394, no. 6694, pp. 656-658, Aug. 1998.

[5] A. Remhof, S. J. Van Der Molen, A. Antosik, A. Dobrowolska, N. J. Koeman, and R. Griessen, "Switchable mirrors for visualization and control of hydrogen diffusion in transition metals," Phys. Rev. B Condens. Matter Mater. Phys., vol. 66, no. 2, pp. 1-4, 2002.

[6] M. A. Butler, "Fiber Optic Sensor for Hydrogen Concentrations near the Explosive Limit," J. Electrochem. Soc., vol. 138, no. 9, p. L46, 1991.

[7] T. Radeva, P. Ngene, M. Slaman, R. Westerwaal, H. Schreuders, and B. Dam, "Highly sensitive and selective visual hydrogen detectors based on Y xMg1-x thin films," Sensors Actuators, B Chem., vol. 203, pp. 745751, Nov. 2014.

[8] A. T. M. van Gogh et al., "Structural, electrical, and optical properties of La1-zYzHx switchable mirrors," Phys. Rev. B - Condens. Matter Mater. Phys., vol. 63, no. 19, p. 195105, Apr. 2001.

[9] L. N. Yannopoulos, R. K. Edwards, and P. G. Wahlbeck, " The Thermodynamics of the Yttrium-Hydrogen System 1 ," J. Phys. Chem., vol. 69 , no. 8, pp. 2510-2515, Aug. 1965.

[10] O. Soroka, J. M. Sturm, R. W. E. van de Kruijs, C. J. Lee, and F. Bijkerk, "Control of YH 3 formation and stability via hydrogen surface adsorption and desorption," Appl. Surf. Sci., vol. 455, pp. 70-74, Oct. 2018.

[11] M. W. Lee and W. P. Shin, "Optical properties of the $\gamma$ phase yttrium

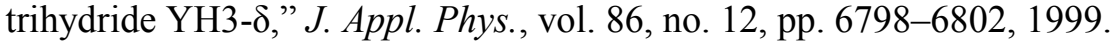

[12] S. J. Van Der Molen, J. W. J. Kerssemakers, J. H. Rector, N. J. Koeman, B. Dam, and R. Griessen, "Hydriding kinetics of Pd capped YHx switchable mirrors," J. Appl. Phys., vol. 86, no. 11, pp. 6107-6119, Nov. 1999.

[13] K. Wang, J. R. Hattrick-Simpers, and L. A. Bendersky, "Phase transformation in an yttrium-hydrogen system studied by TEM," Acta 
Mater., vol. 58, no. 7, pp. 2585-2597, 2010.

[14] M. W. Lee, C. Y. Kuo, H. C. Lin, and H. C. Wang, "Variations of the infrared transmission properties with the metal-insulator transition in thin films of the yttrium-hydride system," J. Appl. Phys., vol. 89, no. 11 I, pp. 6135-6138, 2001.

[15] E. S. Kooij, A. T. M. Van Gogh, D. G. Nagengast, N. J. Koeman, and R. Griessen, "Hysteresis and the single-phase metal-insulator transition in switchable YHx films," Phys. Rev. B - Condens. Matter Mater. Phys., vol. 62, no. 15, pp. 10088-10100, 2000.

[16] D. J. Santjojo, T. Aizawa, and S. Muraishi, "Ellipsometric Characterization on Multi-Layered Thin Film Systems during Hydrogenation," Mater. Trans., vol. 48, no. 6, pp. 1380-1386, 2007.

[17] O. V. Braginsky et al., "Removal of amorphous C and Sn on Mo:Si multilayer mirror surface in Hydrogen plasma and afterglow," J. Appl. Phys., vol. 111, no. 9, p. 093304, May 2012.

[18] D. Ugur, A. J. Storm, R. Verberk, J. C. Brouwer, and W. G. Sloof, "Kinetics of reduction of a $\mathrm{RuO}_{2}(110)$ film on $\mathrm{Ru}(0001)$ by atomic hydrogen," Microelectron. Eng., vol. 110, pp. 60-65, Oct. 2013.

[19] J. Rubio-Zuazo, P. Ferrer, A. López, A. Gutiérrez-León, I. da Silva, and G. R. Castro, "The multipurpose X-ray diffraction end-station of the BM25B-SpLine synchrotron beamline at the ESRF," Nucl. Instruments Methods Phys. Res. Sect. A Accel. Spectrometers, Detect. Assoc. Equip., vol. 716, pp. 23-28, 2013.

[20] J. N. Huiberts et al., "Synthesis of yttrium trihydride films for ex-situ measurements," J. Alloys Compd., vol. 239, no. 2, pp. 158-171, Jun. 1996.

[21] K. L. Kostov, W. Widdra, and D. Menzel, "Hydrogen on Ru (001) revisited: Vibrational structure, adsorption states, and lateral coupling," Surf. Sci., vol. 560, no. 1-3, pp. 130-144, Jul. 2004.

[22] K. A. Gschneidner, "Physical properties of the rare earth metals," Bull. Alloy Phase Diagrams, vol. 11, no. 3, pp. 216-224, 1990.

[23] V. V. Akhachinskij, "Enthalpy of formation of YH1.994 and YH2.792," in PROCEEDINGS OF AN INTERNATIONAL SYMPOSIUM ON THERMODYNAMICS OF NUCLEAR MATERIALS Vol.II, 1980.

[24] D. Khatamian, C. Stassis, and B. J. Beaudry, "Location of deuterium in $\alpha$-yttrium," Phys. Rev. B, vol. 23, no. 2, pp. 624-627, 1981.

[25] I. S. Anderson, J. J. Rush, T. Udovic, and J. M. Rowe, "Hydrogen Pairing and Anisotropic Potential for Hydrogen Isotopes in Yttrium," Phys. Rev. 
Lett., vol. 57, no. 22, pp. 2822-2825, Dec. 1986.

[26] X. Li, X. Lian, and F. Liu, "Rear-End Road Crash Characteristics Analysis Based on Chinese In-Depth Crash Study Data," CICTP 2016 Green Multimodal Transp. Logist. - Proc. 16th COTA Int. Conf. Transp. Prof., vol. 11, pp. 1536-1545, 2016.

[27] H. Oizumi, A. Izumi, K. Motai, I. Nishiyama, and A. Namiki, "Atomic hydrogen cleaning of surface $\mathrm{Ru}$ oxide formed by extreme ultraviolet irradiation of Ru-capped multilayer mirrors in $\mathrm{H}_{2} \mathrm{O}$ ambience," Japanese J. Appl. Physics, Part 2 Lett., vol. 46, no. 25-28, pp. L633-L635, Jun. 2007.

[28] A. T. M. van Gogh, Probing the Metal-insulator Transition in Rare-earth Based Switchable Mirrors (PhD thesis). Vrije Universiteit, 2001.

[29] P. Hones, T. Gerfin, and M. Grätzel, "Spectroscopic ellipsometry of $\mathrm{RuO} 2$ films prepared by metalorganic chemical vapor deposition," Appl. Phys. Lett., vol. 67, no. 21, p. 3078, Nov. 1995.

[30] G. E. Jellison and F. A. Modine, "Parameterization of the optical functions of amorphous materials in the interband region," Appl. Phys. Lett., vol. 69, no. 3, pp. 371-373, Jul. 1996.

[31] I. Nishiyama et al., "Reduction of oxide layer on Ru surface by atomichydrogen treatment," J. Vac. Sci. Technol. B Microelectron. Nanom. Struct., vol. 23, no. 6, p. 3129, Dec. 2006.

[32] C. F. Bohren and D. R. Huffman, Absorption and Scattering of Light by Small Particles. New York: Wiley-Interscience, 1998.

[33] B. A. Belyaev and V. V Tyurnev, "Electrodynamic Calculation of Effective Electromagnetic Parameters of a Dielectric Medium with Metallic Nanoparticles of a Given Size," J. Exp. Theor. Phys., vol. 127, no. 4, pp. 608-619, 2018.

[34] X. Fan, W. Zheng, and D. J. Singh, "Light scattering and surface plasmons on small spherical particles," Light Sci. \&Amp; Appl., vol. 3, p. e179, Jun. 2014. 


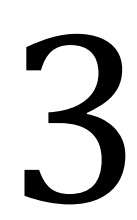

\section{Control of YH3 formation and stability via hydrogen surface adsorption and desorption}

Yttrium is known to form two hydrides: $\mathrm{YH}_{2}$, a metal, and $\mathrm{YH}_{3}$, which is dielectric. However, the stability of $\mathrm{YH}_{3}$ is not fully understood, especially in the context of thin films, where the yttrium layer must be coated to protect it from oxidation. In this work, we show that the stability of a $\mathrm{YH}_{3}$ thin film depends on the capping layer material. Our investigation reveals that $\mathrm{YH}_{3}$ appears to be stabilized by hydrogen that is adsorbed to the capping layer surface. This is evidenced by the $\mathrm{YH}_{3}-\mathrm{YH}_{2}$ transition temperature, which was found to be correlated with the desorption temperature of hydrogen from the surface. We posit that surface-adsorbed hydrogen prevents hydrogen from diffusing out of the thin film, which limits $\mathrm{YH}_{3}$ dissociation to the solubility of hydrogen in the $\mathrm{YH}_{2} / \mathrm{YH}_{3}$ thin film. 


\subsection{Introduction}

The ability of rare-earth metals to form stable hydrides has found various applications in hydrogen storage, hydrogen sensing, and superconductivity. Yttrium is known to form di- and trihydrides, which was demonstrated in early works [1-4]. A pure bulk Y sample, exposed to $\sim 1$ bar of hydrogen and heated to $400^{\circ} \mathrm{C}$, reacts to form $\mathrm{YH}_{2}[1] . \mathrm{YH}_{3}$ is formed once the temperature of $\mathrm{YH}_{2}$ is lowered to $200^{\circ} \mathrm{C}$ at a similar hydrogen pressure [2]. Further research showed that $\mathrm{Y}$, in the form of a thin film (usually capped), does not powderize during hydrogenation, in contrast to bulk Y samples, allowing its electrical and optical properties to be extensively studied [5-9].

Later it was also found that a Y film, capped with a thin layer of Pd, simplifies the conditions needed for $\mathrm{Y}$ hydrogenation: hydride formation happens at lower hydrogen pressures and temperatures [7]. The role played by Pd is generally thought to be two-fold: (i) Pd dissociates $\mathrm{H}_{2}$, providing a supply of reactive atomic hydrogen so that hydrogenation can proceed at room temperature, and (ii) Pd protects $\mathrm{Y}$ from oxidation, allowing hydrogenation. Interestingly, Pd capped $\mathrm{Y}$ hydrides are reversible at room temperature. Once the $\mathrm{H}_{2}$ supply is removed, the $\mathrm{YH}_{3}$ phase dissociates at room temperature to form $\mathrm{YH}_{2}$ and $\mathrm{H}_{2}$ [10]. According to Huiberts et al. [7], $\mathrm{YH}_{3}$ stability in bulk is due to the bulk phase having a lower enthalpy of formation than a thin film. Furthermore, due to the unique catalytic properties of Pd, Y hydrogenation with other capping materials has not been studied.

In this chapter, we present an investigation of the dependence between the stability of $\mathrm{YH}_{3}$ and the capping layer material. We propose that the observed (measured) dissociation temperature of $\mathrm{YH}_{3}$ is more properly associated with the desorption temperature of hydrogen from the surface of the capping layer. In our model, the dissociation temperature of $\mathrm{YH}_{3}$ is lower than room temperature, however, if the hydrogen cannot escape from the surface, hydrogen diffusion is blocked and, thereby, the $\mathrm{YH}_{3}$ phase is stabilized. As a result, $\mathrm{YH}_{3}$ dissociation only occurs at temperatures above the $\mathrm{H}_{2}$ surface desorption temperature of the capping layer.

\subsection{Experimental procedure}

All samples were deposited using DC magnetron sputtering. Sputter deposition took place in a vacuum chamber with a base pressure of $10^{-8}$ mbar using $\mathrm{Y}, \mathrm{Ru}, \mathrm{Pd}$, and Ta targets with a purity of $99.95 \%$, and $\mathrm{Ag}$ and $\mathrm{C}$ targets with purities of $99.99 \%$ 
and $99.999 \%$ respectively. Silicon (100) wafers, precut $15 \times 15 \mathrm{~mm}$, were coated with $70 \mathrm{~nm}$ of $\mathrm{Y}$ and then covered with a capping layer of $\mathrm{Ru}, \mathrm{Pd}, \mathrm{Ag}$ or Ta. To protect the cap metal from oxidation, $5 \mathrm{~nm}$ of carbon was sputtered onto the Ta and Ag capped samples, which was later removed by hydrogen radicals during the hydrogenation experiment.

After deposition, the thickness, roughness, and crystallinity of the deposited layers were measured using X-ray reflectivity (XRR), atomic force microscopy (AFM) (Bruker, Dimension Edge), and X-ray diffraction (XRD) (Panalytical Empyrean). $\mathrm{XRD}$ and XRR were performed using $\mathrm{Cu}-\mathrm{K} \alpha$ radiation with a wavelength of 0.154 $\mathrm{nm}$. For XRD measurements, a parafocusing geometry was chosen with a $0.2 \mathrm{~mm}$ fixed divergence slit and a Ni filter for the incident beam, and a scanning line detector to obtain a higher diffracted intensity and an increased signal to noise ratio. A cross-sectional analysis of a Ru capped Y sample was provided by a High Resolution Transmission Electron Microscope (Philips CM300ST-FEG Transmission Electron Microscope, MESA+ Nanolab at University of Twente). TEM specimens were prepared by dimple grinding/polishing and argon ion etching [11].

Hydrogenation experiments were performed in a vacuum chamber with a base pressure of $1 \times 10^{-7} \mathrm{mbar}$ and a hydrogen pressure of $1.3 \times 10^{-2}$ mbar. For all samples, a constant flow of hydrogen radicals was used. Hydrogen radicals were generated by flowing molecular hydrogen $(108 \mathrm{sccm})$ past a $\mathrm{W}$ filament, placed about $5 \mathrm{~cm}$ from the sample surface, and heated to $2000^{\circ} \mathrm{C}$, as measured by an infrared temperature sensor (Raytek, RayMR1SCCF). Although Pd can dissociate molecular hydrogen, the $\mathrm{H}_{2}$ splitting efficiency of a hot $\mathrm{W}$ filament is much higher, thus, hydrogenation occurs faster in the latter case. The hydrogen radical flux was estimated from the etch rate of a carbon film to be $10^{18}$ at $/ \mathrm{cm}^{2} / \mathrm{s}$ [12]. The sample temperature was monitored using a K-type thermocouple, and maintained at $30-40^{\circ} \mathrm{C}$ by water cooling.

Hydrogenation of $\mathrm{Y}$ was monitored using in situ spectroscopic ellipsometry (Woollam M-2000XI) at an angle of incidence of $75^{\circ}$ and a spectral range of 240$1600 \mathrm{~nm}$. Exposure to H-radicals was stopped when the ellipsometric angles $\Psi$ and $\Delta$ stabilized after a rapid change. The exposed samples were removed from the vacuum and tested with $\mathrm{XRD}$, to characterize the hydride content.

Samples that formed a stable $\mathrm{YH}_{3}$ phase after hydrogenation were heated in a nitrogen atmosphere on a hot stage of the $\mathrm{Cu}-\mathrm{K}$ diffractometer and the dissociation temperature of $\mathrm{YH}_{3}$ was measured. Heating was limited to temperatures below $350^{\circ} \mathrm{C}$, as heating to higher temperatures initiated oxidation of the $\mathrm{Y}$ film. The temperature 
was increased in 10 degree steps, and at each step XRD spectra were measured until no change in diffraction pattern was observed. The temperature at which the (002) peak of $\mathrm{YH}_{3}$ started to decrease was noted as $\mathrm{YH}_{3}$ dissociation temperature.

\subsection{Results and discussions}

\subsubsection{Pre-characterization}

The thicknesses of the $\mathrm{Y}$ films and capping layers were determined using XRR. Typical values are shown in Table 3.1. Overall, Y thickness for all samples was $70-80 \mathrm{~nm}$ and the thickness of single caps was $3-4 \mathrm{~nm}$. Note, that the protective carbon layer on the $\mathrm{Ag}$ cap is significantly thinner than the targeted thickness, which may indicate the intermixing of $\mathrm{Ag}$ and $\mathrm{C}$. In the case of the $\mathrm{Pd} / \mathrm{Ru}$ cap, the thickness of Ru has to be increased to prevent the direct contact between $\mathrm{Y}$ and Pd. It is also important to note that fitting XRR spectra for $\mathrm{Pd} / \mathrm{Ru}$ sample was challenging, because $\mathrm{Ru}$ and $\mathrm{Pd}$ have low contrast for hard X-rays.

Table 3.1. Thicknesses (in $\mathrm{nm}$ ) of $Y$ and capping layers for all sample types.

\begin{tabular}{|c|c|c|c|c|c|}
\hline Caps & $\mathrm{Ta}$ & $\mathrm{Ru}$ & $\mathrm{Pd} / \mathrm{Ru}$ & $\mathrm{Pd}$ & $\mathrm{Ag}$ \\
\hline $\mathrm{Y}$ & 73.6 & 72.4 & 79.7 & 72.3 & 70.2 \\
\hline Cap & 3.8 & 2.9 & $4.4 / 5.4$ & 4 & 3.4 \\
\hline Carbon layer & 5 & - & - & - & 3.6 \\
\hline
\end{tabular}

The XRD spectra of all samples only contain peaks associated with the Y film (and Si substrate), as the peak intensity of the thin capping layer is negligibly small in $\theta$ $2 \theta$ geometry. The $\mathrm{Y}$ peaks of all as-deposited samples appear to be the same, therefore, only the XRD spectra of a Ru capped Y film is shown in Figure 3.1. The vertical lines indicate tabulated Bragg peaks for powders. The peaks are shifted with respect to the tabulated values due to film stress. The small peak around $33^{\circ}$ origi- 
nates from the Si monocrystalline substrate. It is observed that $\mathrm{Y}$, grown on crystalline $\mathrm{Si}$, is poly- or nanocrystalline with (002) and (100) preferential growth directions. The minimal crystallite size was estimated using the Scherrer relation [13]:

$$
d=(0.94 \lambda) /(w \cos \theta),
$$

where $w$ is the full width at the half maximum of the XRD peak, $\lambda$ - the radiation wavelength, and $\theta$ - the diffraction angle. The calculated Y crystallite size (in the direction normal to the sample surface) was estimated to be no less than $15 \mathrm{~nm}$.

The surface of a typical sample is fairly smooth, as can be concluded from an AFM scan (Figure 3.2), with root mean square roughness of $0.6 \mathrm{~nm}$.

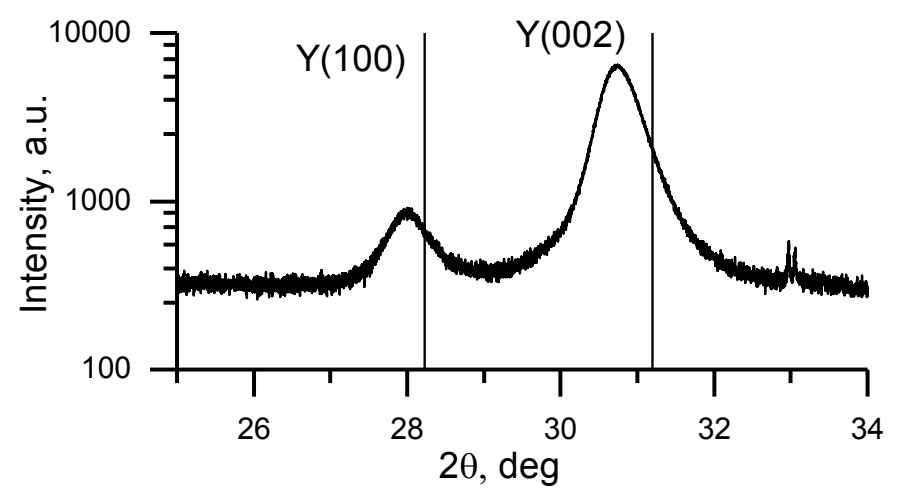

Figure 3.1. XRD spectra of a typical as-deposited sample of $70 \mathrm{~nm} Y$ capped with $3 \mathrm{~nm} \mathrm{Ru}$.

Bright field HRTEM images are shown in Figure 3.3. The image shows that a thin amorphous intermixing layer is formed on the $\mathrm{Ru} / \mathrm{Y}$ interface (visible by its brighter contrast compared to pure $\mathrm{Ru}$, image 1 ). At the $\mathrm{Y} / \mathrm{Si}$ interface, a $4 \mathrm{~nm}$ thick amorphous interface layer is formed (image 2). Its formation was probably induced by the reaction of $\mathrm{Y}$ with $\mathrm{O}$ that was contained in the native Si oxide layer, since $\mathrm{Y}$ oxide has a low enthalpy of formation. The orientation of the $\mathrm{Y}$ crystallites confirms the XRD findings, but the measured d-spacing of $3.06 \AA$ indicates that the $Y$ film is fully oxidized in the process of TEM specimen transfer and preparation.

\subsubsection{Results}

Samples were exposed to hydrogen radicals until no further change in ellipsometric angles $\Psi$ and $\Delta$ were observed. Figure 3.4 shows the time evolution of the ellipsometric angle $\Psi$ at a wavelength of $791 \mathrm{~nm}$ during hydrogenation for samples with 
different capping layers. Depending on the sample, the following features are observed. For Ta and Ag capped samples, $\Psi$ first increases as the carbon layer is removed by $\mathrm{H}^{*}$. Likewise, for samples with $\mathrm{Ru}$ and Pd top surfaces, the first $\Psi$ changes (a decrease in this case) are due to the removal of the native oxide layer. After the removal of the protective coating, $\mathrm{H}$ may diffuse through the capping layer to reach the $\mathrm{Y}$ film and the formation of $\mathrm{YH}_{2}$ starts, which may then be followed by the formation of $\mathrm{YH}_{3}$. The transitions for $\mathrm{Ru}$ and Ta caps show similar dynamics, while almost no change in $\Psi$ for samples with a Ag cap could be detected after a long exposure to $\mathrm{H}^{*}$ (see Figure 3.4).

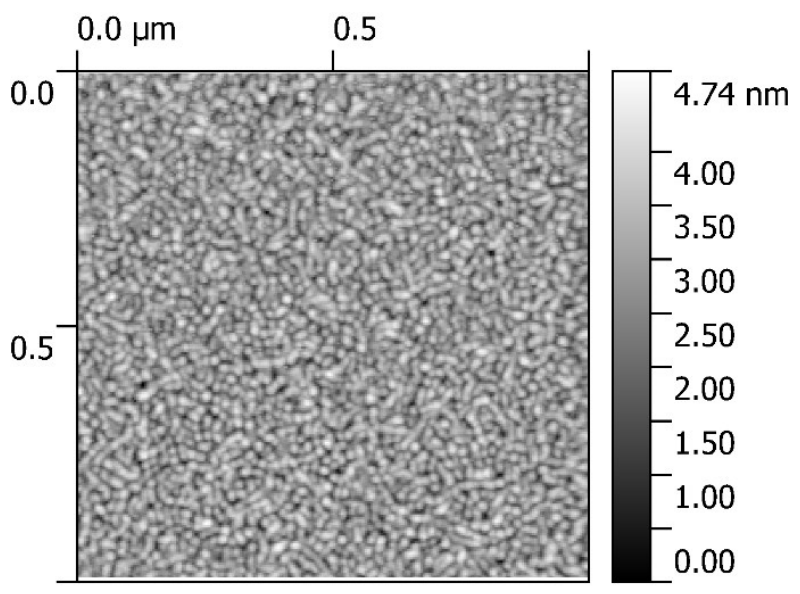

Figure 3.2. AFM picture of the surface of a $3 \mathrm{~nm} R$ Ru/70nm Y sample.

After no change in the SE signal was registered, which suggests that the $\mathrm{Y}$ film is saturated with hydrogen, samples were transferred to the $\mathrm{Cu}-\mathrm{K}$ diffractometer and their XRD spectra were measured under ambient conditions (Figure 3.5). The diffraction patterns for both the $\mathrm{Ru}$ and Ta capped samples contain diffraction peaks of both a dominant $\mathrm{YH}_{3}$ (002) phase, and a weak $\mathrm{YH}_{2}$ (111) phase. On the other hand, the samples with $\mathrm{Pd}$ and $\mathrm{Pd} / \mathrm{Ru}$ caps have a strong $\mathrm{YH}_{2}$ peak along with some traces of a $\mathrm{YH}_{3}(002)$ peak. The sample with $\mathrm{Ag}$ cap remains unchanged (comparing to before exposure, Figure 3.1) except of the shoulder of the Y (002) peak, which may indicate that a minor amount of $\mathrm{YH}_{2}$ is formed.

The growth of the $\mathrm{YH}_{3}$ crystallite size for $\mathrm{Ru}$ capped samples was investigated in more detail. According the Scherrer equation, the $\mathrm{YH}_{3}$ crystallite size was $33.2 \mathrm{~nm}$, 
which is more than twice the deposited Y film crystallite size. This change in crystallite size is not due to lattice expansion after incorporating hydrogen, as the increase of the unit cell volume due to hydrogenation is only $12 \%$. The increase in unit cell volume, however, closely matches XRR measurements, which show that the thickness of the Y film increases by $15 \%$ after hydrogenation. The growth of the crystallites is, thus, much larger than the film thickness growth, which evidences that hydrogenation leads to ordering of crystallites. Notably, the same rearrangement of crystallites in the $\mathrm{Y}$ film is observed for all types of samples where saturation to $\mathrm{YH}_{2}$ or $\mathrm{YH}_{3}$ phase was possible. This suggests that crystallite ordering already happens during the $\mathrm{Y}-\mathrm{YH}_{2}$ transition.

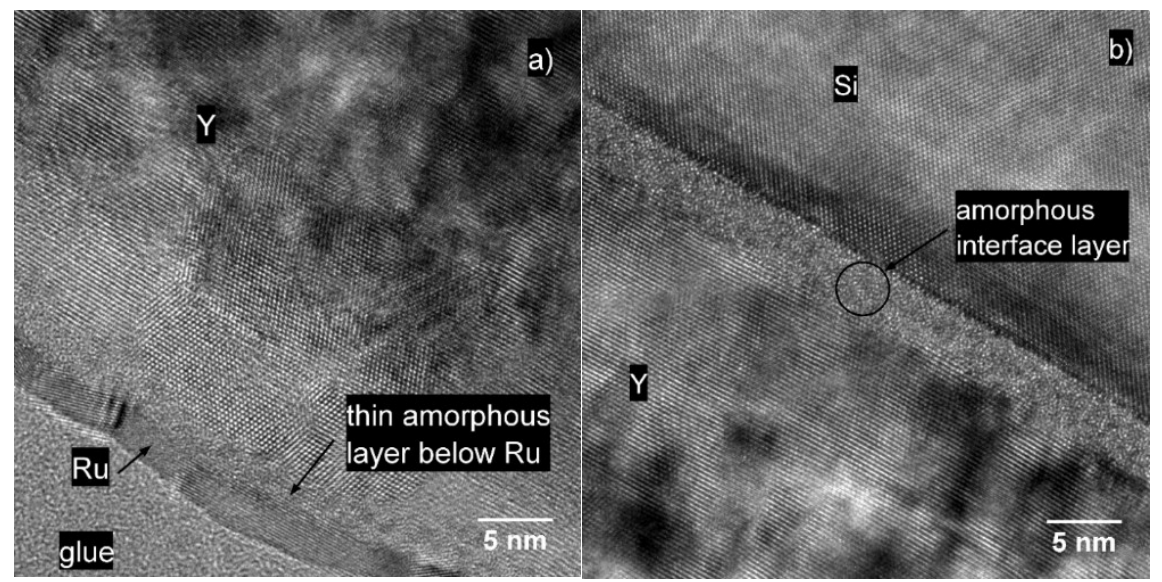

Figure 3.3. HRTEM of 3Ru/70Y: a) Ru/Y interface, b) Y/Si interface.

The $\mathrm{YH}_{3}$ dissociation temperature was measured by heating the samples and measuring the changes in the XRD pattern. It was observed that $\mathrm{YH}_{3}$ in $\mathrm{Ru}$ capped samples dissociated at $423 \mathrm{~K}$, while, for $\mathrm{Ta}$, the $\mathrm{YH}_{3}$ dissociation temperature was above the maximum that could be achieved in our experimental apparatus. For $\mathrm{Ag}$ and $\mathrm{Pd}$ capped samples, $\mathrm{YH}_{3}$ was not stable at room temperature, which was the minimum our setup was capable of. The intensity of the $\mathrm{YH}_{2}(111)$ and $\mathrm{YH}_{3}(002)$ peaks as a function of temperature is shown in Figure 3.6 for the case of a Ru cap. The hydrogen desorption temperature for the Ru surface [14] is close to the dissociation temperature of $\mathrm{YH}_{3}$ that we obtained, while the desorption temperature for Ta is much higher than the temperature limit of the setup (see Table 3.2). 

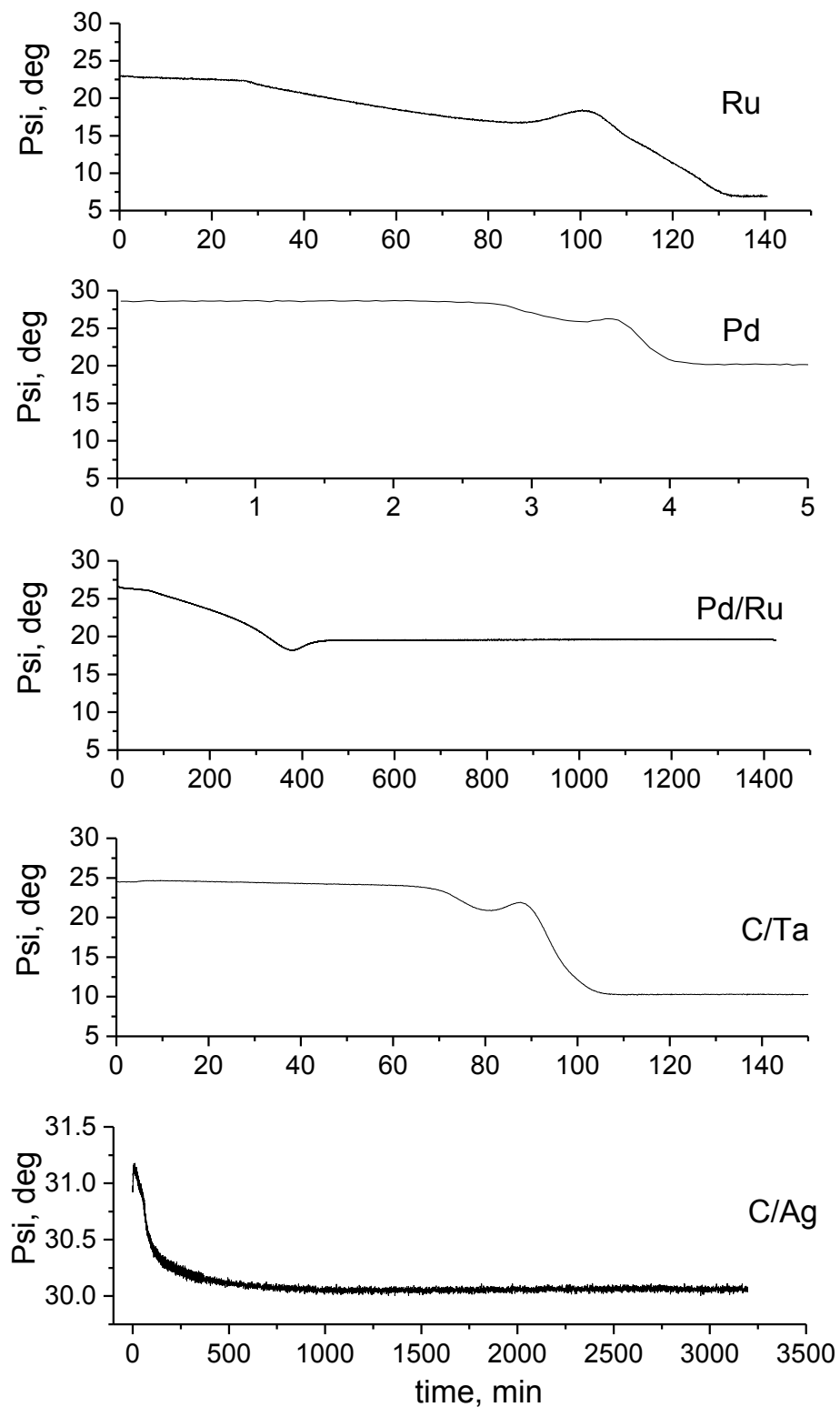

Figure 3.4. Time evolution of ellipsometric angle $\Psi$ for all samples at a wavelength of 791 $\mathrm{nm}$ during exposure to hydrogen radicals. The name of the capping material is indicated on each graph (note that the large difference in $\Psi$-axis scale for Ag capped sample). The $W$ filament was switched on at time 0 and remained on till the end of the measurements shown on the figure. 


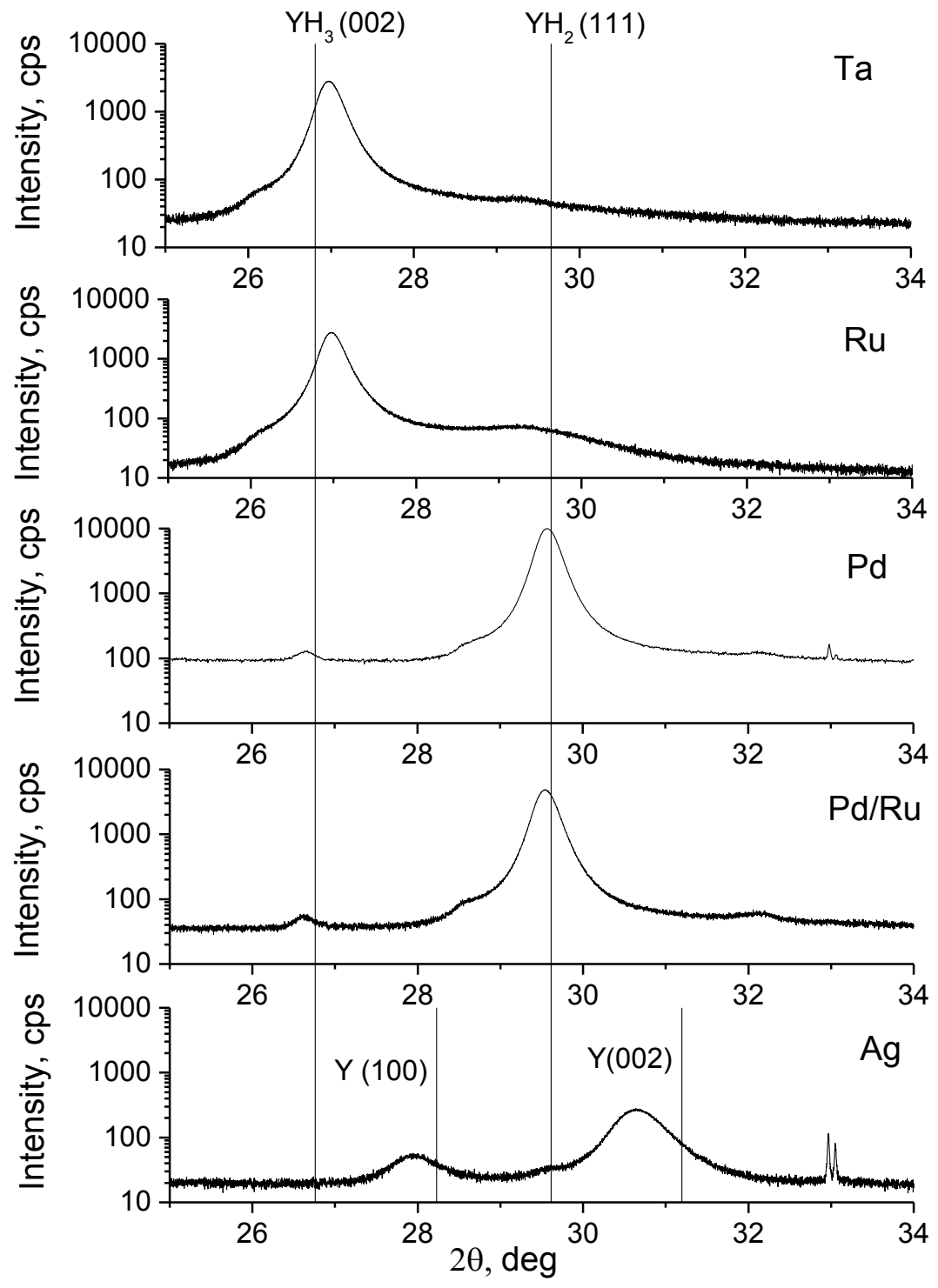

Figure 3.5. XRD spectra of hydrogenated samples with different capping layers. The lines indicate the tabulated peaks for powders. 


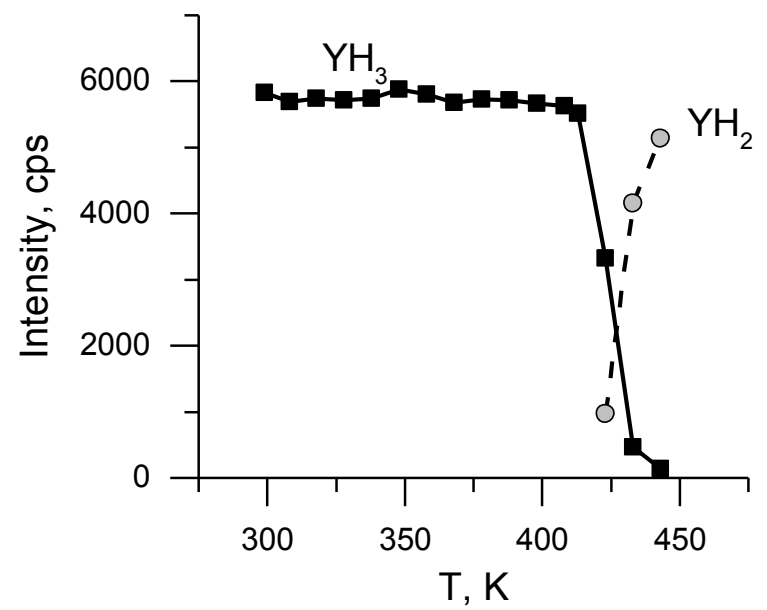

Figure 3.6. Intensity of the diffraction peak (002) of $\mathrm{YH}_{3}$ and (111) of $\mathrm{YH}_{2}$ for a Ru/Y sample versus the temperature.

Table 3.2. Desorption temperatures of hydrogen for capping materials and dominant yttrium hydride phase of the corresponding hydrogenated sample.

\begin{tabular}{|c|c|c|c|c|c|}
\hline & Ta & $\mathbf{R u}$ & $\mathbf{P d} / \mathbf{R u}$ & $\mathbf{P d}$ & $\mathbf{A g}$ \\
\hline $\mathrm{YH}_{\mathrm{x}}$ of saturated sample & $\mathrm{YH}_{3}$ & $\mathrm{YH}_{3}$ & $\mathrm{YH}_{2}$ & No hydride \\
\hline $\begin{array}{c}\text { Hydrogen desorption } \\
\text { temperature of topmost } \\
\text { capping layer, } \mathrm{K}\end{array}$ & $775^{1}$ & $410^{1}$ & $\begin{array}{c}293 \text { (weakly } \\
\text { bounded } \mathrm{H})^{1}\end{array}$ & $160^{1}$ \\
\hline
\end{tabular}

\subsection{Summary and Conclusions}

In this work, we studied the hydrogenation of thin Y films, coated with different materials. In the case of a Ag capping layer, no significant hydrogenation was observed. This may be due to the high desorption rate of hydrogen from the Ag surface at room temperature. For other samples the stable $\mathrm{Y}$ hydride phase was analyzed. For both $\mathrm{Pd}$ and $\mathrm{Pd} / \mathrm{Ru}$ caps, the thermodynamically favorable $\mathrm{YH}_{2}$ phase was formed, while a stable $\mathrm{YH}_{3}$ phase was obtained for the cases of $\mathrm{Ru}$ and Ta caps. The samples with a $\mathrm{YH}_{3}$ phase that was stable at room temperature were heated in an $\mathrm{N}_{2}$ 
atmosphere to measure the temperature of $\mathrm{YH}_{3}$ dissociation. The dissociation temperature for the $\mathrm{Ru} / \mathrm{YH}_{3}$ sample was $423 \mathrm{~K}$, while the dissociation of $\mathrm{YH}_{3}$ was not reached for the Ta capped sample due to the limited maximum temperature of the experimental setup $\left(\mathrm{T}_{\max }=623 \mathrm{~K}\right)$. We note that the measured dissociation temperature for $\mathrm{Ru} / \mathrm{YH}_{3}$ is close to the reported temperature of hydrogen desorption from a $\mathrm{Ru}$ surface. We also noted that the desorption of hydrogen from $\mathrm{Ta}$ is reported to occur at $775 \mathrm{~K},[15]$ which is higher than the experimental setup allowed.

The formation (or lack of formation) of $\mathrm{YH}_{3}$, depending on the cap layer provides reasonable evidence that the observed dissociation temperature of $\mathrm{YH}_{3}$ is actually controlled by desorption of hydrogen from the capping layer surface. This evidence is strengthened by the observation that $\mathrm{Pd}$-capped $\mathrm{Ru} / \mathrm{Y}$ does not have a stable $\mathrm{YH}_{3}$ phase at room temperature. If the direct interaction between the $\mathrm{YH}_{\mathrm{x}}$ phase and the cap-layer were the (de-)stabilizing factor, then $\mathrm{Ru}$ should stabilize $\mathrm{YH}_{3}$ even when the $\mathrm{Ru}$ is capped with $\mathrm{Pd}$. On the other hand, if $\mathrm{YH}_{3}$ thin films are unstable at (or below) room temperature, then a stable $\mathrm{YH}_{3}$ phase should not be observed in any of the samples.

During $\mathrm{YH}_{3}$ dissociation, hydrogen will leave the thin film via diffusion from the surface. At equilibrium, the flux of hydrogen exiting the thin film will balance hydrogen production via dissociation. However, if hydrogen binds to the capping layer surface, the net flux will drop to zero. In this case, $\mathrm{YH}_{3}$ dissociation will form an equilibrium with the hydrogen dissolved (or trapped) in the surrounding material ( $\mathrm{YH}_{\mathrm{x}}$ and capping material). The small volume of dissolved hydrogen in the capping material and the low solubility of hydrogen in $\mathrm{YH}_{\mathrm{x}}$ imply that the majority of hydrogen must remain bound to $\mathrm{Y}$ to form $\mathrm{YH}_{3}$. As a result, we conclude that the apparent stability or instability of $\mathrm{YH}_{3}$ is, in case of thin films, governed by the surface desorption temperature of the capping layer.

\subsection{Acknowledgments}

The authors would like to thank Mr. Goran Milinkovic and Mr. John de Kuster for the technical support, and Mr. Theo van Oijen for deposition of samples. This work is part of the research programme of the Netherlands Organization for Scientific Research (NWO), Domain Applied and Engineering Sciences (AES, previously Technology Foundation STW). The work is additionally supported by ZEISS. We also acknowledge the support of the Industrial Focus Group XUV Optics at the 
MESA+ Institute at the University of Twente, notably the industrial partners ASML, ZEISS, Malvern Panalytical, and the Province of Overijssel.

\subsection{References}

[1] H.E. Flotow, D.W. Osborne, K. Otto, Heat capacities and thermodynamic functions of $\mathrm{YH} 2$ and $\mathrm{YD} 2$ from $5^{\circ}$ to $350^{\circ} \mathrm{K}$ and the hydrogen vibration frequencies, J. Chem. Phys. 36 (1962) 866-872. doi:10.1063/1.1732681.

[2] H.E. Flotow, D.W. Osborne, K. Otto, B.M. Abraham, YH3 and YD3: Heat capacities and thermodynamic functions from $15^{\circ}$ to $350^{\circ} \mathrm{K}$ and infrared absorption spectra, J. Chem. Phys. 38 (1963) 2620-2626. doi:10.1063/1.1733561.

[3] A. Pebler, W.E. Wallace, Crystal structures of some lanthanide hydrides, J. Phys. Chem. 66 (1962) 148-151. doi:10.1021/j100807a033.

[4] C.E. Lundin, J.P. Blackledge, Pressure-Temperature-Composition Relationships of the Yttrium-Hydrogen System, J. Electrochem. Soc. 109 (1963) 838-842.

[5] A.E. Curzon, O. Singh, Thin film studies of yttrium, yttrium hydrides and yttrium oxide, J. Phys. F Met. Phys. 8 (1978) 1619-1625. doi:10.1088/03054608/8/8/003.

[6] D.J. Santjojo, T. Aizawa, S. Muraishi, Ellipsometric Characterization on Multi-Layered Thin Film Systems during Hydrogenation, Mater. Trans. 48 (2007) 1380-1386. doi:10.2320/matertrans.MRA2006193.

[7] J.N. Huiberts, R. Griessen, J.H. Rector, R.J. Wijngaarden, J.P. Dekker, D.G. de Groot, N.J. Koeman, Yttrium and lanthanum hydride films with switchable optical properties, Nature. 380 (1996) 231-234. doi:10.1038/380231a0.

[8] N. Strohfeldt, A. Tittl, M. Schäferling, F. Neubrech, U. Kreibig, R. Griessen, H. Giessen, Yttrium hydride nanoantennas for active plasmonics, Nano Lett. 14 (2014) 1140-1147. doi:10.1021/nl403643v.

[9] P. Ngene, T. Radeva, M. Slaman, R.J. Westerwaal, H. Schreuders, B. Dam, Seeing Hydrogen in Colors: Low-Cost and Highly Sensitive Eye Readable Hydrogen Detectors, Adv. Funct. Mater. 24 (2014) 2374-2382. doi:10.1002/adfm.201303065.

[10] E.S. Kooij, A.T.M. Van Gogh, D.G. Nagengast, N.J. Koeman, R. Griessen, Hysteresis and the single-phase metal-insulator transition in switchable $\mathrm{YHx}$ films, Phys. Rev. B - Condens. Matter Mater. Phys. 62 (2000) 10088-10100. 
doi:10.1103/PhysRevB.62.10088.

[11] E.G. Keim, M.D. Bijker, J.C. Lodder, Preparation of cross-sectional transmission electron microscopy specimens of obliquely deposited magnetic thin films on a flexible tape, J. Vac. Sci. Technol. A Vacuum, Surfaces, Film. 19 (2001) 1191-1194. doi:10.1116/1.1330259.

[12] O. V. Braginsky, A.S. Kovalev, D. V. Lopaev, E.M. Malykhin, T. V. Rakhimova, A.T. Rakhimov, A.N. Vasilieva, S.M. Zyryanov, K.N. Koshelev, V.M. Krivtsun, M. van Kaampen, D. Glushkov, Removal of amorphous $\mathrm{C}$ and $\mathrm{Sn}$ on Mo:Si multilayer mirror surface in Hydrogen plasma and afterglow, J. Appl. Phys. 111 (2012) 093304. doi:10.1063/1.4709408.

[13] A.L. Patterson, The Scherrer Formula for X-Ray Particle Size Determination, Phys. Rev. $56 \quad$ (1939) 978-982. doi:10.1103/PhysRev.56.978.

[14] K.L. Kostov, W. Widdra, D. Menzel, Hydrogen on Ru (001) revisited: Vibrational structure, adsorption states, and lateral coupling, Surf. Sci. 560 (2004) 130-144. doi:10.1016/j.susc.2004.04.025.

[15] D.E. Shleifman, D. Shaltiel, I.T. Steinberger, Thermally stimulated hydrogen desorption from zirconium and tantalum, J. Alloys Compd. 223 (1995) 81-86. doi:10.1016/0925-8388(94)01497-3. 



\section{4}

\section{Hydrogen diffusion through Ru thin films}

In this chapter, an experimental measurement of the diffusion constant of hydrogen in ruthenium is presented. By using a hydrogen indicative $\mathrm{Y}$ layer, placed under the Ru layer, the hydrogen flux through Ru was obtained by measuring the optical changes in the $\mathrm{Y}$ layer. We use optical transmission measurements to obtain the hydrogenation rate of $\mathrm{Y}$ in a temperature range from room temperature to $100{ }^{\circ} \mathrm{C}$. We show that the measured hydrogenation rate is limited mainly by the hydrogen diffusion in $\mathrm{Ru}$. These measurements were used to estimate the diffusion coefficient, $D$, and activation energy of hydrogen diffusion in $\mathrm{Ru}$ thin films to be $D=5.9 \times 10^{-14} \mathrm{~m}^{2} / \mathrm{s} \cdot \exp \left(-0.33 \mathrm{eV} / k_{B} \tau\right)$, with $k_{\mathrm{B}}$ the Boltzmann constant and $\tau$ the temperature. 


\subsection{Introduction}

Due to hydrogen induced embrittlement and corrosion of materials [1], development of a diffusion barrier for hydrogen is crucial for applications such as nuclear fusion technology [2-4], equipment for space applications [5], hydrogen storage [6], construction materials in the oil/gas industry [7] and protection of optical elements for soft X-ray optics and Extreme UV optics [8]. For the latter application, $\mathrm{Ru}$ is often studied as protective layer, since it is relatively inert and can be cleaned from oxide and carbon contamination by atomic hydrogen [9-13].

However, hydrogen transport in Ru has been poorly studied in comparison to other materials: to our knowledge, there are no studies reported on hydrogen diffusion in $\mathrm{Ru}$. Although molecular hydrogen dissociatively adsorbs on clean $\mathrm{Ru}(0001)$ surfaces [14], the heat of solution of hydrogen in $\mathrm{Ru}$ is positive [15], indicating that $\mathrm{H}$ does not readily dissolve in bulk $\mathrm{Ru}$. This low bulk solubility makes $\mathrm{Ru}$ a good candidate as diffusion barrier for hydrogen. There are many techniques (Neutron Scattering, Solid State Nuclei Magnetic Resonance, Elastic Recoil Detection Analysis etc.) that allow the hydrogen content and distribution in a metal film to be quantified, but they are high-cost, not easily accessible, potentially destructive for the investigated sample or not applicable for low hydrogen concentrations in metal [16-18]. Ideally, a technique that allows direct comparison of hydrogen transport in different metals, which can also work with both atomic and molecular hydrogen sources needs to be developed.

An alternative to directly sensing hydrogen is to infer hydrogen transport via changes in material properties. Yttrium (Y) is highly sensitive to hydrogenation, forming di- and trihydrides, which causes a metal $\left(\mathrm{Y}\right.$ and $\left.\mathrm{YH}_{2}\right)$ to insulator $\left(\mathrm{YH}_{3}\right)$ transition. The hydrogenation of a Y film can be easily detected optically, for instance, with the hydrogenography technique. Hydrogenography is a method that enables rapid measurement of the change in optical transmittance of a film due to hydrogen absorption [19]. First, hydrogen dissolves in the Y lattice forming an $\alpha$-phase and then the transition to the $\mathrm{YH}_{2}$ phase starts. When formation of $\mathrm{YH}_{2}$ is complete, the second transition to $\mathrm{YH}_{3}$ takes place. Both transitions, $\mathrm{Y}-\mathrm{YH}_{2}$ or $\mathrm{YH}_{2}-\mathrm{YH}_{3}$, occur consecutive resulting in a two-phase mixture at any given moment during $\mathrm{Y}$ hydrogenation. According to the Beer-Lambert law, the change in transmittance depends exponentially on hydrogen concentration for such a two-phase system. Thus, after applying a scaling factor to the transmittance, the changes in hydrogen concentration in $\mathrm{Y}$ can be readily obtained. Although hydrogenography only provides a relative measure of hydrogen content, 
the measurements can be implemented in situ, which allows the hydrogenation rate of a Y film to be obtained. The hydrogenation rate may be used for estimation of hydrogen diffusivity in $\mathrm{Ru}$.

It was demonstrated that $\mathrm{Y}$ films can be used for measuring the hydrogen lateral mobility in metal films [20]. We here propose to use a trilayer stack for hydrogen diffusion studies through thin Ru films, similar to the structure used in a previously reported $\mathrm{Mg}_{2} \mathrm{Ni}$ hydrogenation kinetics study [21]. A sketch of the structure is shown in Figure 4.1a. A sensing Y layer is covered with a diffusion barrier ( $\mathrm{Ru}$ film) and a continuous Pd cap is added on the top. The purpose of the Pd layer is to accelerate hydrogen adsorption, protect the material under investigation from oxidation, and dissociate molecular hydrogen. Hydrogen uptake by such a Pd/Ru/Y structure can be monitored by measuring the change in its optical transmittance.

Generally speaking, the hydrogen uptake by Y depends on both surface (ad-and desorption, sticking probability) and bulk (enthalpy of solution, diffusion, interface penetration) processes that hydrogen atoms undergo in the $\mathrm{Pd} / \mathrm{Ru} / \mathrm{Y}$ stack. This complicates the analysis unless one process, such as diffusion through the middle ( $\mathrm{Ru})$ layer, is the rate limiting step. Under these conditions, all processes apart from the rate limiting step can be neglected. In this study, a method, demonstrated in [22] by Borgschulte et al. was used to distinguish the rate limiting process (under the experimental conditions given below) by measuring the hydrogenation rate at varied hydrogen pressure. It is shown that the hydrogen diffusion through the $\mathrm{Ru}$ layer is significantly slower than all other processes, and, therefore, the hydrogenation rate can be attributed to diffusion through $\mathrm{Ru}$.

This allows the diffusion kinetics of hydrogen through thin polycrystalline $\mathrm{Ru}$ films to be studied. Assuming a steady hydrogen flux through $\mathrm{Ru}$, the diffusion coefficient and activation energy of hydrogen diffusion in Ru was estimated. The validity of this estimation is further discussed.

\subsection{Experimental section}

Sample preparation and characterization. In this study, all layered structures were deposited using DC magnetron sputtering in a vacuum system with a base pressure about $10^{-8}$ mbar. For optical transmission measurements at varied hydrogen pressure, $10 \times 10 \mathrm{~mm}$ polished quartz (PGO) substrates were used. For the measurements at different temperatures, different kinds of substrates (quartz 
from three different suppliers, sapphire and $\mathrm{SrTiO}_{3}$ single crystal substrates) were coated with identical $\mathrm{Pd} / \mathrm{Ru} / \mathrm{Y}$ tri-layers in the same deposition run. The surface roughness of the deposited samples was measured with AFM (the typical root mean square values are $0.4-0.8 \mathrm{~nm}$ for quartz substrates and $0.2 \mathrm{~nm}$ for single crystal substrates) before and after loading with hydrogen. No significant roughening upon hydrogenation was detected.

Hydrogenography. Yttrium was chosen as an indicator due to its ability to change optical transmittance during hydrogen absorption. Yttrium forms hydrides with different structural and optical properties. First, the metallic $\mathrm{YH}_{2}$ phase forms and then the transition to the dielectric $\mathrm{YH}_{3}$ phase takes place. Measuring changes in the sample transparency during either $\mathrm{Y}-\mathrm{YH}_{2}$ or $\mathrm{YH}_{2}-\mathrm{YH}_{3}$ transition allows to find the ratio of two phases at every moment of hydrogen loading.

A detailed description of the hydrogenography setup can be found elsewhere [23]. A sample holder enabled simultaneous measurement of up to nine $10 \times 10$ $\mathrm{mm}$ samples. Pure hydrogen gas was used in measurements at different temperatures, while a mixture of $4 \% \mathrm{H}_{2}$ in Ar was used in measurements at varied $\mathrm{H}_{2}$ pressures. Discrepancies in time needed for the $\mathrm{YH}_{2}$ phase to form for identical samples was observed during the first loading from $\mathrm{Y}$ to $\mathrm{YH}_{3}$. Therefore, the data from the first cycle of hydrogenation to $\mathrm{YH}_{3}$ and dehydrogenation to $\mathrm{YH}_{2}$ was excluded from analysis. The $\mathrm{YH}_{2}-\mathrm{YH}_{3}$ transition in the following cycles was used for determination of the hydrogenation rate. At higher temperatures the hydrogenation rate was faster than the pressure ramp, which limited the temperature range up to $100^{\circ} \mathrm{C}$.

\subsection{Results and discussion}

\subsubsection{Limiting processes for the hydrogenation rate}

To identify the limiting step for hydrogen transport in a $\mathrm{Pd} / \mathrm{Ru} / \mathrm{Y}$ trilayer, the pressure dependence of the hydrogenation rate was measured for two structures, $\mathrm{Pd} / \mathrm{Ru} / \mathrm{Y}$ itself and $\mathrm{Pd} / \mathrm{Ru} / \mathrm{Pd} / \mathrm{Y}$ (with a spacing $\mathrm{Pd}$ layer between $\mathrm{Ru}$ and $\mathrm{Y}$ ), which allows the effect of the $\mathrm{Ru} / \mathrm{Y}$ interface presence to be investigated. For these measurements, the hydrogenation rate is calculated from a linear fit of the $\ln \left(T / T_{0}\right)$ slope, where $T$ is transmission and $T_{0}$ is the initial transmittance before hydrogen loading, when loading the yttrium film from $\mathrm{YH}_{2}$ to $\mathrm{YH}_{3}$. The order, 
$\alpha$, of the rate dependence on the applied hydrogen pressure, $R \sim p^{\alpha}$, indicates whether the hydrogenation rate is limited mainly by surface $\left(\mathrm{H}_{2}\right.$ dissociation, $\alpha=1$ ) or bulk ( $\alpha=0.5)$ processes involved in hydrogen transport to the $\mathrm{Y}$ layer. Prior research [22] showed that $\alpha$ is close to unity in a $\mathrm{Pd} / \mathrm{Y}$ structure and, therefore, hydrogen uptake in this structure is mostly limited by $\mathrm{H}_{2}$ dissociation on the Pd surface. Here, we find that inserting a Ru layer shifts the power very close to a square root $(\alpha=0.58$, Figure 4.1a), which indicates that the measured rates are mostly limited by the diffusion through $\mathrm{Ru}$ (but $\mathrm{H}_{2}$ dissociation still has small influence). Adding a spacer Pd layer between Ru and Y (Figure 4.1b) did not change $\alpha$ significantly, which excludes that the $\mathrm{Ru} / \mathrm{Y}$ interface in the original trilayer limits the hydrogen transport. Similarly, we assume that the $\mathrm{Pd} / \mathrm{Ru}$ interface is not rate limiting.
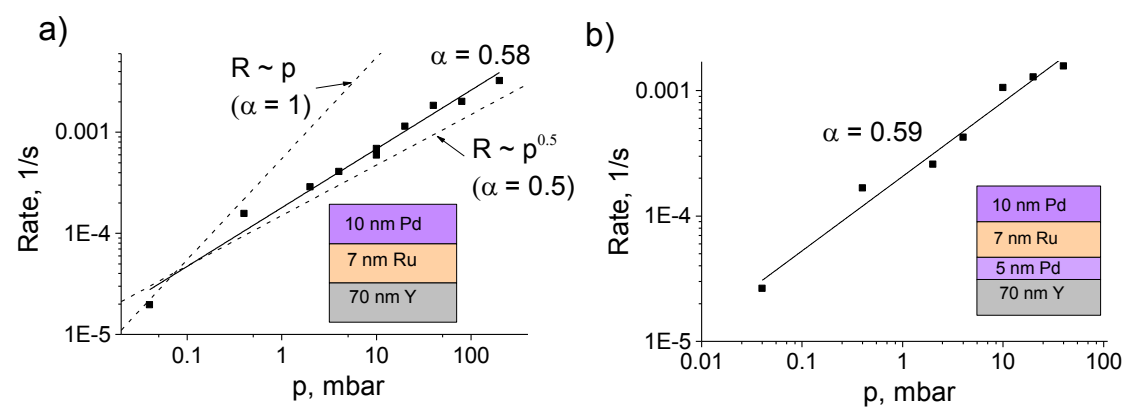

c) Hydrogen uptake limiting process
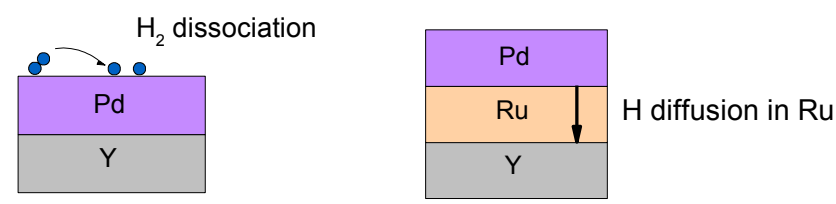

Figure 4.1. The rate of hydrogenation (in terms of a time derivative of $\ln \left(T / T_{0}\right)$ ) versus the applied hydrogen pressure for $P d / R u / Y$ (a) and $P d / R u / P d / Y$ (b) structures on $P G O$ quartz substrates at room temperature. The dashed lines in (a) indicate two extreme cases, when $\alpha=0.5$ (diffusion limited) and 1 ( $\mathrm{H}_{2}$ dissociation limited); (c) A sketch highlighting the rate-limiting process for samples without and with a Ru layer.

From reference experiments performed in our group, it is known that the effective interface width of the Pd-on-Ru interface is $0.7 \pm 0.2 \mathrm{~nm}$.[24] Since this is much smaller than the layer thicknesses of the Pd and Ru layers, it is expected that the influence of the Pd layer on hydrogen diffusion inside the Ru layer is 
negligible. In addition, the reported hydrogen diffusion coefficients at room temperature of $1.9 \times 10^{-15} \mathrm{~m}^{2} / \mathrm{s}$ for $\mathrm{Pd}[25]$ and $3 \times 10^{-14} \mathrm{~m}^{2} / \mathrm{s}$ for $\mathrm{Y}[26]$ thin films are 4 to 5 orders of magnitude larger than the $\mathrm{H}$ diffusion coefficient in $\mathrm{Ru}$ of $1.9 \times 10^{-19} \mathrm{~m}^{2} / \mathrm{s}$ that follows from this work. Thus, it can be concluded that for the test stacks employed in this work, the hydrogenation rate is mainly limited by transport through the $\mathrm{Ru}$ film. In view of the much faster $\mathrm{H}$ diffusion through $\mathrm{Pd}$ and $\mathrm{Y}$, compared to $\mathrm{Ru}$, it is expected that the exact layer thicknesses of Pd and $\mathrm{Y}$ will not affect the measured diffusion kinetics, as long as the Pd film is thick enough to protect the $\mathrm{Ru}$ from oxidation.

\subsubsection{Hydrogen flux calculation}

To estimate the diffusion coefficient of $\mathrm{H}$ in $\mathrm{Ru}$, the hydrogen flux should be calculated first. For that, since the change in the optical transmission, $T$, during the hydrogen loading is attributed to the formation of yttrium hydrides (the transmittance change in the Pd layer is negligibly small and, therefore, omitted), the transmittance is translated into hydrogen concentration $x$ in $\mathrm{YH}_{\mathrm{x}}$. According to the pressure concentration isotherms [27], thermodynamic equilibrium for hydrogen concentrations within the $\mathrm{YH}_{2}-\mathrm{YH}_{3}$ transition is achieved at a constant (plateau) pressure. The Beer-Lambert law then can be applied within this concentration range. Therefore, the hydrogen concentration, $x$, is proportional to $\ln \left(T / T_{0}\right)$ during the $\mathrm{YH}_{2}-\mathrm{YH}_{3}$ transition. Assuming that the saturation state corresponds approximately to $x=2.7$ [28] and a 'shoulder' in the time evolution of transmittance corresponds to $x=2.1$ (see Supplemental Information), the hydrogen concentration can be calculated for each $T$ value from the initial loading from $\mathrm{Y}$ to $\mathrm{YH}_{3}$ (since the 'shoulder' can be reliably measured only during the first loading). The initial loading from $\mathrm{Y}$ to $\mathrm{YH}_{2}$ is not used for the analysis due to irreversible changes in the film structure. However, the difference between times needed to reach the $\mathrm{YH}_{2}$ state in a sample without and with a $\mathrm{Ru}$ layer is evident in the initial cycle as well (see Appendix, section 4.6).

All further analysis is based on repeated cycles of the $\mathrm{YH}_{2}$ to $\mathrm{YH}_{3}$ transition. One such cycle is shown in Figure 4.2b. Once the pressure ramp is finished, the $\mathrm{H}$ concentration grows linearly with time. Extracting the slope from a linear fit yields the hydrogenation rate of the $\mathrm{Y}$ film. Taking into account the thickness of the $\mathrm{Y}$ layer, the hydrogen flux can be calculated.

The following non-linear saturation to the $\mathrm{YH}_{3}$ phase is probably caused by slowing down of the reaction rate due to limited amount of $\mathrm{YH}_{2}$ [29]. On the other 
hand, Mooij et al. in [30] showed in their study of magnesium hydride that similar behavior happens due to the non-homogeneous nucleation of metal hydride (in our case, nucleation of $\mathrm{YH}_{3}$ ).
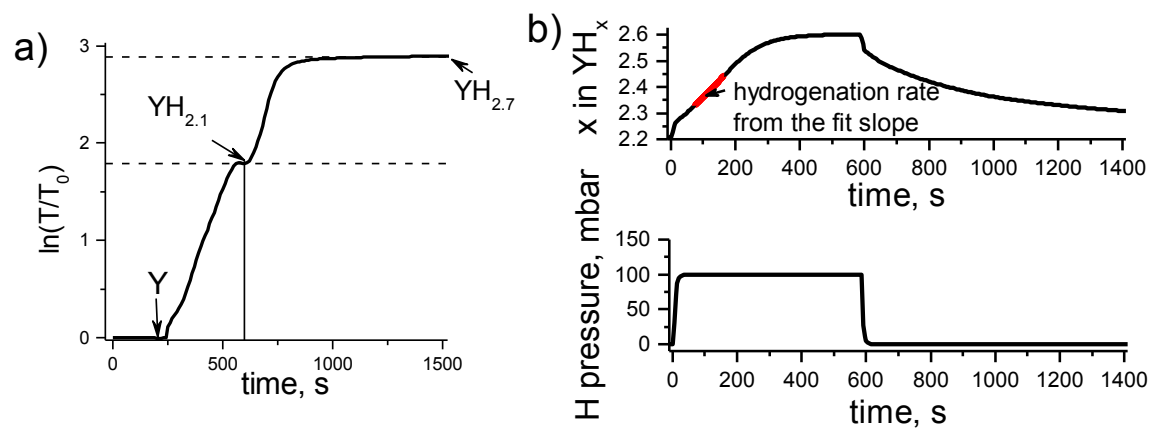

Figure 4.2. (a) The initial loading of $P d / R u / Y$ trilayer on quartz (MaTeck) substrate at room temperature. The moment of switching on 1000 mbar of hydrogen coincides with zero of time axis (b) The calculated hydrogen concentration in Y during loading at 100 mbar hydrogen at $40{ }^{\circ} \mathrm{C}$. The bottom subplot shows the H pressure during loading. The pressure ramp leads to a 'jump' of $x$ in the beginning of the top subplot.

\subsubsection{Diffusion coefficient of hydrogen in $R u$}

Within the chosen concentration range for cycles, $x$ grows linearly with time (see Figure 4.2b). This means that the hydrogen flux throughout the $\mathrm{Pd} / \mathrm{Ru} / \mathrm{Y}$ stack is constant and, hence, Fick's first law can be applied:

$$
F=D(\tau) \frac{\partial C}{\partial z}
$$

where $F$ is the hydrogen flux, $D$ is the hydrogen diffusion coefficient in Ru (diffusion in $\mathrm{Pd}$ and $\mathrm{Y}$ is assumed to be instant), $C$ is the hydrogen concentration distribution along the $z$-axis (normal to the sample surface). We can assume that $F(\tau) \propto D(\tau)$ only when the concentration gradient is kept constant for all measurements. Let us consider the main factors that influence this concentration gradient. From the top side of the Ru film, there is a concentration of dissolved hydrogen in $\mathrm{Pd}, C_{P d}^{H}$. It is constant within one measurement for a given temperature and hydrogen pressure, since equilibrium with $\mathrm{H}_{2}$ gas is reached much faster than transport through $\mathrm{Ru}$ (see Figure 4.3a). With Ru having a low hydrogen solubility and forming no hydride [31], the yttrium layer acts like a sink, binding hydrogen as soon as it reaches the $\mathrm{Ru} / \mathrm{Y}$ boundary due to low chemical 
potential and fast diffusion of $\mathrm{H}$ atom in $\mathrm{Y}[32,33]$. Also, a prior XRD study [34], where no interstitial free hydrogen was detected during the $\mathrm{YH}_{2}-\mathrm{YH}_{3}$ transition, supports this assumption. Thus, the hydrogen concentration on the $\mathrm{Ru} / \mathrm{Y}$ boundary can be assumed to be zero. The concentration gradient then only depends on $C_{P d}^{H}$ and the thickness of the Ru layer $d_{R u}$, which results in a concentration gradient along the z-axis, $\frac{\partial C}{\partial z}=C_{P d}^{H} / d_{R u}$. Taking into account that the concentration $x=C_{H} / C_{Y}$, where $C_{Y}$ is the yttrium atomic concentration, the calculated rate, $R=d x / d t$, can then be used to calculate the hydrogen flux, $F$, through the Ru film in the following way: $F=R C_{Y} d_{Y}$ ( $d_{Y}$ is the $\mathrm{Y}$ thickness). Thus, the diffusion coefficient can be estimated as:

$$
D(\tau)=\frac{F}{d C / d z}=\frac{C_{Y} d_{Y} d_{R u}}{C_{P d}^{H}} R(\tau)
$$

We make use of the saturation of hydrogen concentration in palladium to ensure that $C_{P d}^{H}$ is kept constant. This is achieved by using earlier results [35] to set the applied hydrogen pressure such that the final optical transmission corresponds to a fixed value for $x(x=2.6)$. The starting concentration, $x$, is chosen to be greater than 2.1 to keep the coefficient of the proportionality between the concentration and the intensity ratio the same during the measurements (see Supplemental information). As a result, in these experiments, the hydrogen concentration in yttrium was cycled between $x=2.2$ and $x=2.6$ (Figure 4.3b).

By measuring the hydrogenation rate for various temperatures, we can estimate the activation energy, $E_{a}$, of this diffusion process using the Arrhenius equation $D=D_{0} \exp \left(-E_{a} / k_{B} \tau\right)$, where $D_{0}$ is the pre-factor of the diffusion constant, $k_{B}$ is the Boltzmann constant and $\tau$ is the temperature. However, this expression is only valid when the hydrogen diffusion through $\mathrm{Ru}$ is the rate limiting step for the entire temperature range. As shown in the previous section, the hydrogen uptake by the $\mathrm{Y}$ layer is limited by hydrogen transport through $\mathrm{Ru}$ at room temperature. An increase of temperature leads to acceleration of the $\mathrm{H}_{2}$ dissociation, but the kinetics of the hydrogenation is assumed to remain limited by the $\mathrm{Ru}$ layer. On the other hand, higher temperatures lead to a lower equilibrium concentration of hydrogen in Pd. This affects the hydrogen concentration gradient through the Ru layer and complicates the analysis of the diffusion through $\mathrm{Ru}$. To compensate for this, at each temperature the hydrogen pressure is adapted such that the same hydrogenation state of $Y$ is achieved. In this way, we measure 
the temperature dependence of the hydrogen transport in $\mathrm{Ru}$ with the same driving force.

It is well known that the surface roughness of a substrate can influence the structure of an overlaying thin film. This will also change the rate of diffusion through the layer. In order to understand the influence of the substrate on diffusion, the experiment and calculation described above was performed for several different substrate types. An Arrhenius plot of the diffusion coefficient of hydrogen in $\mathrm{Ru}$ is shown in Figure 4.3c. Because of the large difference between the data points of identical samples (S1 and S2, Figure 4.3c), the fit is performed for each sample separately. Since the largest deviations are observed between identical film stacks on quartz substrates (see the legend of Figure 4.3c), we believe that the substrate roughness has an impact on the hydrogen flux. The results of the fit are shown in Figure 4.3d. The higher error in the activation energy obtained for sapphire, $\mathrm{SrTiO}_{3}$ and quartz (Esco) samples is due to increased uncertainty in the final hydrogenation state of the yttrium layer ( $\mathrm{YH}_{2.6}$ for these conditions). This uncertainty is induced by a mismatch between the needed hydrogen pressure to reach $x=2.6$ and its set value. The average $D_{0}$ and $E_{a}$ over all samples are $5.9 \cdot 10^{-14} \mathrm{~m}^{2} / \mathrm{s}$ and $0.33 \mathrm{eV}$.

To check the validity of the used steady state approximation, the hydrogenation times were calculated with a diffusion model, which takes into account the diffusion through the Ru layer only, based on Fick's second law:

$$
\frac{\partial C}{\partial t}=D_{R u}(R T) \frac{\partial^{2} C}{\partial z^{2}},
$$

where $D_{R u}(R T)=1.9 \cdot 10^{-19} \mathrm{~m}^{2} / \mathrm{s}$, is the diffusion coefficient in $\mathrm{Ru}$ at room temperature calculated with obtained $D_{0}$ and $E_{a}$ values. The boundary conditions for the Ru diffusion layer are (Figure 4.3a, top):

$$
C\left(z_{P d / R u}, t\right)=C_{P d}^{H}, C\left(z_{R u / Y}, t\right)=0,
$$

with the initial concentration distribution $C(z, 0)=\left\{\begin{array}{c}C_{P d}^{H}, \quad z=z_{P d / R u} \\ 0, \quad z>z_{P d / R u}\end{array}\right.$.

Using this model, we can assess the number of accumulated hydrogen atoms in the $\mathrm{Y}$ layer as a function of time. According to this calculation, it takes about 80 $\mathrm{s}$ to reach $90 \%$ of a steady $\mathrm{H}$ flux through the Ru layer (i.e. time to establish a 
linear concentration profile in the $\mathrm{Ru}$ layer) and about $1000 \mathrm{~s}$ to accumulate enough hydrogen atoms to form the $\mathrm{YH}_{3}$ phase. Thus, steady state diffusion is reached in the beginning of the whole process, which justifies the use of Fick's first law for diffusion coefficient extraction.

The hydrogen solubility in Ru is expected to be very low and this would change the hydrogen concentration distribution across the Ru layer. As described by Borgschulte et al., the chemical potential of hydrogen (not the concentration) in a multilayer system should be a continuous function [21,32]. When the heat of solution of hydrogen (or the heat of hydride formation) in two layers forming an interface is different, this will result in a sudden change in hydrogen concentration at the interface [32]. The concentration jump at $\mathrm{Pd} / \mathrm{Ru}$ interface was estimated from the chemical potential equality at the interface (see Pasturel et al. [21]) using the $\mathrm{H}$ enthalpy of solution in $\mathrm{Ru},+0.55 \mathrm{eV} /$ at $\mathrm{H} \mathrm{[36]} \mathrm{and} \mathrm{the} \mathrm{enthalpy}$ of formation of palladium hydride, $-0.26--0.1 \mathrm{eV} /$ at $\mathrm{H}$ [21]. The calculated $\mathrm{H}$ concentration in $\mathrm{Ru}$ is ten orders of magnitude smaller, which would lead to a ten orders higher diffusion coefficient than calculated.

From the other hand, even though the hydrogen concentration in defect-free $\mathrm{Ru}$ should be negligibly low, $\mathrm{Ru}$ is expected to have a significant $\mathrm{H}$ concentration at grain boundaries and defects, since hydrogen readily adsorbs at clean $\mathrm{Ru}$ surfaces with coverage up to unity, when exposed to molecular or atomic hydrogen $[14,37]$. Additionally, the catalytic activity of $\mathrm{Ru}$ should be noted $[38,39]$, which can have an impact on hydrogen migration along the grain surfaces. The local $\mathrm{H}$ concentration at Ru grain boundaries near the $\mathrm{Pd} / \mathrm{Ru}$ interface is therefore expected to be similar to the concentration in Pd. If we assume that transport along grain boundaries is the dominating diffusion mechanism, this justifies the usage of $\mathrm{C}_{\mathrm{Pd}} \mathrm{H} / \mathrm{d}_{\mathrm{Ru}}$ as approximation of the concentration gradient over the diffusion pathways through the $\mathrm{Ru}$ film. It has been demonstrated that our $7 \mathrm{~nm} \mathrm{Ru}$ films are above the threshold thickness for polycrystalline growth [40, 41]. We therefore expect that diffusion will be dominated by hopping between defects or transport along grain boundaries. All film stacks in this work were deposited using the same coating procedure, or even produced within the same deposition run. This should give a negligible difference in film thicknesses, although some structure difference may occur due to different roughness of the starting substrate. It should be noted that other Ru deposition methods or Ru thicknesses may lead to a different grain structure, which may result in Ru films with a different diffusion constant from the value reported in this work. 
a)
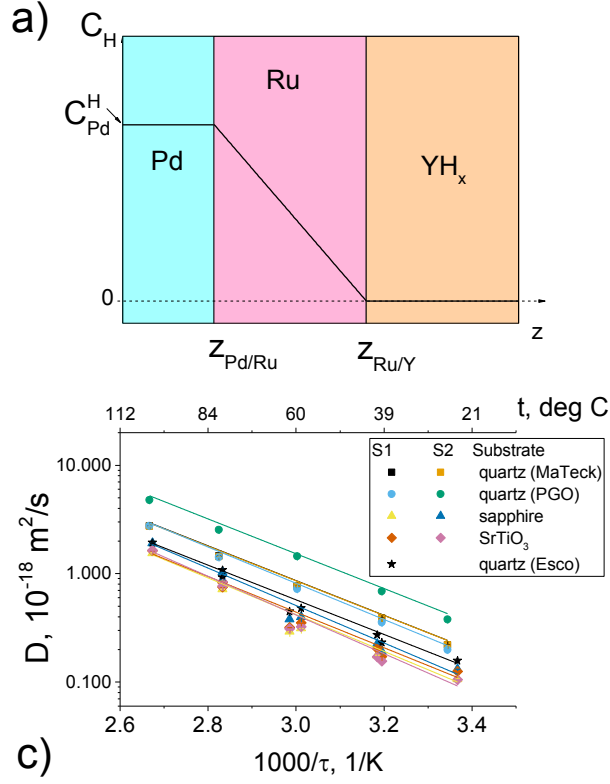

b)
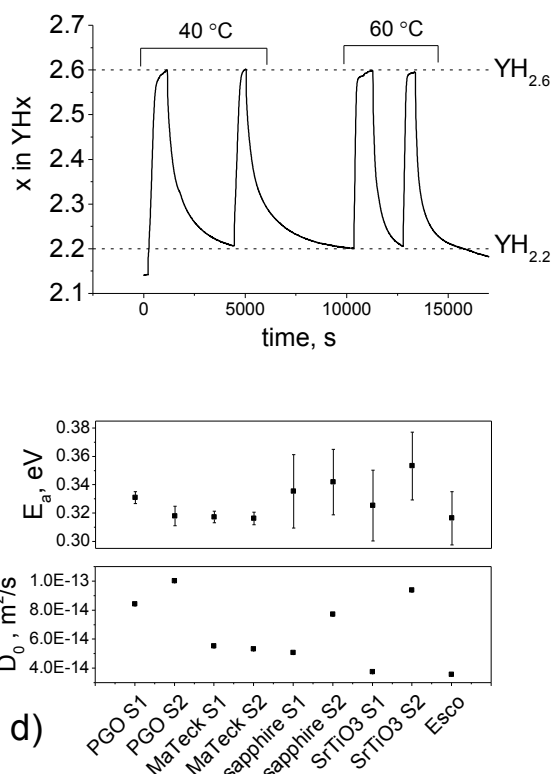

Figure 4.3. (a) A sketch of the Pd/Ru/Y structure and the hydrogen concentration profile in the Ru layer when the steady state regime of the diffusion is achieved: a linear $H$ concentration profile with $C_{P d}^{H}$ on Pd/Ru and zero on Ru/Y boundary; (b) Loading-unloading cycles at 40 and $60{ }^{\circ} \mathrm{C}$ for the S1 sample on a MaTeck substrate; (c) Arrhenius plot for each sample: the diffusion coefficient in Ru (log scale) versus inverse temperature for the same Pd/Ru/Y structure on different substrates (marked with symbol types). The rms roughness derived from AFM scans is indicated for each substrate type in the legend. Different samples within one substrate type are marked with different colors (S1 and S2). The standard error of the data points is smaller than symbol size; (d) The results of a linear fit in (c) for each sample. The error bars correspond to the standard error of the linear fit.

\subsection{Conclusions}

In summary, hydrogen diffusion through a thin $\mathrm{Ru}$ film was studied for the first time using hydrogenography on specially prepared multilayer films. Combination of (a) the promotion of $\mathrm{H}_{2}$ dissociation by a Pd cap and (b) slow permeation in the $\mathrm{Ru}$ layer compared to $\mathrm{Pd}$ and $\mathrm{Y}$ enabled a direct measurement of the hydrogen diffusion rate through $\mathrm{Ru}$. This method can be applied to materials with hydrogen solubilities and diffusivities much lower than in yttrium and Pd. The 
pre-factor, $D_{0}$, of the hydrogen diffusion coefficient of $\mathrm{Ru}$ and the activation energy was estimated from loadings at different temperatures and are $5.9 \cdot 10^{-14} \mathrm{~m}^{2} / \mathrm{s}$ and $0.33 \mathrm{eV}$, respectively. The main advantage of the presented method for measuring the $\mathrm{H}$ diffusion constant through $\mathrm{Ru}$, is that the method provides direct evidence that the measured diffusion rate is limited by diffusion through the $\mathrm{Ru}$ film and not by surface or interface processes. In addition, the method can readily be applied to materials that have a low solubility for hydrogen, unlike other common methods as volumetric or desorption measurements.

\subsection{Acknowledgments}

The authors thank Mr. Theo van Oijen for depositing samples. This work is part of the research programme of the Netherlands Organization for Scientific Research (NWO), Domain Applied and Engineering Sciences (AES, previously Technology Foundation STW). The work is additionally supported by Carl Zeiss SMT GmbH. We also acknowledge the support of the Industrial Focus Group XUV Optics at the MESA+ Institute at the University of Twente, notably the industrial partners ASML, Carl Zeiss SMT GmbH, Malvern Panalytical, and the Province of Overijssel.

\subsection{Appendix}

\subsubsection{The initial loading of $P d / R u / Y$ and $P d / Y$ stacks}

To check reliability of the change in optical transmission during hydrogenation of $Y$, the samples were loaded at low hydrogen pressures (10-100 mbar). The first loading of $\mathrm{Pd} / \mathrm{Y}$ and $\mathrm{Pd} / \mathrm{Ru} / \mathrm{Y}$ sample is shown in Figure $4.4 \mathrm{a}$ and $\mathrm{b}$, respectively.

Prior work [27] shows that, during the transition from $\mathrm{Y}$ to $\mathrm{YH}_{3}$, the phase transition from $\mathrm{YH}_{1.9}$ to $\mathrm{YH}_{2.1}$ is accompanied by a reduction in the optical transmission averaged over the visible wavelength range (Figure 4.4a, the reduction in transparency between $\mathrm{YH}_{1.9}$ and $\left.\mathrm{YH}_{2.1}\right)$. Since the same behavior was not observed for stacks with a Ru layer (Figure 4.4b), the transmission, as recorded by the red, green and blue channels of the CCD camera, were examined separately. 

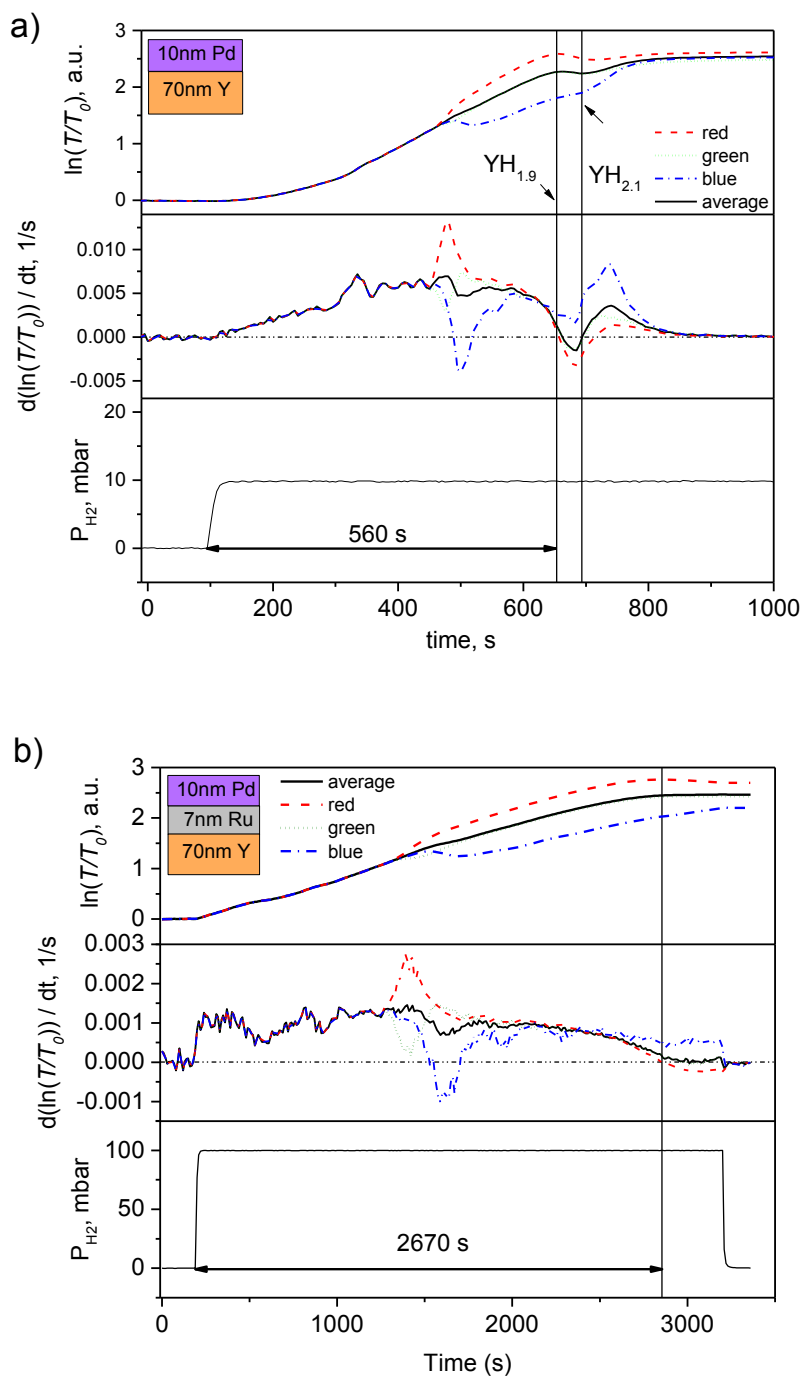

Figure 4.4. The change of the optical transmittance over time during the initial loading with hydrogen for two structures: $\mathrm{Pd} / \mathrm{Y}$ at $10 \mathrm{mbar}$ of $\mathrm{H}_{2}(\mathrm{a})$ and $\mathrm{Pd} / \mathrm{Ru} / \mathrm{Y}$ at $100 \mathrm{mbar}$ of $\mathrm{H}_{2}$ (b). The inset in each graph shows the corresponding sample structure and layer thicknesses. The signals of three channels: red (dash), green (dot), and blue (dash+dot) are shown along with their average signal (solid). The first derivative of the relative transmittance is shown on the second subplot of each graph for clear comparison of maxima $\left(Y_{1.9}\right)$ and minima $\left(Y_{2.1}\right)$ positions. The color and type of lines correspond to the first subplot. No minimum at $Y_{2.1}$ is observed in Tfor the sample with Ru in contrast to Pd capped sample. 
Interestingly, the signal of the red channel has a maximum when, according to previous research, the $\mathrm{YH}_{1.9}$ phase is formed, which can be better seen from the corresponding derivative graph. The nature of this red shift in transmittance is unclear and needs to be further studied. One of the possible explanations is the stress release in a Y film during the crystal lattice reconstruction behaves differently depending on the adhesion of the capping layer.

Despite the higher applied pressure to the stack with $\mathrm{Ru}$ (100 mbar compared to 10 mbar), the time needed to reach the same hydrogenation state is 4.7 times greater than for the $\mathrm{Pd} / \mathrm{Y}$ stack. This is additional evidence that the speed of the process is limited by hydrogen transport through the polycrystalline Ru layer.

\subsection{References}

[1] S. K. Dwivedi and M. Vishwakarma, "Hydrogen embrittlement in different materials: A review," Int. J. Hydrogen Energy, vol. 43, no. 46, pp. 21603-21616, 2018.

[2] X. Xiang, X. Wang, G. Zhang, T. Tang, and X. Lai, "Preparation technique and alloying effect of aluminide coatings as tritium permeation barriers: A review," International Journal of Hydrogen Energy, vol. 40, no. 9. pp. 3697-3707, 2015.

[3] G. Zhang, X. Wang, F. Yang, Y. Shi, J. Song, and X. Lai, "Energetics and diffusion of hydrogen in hydrogen permeation barrier of $\alpha$ $\mathrm{Al} 2 \mathrm{O} 3 / \mathrm{Fe} A 1$ with two different interfaces," Int. J. Hydrogen Energy, vol. 38, no. 18, pp. 7550-7560, Jun. 2013.

[4] B. Zajec, "Hydrogen permeation barrier - Recognition of defective barrier film from transient permeation rate," Int. J. Hydrogen Energy, vol. 36, no. 12, pp. 7353-7361, 2011.

[5] A. J. Corso and M. G. Pelizzo, "Extreme Ultraviolet Multilayer Nanostructures and Their Application to Solar Plasma Observations: A Review," J. Nanosci. Nanotechnol., vol. 19, no. 1, pp. 532-545, Jan. 2018.

[6] S.-I. Orimo, Y. Nakamori, J. R. Eliseo, A. Züttel, and C. M. Jensen, "Complex Hydrides for Hydrogen Storage," Chem. Rev., vol. 107, no. 10, pp. 4111-4132, 2007.

[7] B. Luo et al., "Vapor-deposited iron sulfide films as a novel hydrogen permeation barrier for steel: Deposition condition, defect effect, and hydrogen diffusion mechanism," Int. J. Hydrogen Energy, vol. 43, no. 
32, pp. 15564-15574, Aug. 2018.

[8] E. Louis, a. E. Yakshin, T. Tsarfati, and F. Bijkerk, "Nanometer interface and materials control for multilayer EUV-optical applications," Prog. Surf. Sci., vol. 86, no. 11-12, pp. 255-294, 2011.

[9] D. Ugur, A. Storm, and R. Verberk, "Kinetics of Reduction of a $\mathrm{RuO} 2$ (110) Film on Ru (0001) by H2," J. Phys. Chem. C, vol. 116, no. 110, pp. 26822-26828, 2012.

[10] W. Li et al., "A short review of recent advances in $\mathrm{CO} 2$ hydrogenation to hydrocarbons over heterogeneous catalysts," $R S C A d v$., vol. 8, no. 14, pp. 7651-7669, 2018.

[11] S. Bajt et al., "Improved reflectance and stability of Mo-Si multilayers," Opt. Eng., vol. 41, no. 8, p. 1797, Aug. 2002.

[12] J. Chen et al., "In situ ellipsometry study of atomic hydrogen etching of extreme ultraviolet induced carbon layers," Appl. Surf. Sci., vol. 258, no. 1, pp. 7-12, Oct. 2011.

[13] K. Motai et al., "Cleaning technology for EUV multilayer mirror using atomic hydrogen generated with hot wire," Thin Solid Films, vol. 516, no. 5, pp. 839-843, Jan. 2008.

[14] K. L. Kostov, W. Widdra, and D. Menzel, "Hydrogen on Ru (001) revisited: Vibrational structure, adsorption states, and lateral coupling," Surf. Sci., vol. 560, no. 1-3, pp. 130-144, Jul. 2004.

[15] R. Griessen and T. Riesterer, "Heat of formation models," Hydrog. Intermet. Compd. Electron., pp. 219-284, 1988.

[16] R. Kirchheim and A. Pundt, "Hydrogen in Metals," in Physical Metallurgy, vol. 1, Elsevier, 2014, pp. 2597-2705.

[17] H. Horinouchi, M. Shinohara, T. Otsuka, K. Hashizume, and T. Tanabe, "Determination of hydrogen diffusion and permeation coefficients in pure copper at near room temperature by means of tritium tracer techniques," J. Alloys Compd., vol. 580, no. SUPPL1, pp. S73-S75, 2013.

[18] A. Mézin, J. Lepage, and P. B. Abel, "Hydrogen permeation properties of molybdenum coatings from absorption-desorption experiments," Thin Solid Films, vol. 272, no. 1, pp. 132-136, Jan. 1996.

[19] J. N. Huiberts et al., "Yttrium and lanthanum hydride films with switchable optical properties," Nature, vol. 380, no. 6571, pp. 231-234, Mar. 1996.

[20] A. Remhof, S. J. Van Der Molen, A. Antosik, A. Dobrowolska, N. J. 
Koeman, and R. Griessen, "Switchable mirrors for visualization and control of hydrogen diffusion in transition metals," Phys. Rev. B Condens. Matter Mater. Phys., vol. 66, no. 2, pp. 1-4, 2002.

[21] M. Pasturel et al., "Influence of the chemical potential on the hydrogen sorption kinetics of $\mathrm{Mg} 2 \mathrm{Ni} / \mathrm{TM} / \mathrm{Pd}(\mathrm{TM}=$ transition metal) trilayers," Chem. Mater., vol. 19, no. 3, pp. 624-633, Feb. 2007.

[22] A. Borgschulte, R. J. Westerwaal, J. H. Rector, H. Schreuders, B. Dam, and R. Griessen, "Catalytic activity of noble metals promoting hydrogen uptake," J. Catal., vol. 239, no. 2, pp. 263-271, Apr. 2006.

[23] R. Gremaud et al., "Hydrogenography: An optical combinatorial method to find new light-weight hydrogen-storage materials," Adv. Mater., vol. 19, no. 19, pp. 2813-2817, Oct. 2007.

[24] A. Chandrasekaran, R. W. E. van de Kruijs, J. M. Sturm, A. A. Zameshin, and F. Bijkerk, "Nanoscale Transition Metal Thin Films: Growth Characteristics and Scaling Law for Interlayer Formation," ACS Appl. Mater. Interfaces, p. acsami.9b14414, Dec. 2019.

[25] Y. Li and Y. T. Cheng, "Hydrogen diffusion and solubility in palladium thin films," Int. J. Hydrogen Energy, vol. 21, no. 4, pp. 281-291, Apr. 1996.

[26] A. Borgschulte et al., "Combinatorial method for the development of a catalyst promoting hydrogen uptake," J. Alloys Compd., vol. 404-406, no. SPEC. ISS., pp. 699-705, 2005.

[27] T. Radeva, P. Ngene, M. Slaman, R. Westerwaal, H. Schreuders, and B. Dam, "Highly sensitive and selective visual hydrogen detectors based on Y xMg1-x thin films," Sensors Actuators, B Chem., vol. 203, pp. 745751, Nov. 2014.

[28] M. Kremers et al., "Optical transmission spectroscopy of switchable yttrium hydride films," 1998.

[29] P. Atkins and J. de Paula, Physical Chemistry, 8th ed. New York: W. H. Freeman and Company, 2006.

[30] L. Mooij and B. Dam, "Nucleation and growth mechanisms of nano magnesium hydride from the hydrogen sorption kinetics," Phys. Chem. Chem. Phys., vol. 15, no. 27, pp. 11501-11510, 2013.

[31] W. M. Mueller, J. P. Blackledge, and G. G. Libowitz, Metal hydrides, 5th ed. New York: Academic Press, 1968.

[32] A. Borgschulte, R. Gremaud, and R. Griessen, "Interplay of diffusion and dissociation mechanisms during hydrogen absorption in metals," Phys. Rev. B - Condens. Matter Mater. Phys., vol. 78, no. 9, p. 094106, Sep. 
2008.

[33] M. A. Kuzovnikov and M. Tkacz, "Synthesis of ruthenium hydride," Phys. Rev. B, vol. 93, no. 6, p. 064103, 2016.

[34] O. Soroka et al., "Hydrogenation dynamics of Ru capped Y thin films," J. Appl. Phys., vol. 126, no. 14, p. 145301, Oct. 2019.

[35] Y. Pivak, H. Schreuders, M. Slaman, R. Griessen, and B. Dam, "Thermodynamics, stress release and hysteresis behavior in highly adhesive Pd-H films," Int. J. Hydrogen Energy, vol. 36, no. 6, pp. 40564067, Mar. 2011.

[36] R. B. McLellan and W. A. Oates, "The solubility of hydrogen in rhodium, ruthenium, iridium and nickel," Acta Metall., vol. 21, no. 3, pp. 181-185, Mar. 1973.

[37] M. S. Hofman, D. Z. Wang, Y. Yang, and B. E. Koel, "Interactions of incident H atoms with metal surfaces," Surf. Sci. Rep., vol. 73, no. 4, pp. 153-189, 2018.

[38] R. Noyori and S. Hashiguchi, "Asymmetric Transfer Hydrogenation Catalyzed by Chiral Ruthenium Complexes," Acc. Chem. Res., vol. 30, no. 2, pp. 97-102, Feb. 1997.

[39] R. H. Morris, "Exploiting Metal-Ligand Bifunctional Reactions in the Design of Iron Asymmetric Hydrogenation Catalysts," Acc. Chem. Res., vol. 48, no. 5, pp. 1494-1502, May 2015.

[40] O. Soroka, J. M. Sturm, R. W. E. van de Kruijs, C. J. Lee, and F. Bijkerk, "Control of YH 3 formation and stability via hydrogen surface adsorption and desorption," Appl. Surf. Sci., vol. 455, pp. 70-74, Oct. 2018.

[41] R. Müller et al., "Growth of Atomic Layer Deposited Ruthenium and Its Optical Properties at Short Wavelengths Using Ru(EtCp)2 and Oxygen," Coatings, vol. 8, no. 11, p. 413, Nov. 2018. 



\section{Comparative $\mathrm{H}$ diffusion measurement through metal and non-metal nano-layers using optical sensing}

In this work, a technique for hydrogen diffusion measurements through thin films is proposed and demonstrated. A yttrium film, which changes its refractive index upon hydrogen absorption, is used as an optical sensor to detect hydrogen. The yttrium sensor is coated with a thin (up to $12 \mathrm{~nm}$ ) layer of test material and exposed to atomic hydrogen. To ensure that the calculated diffusion constant is not artificially changed by surfaces processes, the test layer is coated with palladium. Hydrogen diffusion through test layers of $\mathrm{Si}, \mathrm{Al}, \mathrm{Ag}, \mathrm{Ru}, \mathrm{Mo}, \mathrm{Al}_{2} \mathrm{O}_{3}$ and $\mathrm{SiO}_{2}$ were measured and compared with existing data. The hydrogenation time (time to form $\mathrm{YH}_{2}$ ) was found to exponentially scale with the enthalpy of hydrogen solution in the test material. Comparison between measured diffusion coefficients for different film thicknesses, as well as previously reported results, highlights the strong dependence of the diffusion constant on sample fabrication conditions, and hydrogen exposure conditions. It is concluded that diffusion through thin films can be reliably compared only when specimen form and exposure conditions are the same. The relevance of this study for applications is discussed. 


\subsection{Introduction}

Understanding the interactions between hydrogen and solids has been a focus of many studies. Interest in this topic has been motivated by the high susceptibility of many materials to hydrogen containing environments. Furthermore, uptake of hydrogen can induce changes in material properties, such as conductivity and durability. This is due to the small size of the hydrogen atom that allows its fast diffusion into the bulk of materials, and the high reactivity of hydrogen with metals and other materials.

Studies of hydrogen interactions with solid materials span decades and a large variety of measurement techniques have been employed, depending on measured parameters and type of sample under investigation. To measure the hydrogen concentration absorbed by a material, techniques such as volumetric and mass difference measurements, nuclear reaction analysis and elastic recoil detection analysis have been employed [1]. For the measurement of $\mathrm{H}$ mobility, permeation measurements $[2,3]$, and optical techniques like hydrogenography [4] are often used. However, the measured parameters may have different definitions, depending on both the chosen method, and the size and shape of the specimen. Indeed, a wide variety of solid materials have been investigated, including powders, micrometer-thick membranes, wires, tubes, and nanometer-thick thin films, which makes a direct comparison between the hydrogen mobilities or concentrations obtained from different studies unreliable.

Hydrogen uptake by and mobility in thin films is not the same as in a bulk sample due to structural differences, making comparison (direct or indirect) between experimental results extremely challenging. Yet, knowledge of hydrogen permeability through micro- and nanometer-thick layers is essential for hydrogen barrier applications. Shielding materials for hydrogen is relevant to applications such as nuclear fusion reactors [5], eXtreme UltraViolet (XUV) lithography [6, 7], and space engineering, since uptake of hydrogen can lead to, for example, hydrogen embrittlement [8] or blister formation [9]. It is, therefore, highly desirable to develop a method that makes a direct comparison between hydrogen permeation through thin films of different materials possible.

Optical sensors are often used to measure the uptake of hydrogen. Optical sensors offer safe integration into hydrogen environments, since they do not need electrical contacts to the sample under investigation, as would be the case with resistivity 
methods. In addition, optical measurements are easily accessible, straightforward to apply in situ, and can be used over a wider pressure range, as opposed to ion beam methods [10].

In this work, we demonstrate an effective method for comparing the hydrogen transport through thin films of different materials. The hydrogen permeation through test layers of $\mathrm{Ag}, \mathrm{Al}, \mathrm{Si}, \mathrm{Ru}, \mathrm{Mo}, \mathrm{Cu}, \mathrm{SiO}_{2}$ and $\mathrm{Al}_{2} \mathrm{O}_{3}$ was studied using a Y sensor layer. Diffusion constants are obtained for several samples, which show that for many ultrathin films, the diffusion constant is strongly dependent on the film thickness. By comparing the tabulated heat of dissolution with the time it takes to saturate the $\mathrm{Y}$ layer, it is possible to qualitatively determine the relative contribution between dissolution and other diffusive mechanisms. By comparing the hydrogenation rates, the limiting processes for hydrogen transport are discussed. This work builds upon previous work in our group on studying the interaction of hydrogen with thin film materials, using a Y sensor layer. The knowledge on the influence of the surface material properties on $\mathrm{H}$ uptake kinetics [11] allowed a sample structure to be designed, and exposure conditions chosen, for which diffusion through the test layer limits the overall hydrogenation rate, as detailed in section 5.2. Together with our previous calibration of ellipsometry signatures of different $Y$ hydride phases [12], this allowed us to study diffusion through a larger set of materials and compare these results to literature data and our previous publication on $\mathrm{H}$ diffusion through $\mathrm{Ru}[13]$.

\subsection{Sensor model}

Some metals show large changes in optical properties upon hydride formation, which makes them good candidates as a hydrogen sensor [14, 15]. For instance, Y forms di- and tri-hydride upon exposure to hydrogen, which can be readily detected optically with, for example, ellipsometry or transmission measurements. When depositing a test layer of material under investigation on a Y film, it is possible, provided that the layer stack and exposure conditions are properly chosen, to relate the measured hydrogenation rate of $\mathrm{Y}$ to hydrogen diffusivity through the test layer. Effectively, to obtain the diffusivity of the test layer and to compare diffusion constants, the layer stack must be chosen such that differences in surface processes are eliminated $[11,16]$, that the flux through the sample surface is known, and that the diffusion through the test layer is slow compared to diffusion through all other layers 
in the stack [13]. The results below indicate that these conditions may be readily met for a wide range of materials.

Previous studies on hydrogenation kinetics of Y films with a protective or catalytic capping layer showed that the hydrogenation process may be limited by surface processes on the capping layer, bulk diffusion processes, or interface processes [16, 17] Surface processes may even determine which hydride forms. For instance, a Ru cap leads to the formation of $\mathrm{YH}_{3}$, while a $\mathrm{Ag}$ cap prevents any measurable hydrogenation [11]. To eliminate the difference in ad- and desorption kinetics of hydrogen for each material and its influence on the saturation level of the $\mathrm{Y}$ layer with hydrogen [11], a palladium capping layer is added on top of the test layer to promote hydrogen adsorption and make the influence of the surface processes equal for all test layer materials. In this way, as was proposed in prior work [13], the transport of hydrogen through test layers can be studied and compared for different materials. In addition, the use of Pd capping layer in so-called switchable Y mirrors has been demonstrated in a prior study [18].

In order to obtain the diffusivity, the flux of (atomic) hydrogen through the test layer must be known. In most research, the sample is subjected to a known molecular hydrogen pressure, which requires that the influence of the $\mathrm{H}_{2}$ chemisorption and dissociation on the measured hydrogenation rate should be taken into account in order to calculate the flux. To eliminate the influence of dissociation, we expose test samples to atomic $\mathrm{H}$. Atomic $\mathrm{H}$ also has a higher sticking probability than $\mathrm{H}_{2}$, which allows saturated surface coverage to be reached at low hydrogen pressures, thereby reducing the role of surface processes on the overall hydrogen diffusion rate through the stack. The experimental evidence of the accelerated diffusion rate when using an atomic hydrogen source in combination with a Pd cap is shown further in the Results and discussion section (see Figure 5.2 and Figure 5.3).

Pd has a large hydrogen diffusion constant and (in comparison to other metals) absorbs hydrogen rapidly [19]. Provided that the test materials have a lower diffusion constant than Pd, the combination of atomic hydrogen and Pd ensures that all test materials, Ma, will be exposed to the same (relatively high) hydrogen concentration at the $\mathrm{Pd} / \mathrm{Ma}$ interface. Thus, by creating samples that have the same surface (Pd in our case) and ensuring that the top Pd layer is saturated, then the hydrogenation rate of the sensor film can be associated with hydrogen permeation through the test layer. 
This has the additional advantage of working at hydrogen pressures that are compatible with (ultra) high vacuum systems, in contrast to previous work with molecular $\mathrm{H}_{2}$ [13].

\subsection{Experimental}

For this study, pre-cut $15 \times 15 \mathrm{~mm}^{2} \mathrm{Si}(001)$ wafer pieces were coated with thin films using DC magnetron sputtering, with the substrate held at room temperature. Deposition rates were calibrated with the aid of thickness measurements by $\mathrm{Cu} \mathrm{K}_{\alpha} \mathrm{X}$ ray reflection measurements. In combination with long term reproducibility of deposition rates, this leads to thickness errors of about $2 \%$ of the deposited film thickness. The film stacks consisted of a Y sensing layer, a test layer (Ma), and a Pd capping layer, which promotes hydrogen absorption (see Figure 5.1a and Table 5.1). The consecutive layers were deposited without breaking vacuum. Four sets of samples with test layer thicknesses between 3-12 nm (see Table 5.1) were made for each material type. The oxide test layers $\mathrm{Al}_{2} \mathrm{O}_{3}$ and $\mathrm{SiO}_{2}$ were reactively sputtered in $\mathrm{Ar} / \mathrm{O}_{2}$ plasma. Prior to reactive deposition of the oxide film, $2 \mathrm{~nm} \mathrm{Al}$ (or $\mathrm{Si}$ in case of $\mathrm{SiO}_{2}$ ) layer was deposited on the $\mathrm{Y}$ film to prevent $\mathrm{Y}$ oxidation by exposure to reactive $\mathrm{O}$ species in the plasma (see Figure 5.1b). The stoichiometry of the oxides and purity of the Y layer were confirmed with X-ray photoelectron spectroscopy (XPS, Thermo Fisher) after deposition. The roughness of the samples is dominated by the roughness of the $70 \mathrm{~nm}$ Y film. Typical samples show a $0.6 \mathrm{~nm}$ root mean square roughness measured in a $1 \times 1 \mu \mathrm{m}^{2}$ atomic force microscopy image [11].
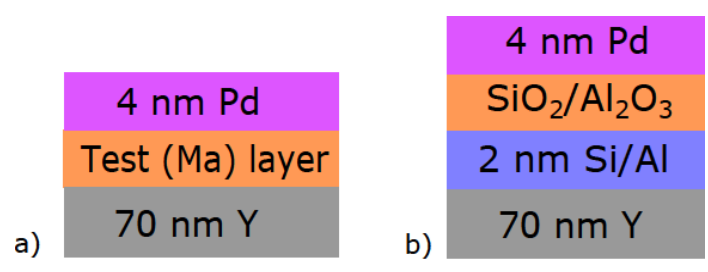

Figure 5.1. Sketch of the sample structure (a) with metal or Si test layer and (b) with oxide test layer (additional thin metal layer is added for protection of the Y film from oxidation).

For exposures to atomic hydrogen $\mathrm{H} \cdot$, the samples were moved in air to a vacuum chamber with a base pressure of $2 \times 10^{-8} \mathrm{mbar}$. Atomic hydrogen was generated by flowing $100 \mathrm{sccm} \mathrm{H}_{2}$ gas over a tungsten filament heated to $2000^{\circ} \mathrm{C}$, which was 
confirmed by measuring the temperature with an infrared temperature sensor (Raytek, RayMR1SCCF). A spectroscopic ellipsometer (Woollam M-2000XI, spectral range $240-1600 \mathrm{~nm}$ ) was mounted to the vacuum system at an incidence angle of approximately $75^{\circ}$ with respect to the surface normal, illuminating the front side of the sample. This allowed the evolution of Y hydrogenation to be measured in situ. The hydrogen exposure was terminated when the ellipsometric angles stopped changing, which previous work had confirmed to correspond to a formed $\mathrm{YH}_{2}$ phase [12]. Additionally, post-exposure X-Ray diffraction (XRD, Panalytical Empyrean) measurements were used to verify the presence of $\mathrm{YH}_{2}$.

Table 5.1. List of the test materials Ma layer thicknesses in the Pd/Ma/Y layer stacks. The Pd layer was $4 \mathrm{~nm}$ for all samples. Values that differ from the rest are highlighted in bold.

\begin{tabular}{|c|c|c|}
\hline \multicolumn{2}{|c|}{ Test layer } & Y layer \\
\hline Material & Thicknesses, $\mathrm{nm}$ & Thickness, $\mathrm{nm}$ \\
\hline $\mathrm{Si}$ & $3,6,9,12$ & 70 \\
\hline $\mathrm{Al}$ & $3,6,9,12$ & 70 \\
\hline $\mathrm{Ag}$ & $3,6,9,12$ & 70 \\
\hline $\mathrm{Ru}$ & $\mathbf{5 , 7}, 9,12$ & 70 \\
\hline $\mathrm{Mo}$ & $3,6,9,12$ & $\mathbf{8 0}$ \\
\hline $\mathrm{Cu}$ & $3,6,9,12$ & 70 \\
\hline $\mathrm{SiO} 2$ & $3,6,9,12$ & 70 \\
\hline $\mathrm{A} 12 \mathrm{O} 3$ & $3,6,9,12$ & 70 \\
\hline
\end{tabular}

\subsection{Results and discussion}

Before comparing the diffusion of hydrogen through thin films of different materials, we first demonstrate results showing the relevance of the Pd capping layer and atomic hydrogen source used in this work. In prior diffusion experiments, where molecular $\mathrm{H}_{2}$ was used as hydrogen source, Pd caps acted both as a catalyst for $\mathrm{H}_{2}$ dissociation, and as a protective layer for avoiding oxide formation on $\mathrm{Y}$ [14]. In this work, the Pd cap ensures that the test layer is subjected to the same atomic hydrogen concentration. For comparison, the hydrogenation of a multilayer with and without a $\mathrm{Pd}$ capping layer $(\mathrm{Pd} / \mathrm{Ru} / \mathrm{Y}$ and $\mathrm{Ru} / \mathrm{Y})$ is shown in Figure 5.2. The speed of hydrogenation is significantly faster indicating the importance of surface processes. 
The influence of the surface is further illustrated in Figure 5.3, where the speed of hydrogenation for molecular and atomic hydrogen fluxes are compared. Atomic hydrogen clearly allows for much faster hydrogenation due to the elimination of the dissociation process and the increase in the sticking coefficient.

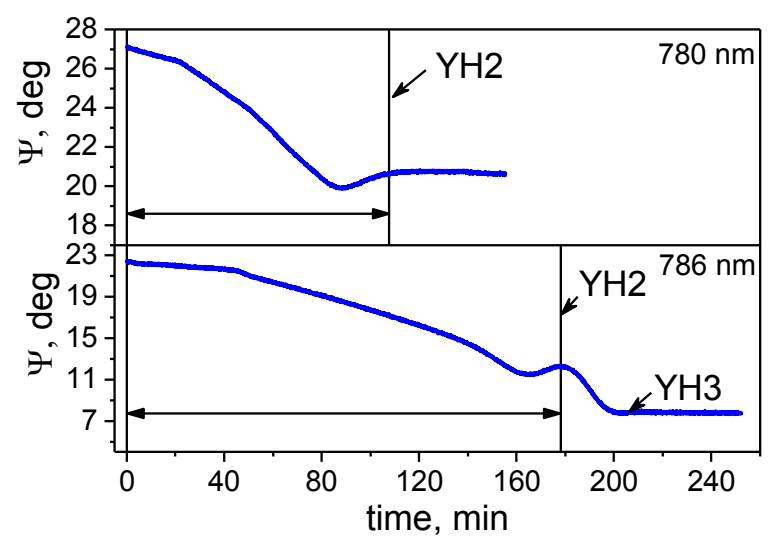

Figure 5.2. Ellipsometry monitoring of hydrogenation with and without a Pd capping layer. In the presence of a Pd cap, the hydrogenation of $Y$ saturates at the $\mathrm{YH}_{2}$ phase (top), while a Ru/Y bilayer hydrogenates to a higher hydride, $\mathrm{YH}_{3}$ (bottom).

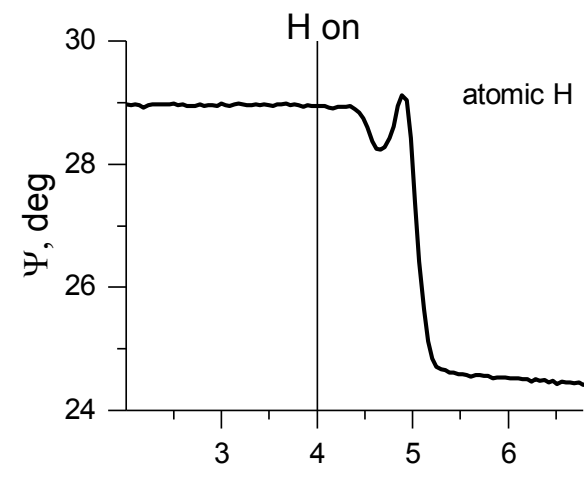

a)

time, $\min$

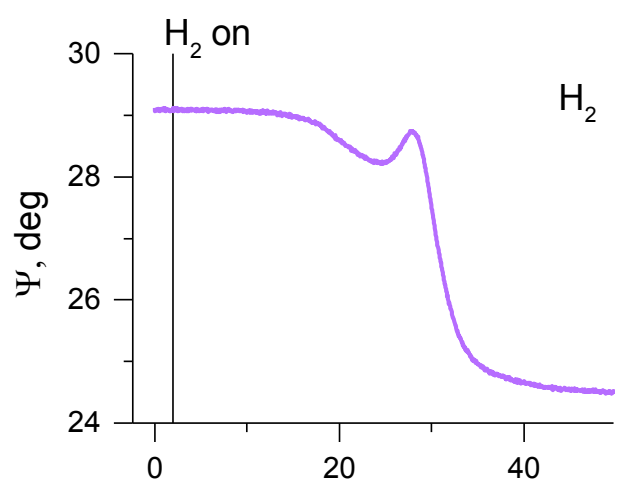

b) time, $\min$

Figure 5.3. Ellipsometry monitoring (at wavelength $1111.9 \mathrm{~nm}$ ) of hydrogenation of a $\mathrm{Pd} / \mathrm{Y}$ bilayer with (a) atomic hydrogen (generated with $\mathrm{W}$ filament) with a $\mathrm{H}_{2}$ flow of $100 \mathrm{sccm}$ and (b) with only molecular hydrogen of $200 \mathrm{sccm}$ flow. For atomic hydrogen exposure the filament was switched on before introducing hydrogen to the chamber. The vertical line ' $\mathrm{H}_{2}$ on' marks the time at which hydrogen is admitted in the chamber. 


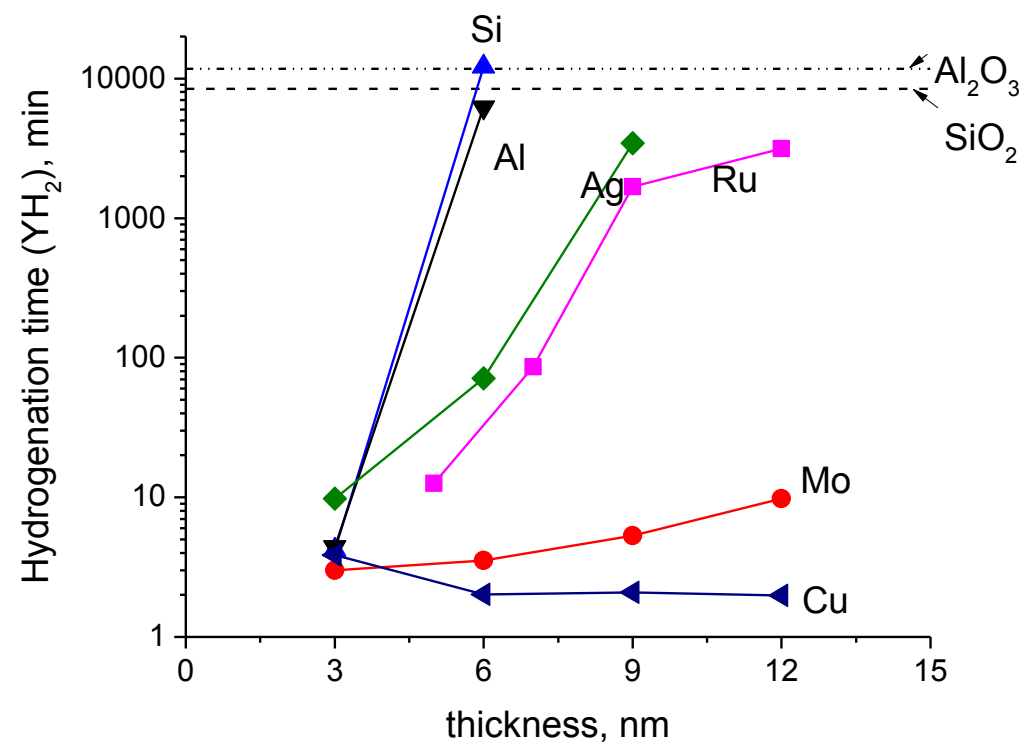

Figure 5.4. Time required for $\mathrm{YH}_{2}$ formation for different test layers (Cu, Mo, $\mathrm{Ru}, \mathrm{Ag}, \mathrm{Al}$, and $\mathrm{Si}$ ) depending on the thickness of the test layer. The hydrogen flow was set to $100 \mathrm{sccm}$ for all test layers except for Mo, where it was reduced to $26 \mathrm{sccm}$ in order to prevent that hydrogenation would be faster than the time resolution of ellipsometry monitoring. No measurable hydrogenation was observed for 3 and $6 \mathrm{~nm}$ thick $\mathrm{Al}_{2} \mathrm{O}_{3}$ and $\mathrm{SiO}_{2}$ test layers in the indicated times.

The $\mathrm{Pd} / \mathrm{Ma} / \mathrm{Y}$ structured samples were exposed to atomic hydrogen until the $\mathrm{Y}$ layer was saturated and $\mathrm{YH}_{2}$ formed. Formation of $\mathrm{YH}_{2}$ is derived from saturation of the values of ellipsometry angles $\Psi$ and $\Delta$ after a characteristic change as visible in Figures 5.2 and $5.3[11,12]$. It should be noted that the exact values of $\Psi$ and $\Delta$ that correspond to $\mathrm{YH}_{2}$ formation depend on the type of sample, since the ellipsometry signal is also influenced by the thicknesses and materials of other layers in the sample. Figure 5.4 shows the time taken to obtain the $\mathrm{YH}_{2}$ phase for different Ma layer thicknesses. Note that the hydrogenation time for copper and molybdenum is, for the thickest layers, more than two orders of magnitude faster than for the remaining materials. Furthermore, both $\mathrm{Si}$ and $\mathrm{Al}$ samples could only be hydrogenated for layers up to $6 \mathrm{~nm}$ thick in the time allowed for the experiment (up to 10 days of continuous exposure, limited by the lifetime of the $\mathrm{W}$ filament). When the hydrogen exposure was started, changes in the ellipsometric angles $\Psi$ and $\Delta$ due to $\mathrm{Y}$ lattice 
expansion [12] (similar to the first 40 min of exposure in the bottom graph in Figure 5.2), were immediately apparent on all non-oxide samples, even for samples with slow hydrogenation, such as those with $6 \mathrm{~nm}$ Si or Al. The $\mathrm{Al}_{2} \mathrm{O}_{3}$ and $\mathrm{SiO}_{2}$ oxide layers, on the contrary, showed no evidence that hydrogenation of the $\mathrm{Y}$ film had started after exposure to atomic hydrogen for times $195 \mathrm{~h}$ and $141 \mathrm{~h}$, respectively (indicated with dotted lines). This was confirmed later with XRD measurements of the exposed samples, which found diffraction peaks for the $\mathrm{Y}$ phase only and no evidence of $\mathrm{YH}_{2}$ formation.

There is no increase of the hydrogenation time for thicker $\mathrm{Cu}$ layers (Figure 5.4). This indicates that $\mathrm{Cu}$ is not a limiting factor for hydrogen transport through the layered stack. It is interesting to note that the hydrogenation time actually decreases for a $\mathrm{Cu}$ thickness larger than $3 \mathrm{~nm}$. It may be that alloying of $\mathrm{Pd}$ and $\mathrm{Cu}$ influences the hydrogenation speed [20]. The $3 \mathrm{~nm} \mathrm{Cu}$ layer has a thinner interface with $\mathrm{Pd}$ and, consequently, forms a Pd-Cu alloy with a higher Pd content. For the thicker $\mathrm{Cu}$ layers, the thickness of the interface is likely to be the same, though it is thicker than for the $3 \mathrm{~nm} \mathrm{Cu}$ layer. This results in a higher concentration of $\mathrm{Cu}$ in the $\mathrm{Pd}-\mathrm{Cu}$ alloy, which leads to a higher $\mathrm{H}$ diffusivity and smaller measured times [20].

It is likely that the hydrogen transport for $3 \mathrm{~nm}$ thick test layers of $\mathrm{Al}$ and $\mathrm{Si}$ is much faster compared to $6 \mathrm{~nm}$ thick layers because the $3 \mathrm{~nm}$ thick films do not form a closed layer. The failure to form a closed layer may be due to intermixing with Y or surface segregation of $Y$ [21]. This results in pinholes forming, allowing direct contact between $\mathrm{Pd}$ and $\mathrm{Y}$, which creates faster pathways for hydrogen transport compared to the pathway through the test layer.

The measured hydrogenation time grows with the thickness of the layer for all test layers except $\mathrm{Cu}$. The times only reflect the accumulation of hydrogen in the Y sensor layer, which may be limited by a number of processes, including $\mathrm{H}$ adsorption on the Pd surface, surface-to-bulk transport at the Pd surface, diffusion in Pd, Y and, of course, diffusion through the test layer. When the measured hydrogenation time increases for thicker test layers, this indicates that the $\mathrm{H}$ permeability through the test layer has considerable impact on the overall hydrogenation kinetics. On the other hand, when the hydrogenation time is independent of, or do not increase with, test layer thickness, as in case of $\mathrm{Cu}, \mathrm{H}$ permeates through the test layer much faster compared to the other processes. Therefore, we exclude $\mathrm{Cu}$ containing samples from the following analysis. Instead, $\mathrm{Cu}$ hydrogenation times are used as a limiting case to estimate the influence of surface processes on hydrogenation kinetics. 
As prior research shows [22], hydrogen uptake in the $\mathrm{Pd} / \mathrm{Y}$ system is limited by surface processes. The use of $\mathrm{H} \cdot$ accelerates $\mathrm{H}$ uptake significantly, but the hydrogenation still takes several minutes in the conditions of our experiment. Taking into account the diffusion coefficients of hydrogen in $\mathrm{Pd}$ and $\mathrm{Y}$ at room temperature (shown in Table 5.2) a diffusion model as described in previous work (see ref. [13] and further explanation in this paper) can be used to estimate the diffusion time through Pd and Y layers $[13,23]$. Using this model, the time that is needed to obtain the required hydrogen fluence for $\mathrm{YH}_{2}$ saturation through $4 \mathrm{~nm} \mathrm{Pd}$ and $70 \mathrm{~nm}$ of $\mathrm{Y}$ would be about 0.01 and $0.21 \mathrm{~s}$, respectively. Since this is few orders of magnitude faster than the observed hydrogenation time, this confirms our assumption that the uptake is limited by surface processes in the case of a $\mathrm{Cu}$ test layer.

In order to evaluate the relative speed of diffusion through the different test materials, we now focus on measured hydrogenation times for $6 \mathrm{~nm}$ test layers, since, for that thickness, saturation to $\mathrm{YH}_{2}$ could be reached for all non-oxide test materials, while artefacts due to pinholes are expected to be absent. In Figure 5.5, these hydrogenation times are compared to the heat of solution of $\mathrm{H}$ in the test material, where a lower heat of solution indicates that it is thermodynamically more favorable to dissolve hydrogen in the material. Though the mechanism of the hydrogen transport may vary from one material to another, the apparent hydrogenation time (which is inversely proportional to the diffusion constant) exponentially scales with the heat of $\mathrm{H}$ solution. This suggests that the heat of $\mathrm{H}$ solution can serve as an initial reference parameter for estimating the hydrogen transport rate through thin films. It should be noted that, to our knowledge, there is no theoretical explanation available in literature that relates hydrogen diffusion with heat of solution in a material.

For $\mathrm{Ru}, \mathrm{Ag}, \mathrm{Al}$ and $\mathrm{Si}$ the hydrogenation time increases much faster with layer thickness compared to Mo, where the results follow a linear diffusion model described earlier [13]. We speculate that for polycrystalline materials ( $\mathrm{Ru}, \mathrm{Al}$ and $\mathrm{Ag}$ ), where the hydrogen solubility is low compared to Mo, defects and grain boundaries are the main pathway for hydrogen diffusion. Since the grain structure (and possibly also the defect density) is expected to change as a function of film thickness, the hydrogen permeability of the test material can be expected to depend on film thickness. $\mathrm{Si}$, on the other hand, forms a non-crystalline amorphous layer, which eliminates grain boundary diffusion, making the influence of defects more significant. Defects in amorphous silicon are known to trap hydrogen and, consequently, should increase the hydrogenation time [24]. 


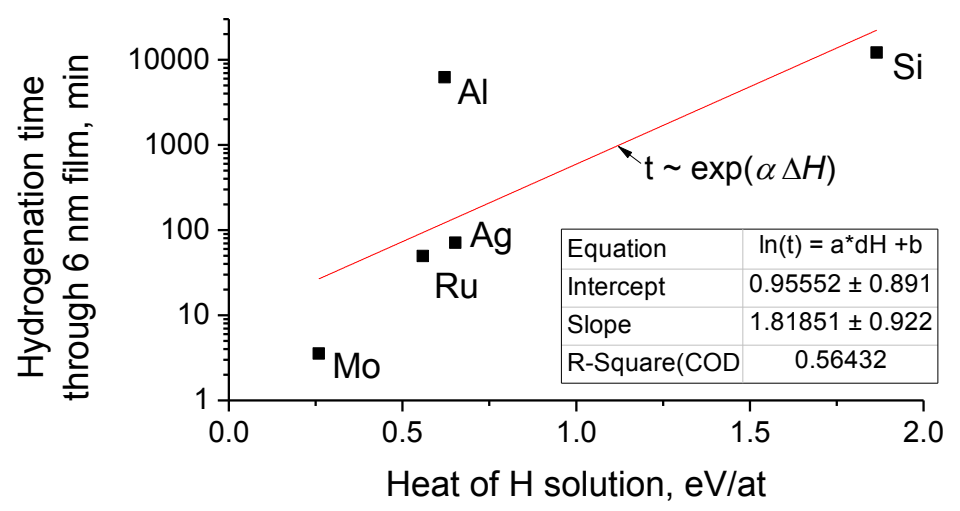

Figure 5.5. Hydrogenation time for layer stacks with $6 \mathrm{~nm}$ films of test material versus the heat of solution of hydrogen in test materials (note the logarithmic scale). The time scales with the heat of solution exponentially. The fitted line proportional to $\exp (\alpha \Delta H)$.

When the test layer limits hydrogen uptake, a concentration gradient of hydrogen forms across the test layer. In the case of thin layers, the steady state regime of diffusion is reached much faster than the $\mathrm{H}$ loading time. Therefore, the concentration gradient can be assumed linear and time-independent during the entire hydrogenation process, as was previously shown by Borgschulte and Gremaud [23]. Assuming that hydrogen uptake is limited by diffusion through the test layer (via grain boundaries or bulk), the hydrogenation rates should scale linearly with the diffusion constant of the test layer. To test this, the hydrogenation times were calculated with a simplified model (described in detail in [13]) for hydrogen diffusion through a layered stack [13]. According to Fick's second law, the change in hydrogen concentration, $C$, with respect to time, $t$, in the test layer can be expressed as a function of the diffusion constant, $D$, and depth, $z$, in the test layer:

$$
\frac{\partial C}{\partial t}=D \frac{\partial^{2} C}{\partial z^{2}}
$$

The model takes into account $\mathrm{H}$ diffusion in the test layer resulting from a fixed concentration at the boundaries, assuming the concentrations at the $\mathrm{Pd} / \mathrm{Ma}$ and $\mathrm{Ma} / \mathrm{Y}$ interfaces to be $C_{P d}$ (justified by the rapid absorption in Pd compared to diffusion through the test layer) and zero, respectively (see Figure 5.6a). At the Ma/Y interface, the negative enthalpy of formation of $\mathrm{YH}_{2}$ (compared to positive enthalpy 
of formation for the test materials) ensures that $\mathrm{Y}$ acts as a sink for $\mathrm{H}$, such that the concentration can be assumed to be close to zero [13]. The hydrogen flux at $\mathrm{Ma} / \mathrm{Y}$ interface is calculated using the diffusion equation (5.1). The total number of hydrogen atoms accumulated in Y film can be then obtained by integrating the calculated hydrogen flux over the exposure time. This allows the hydrogenation time of the Y film to be estimated as a function of the thickness of the test layer. The calculation results for three different diffusion coefficients are presented in Figure 5.6b. A higher diffusion coefficient leads to faster hydrogenation, however, the slope of time versus test layer thickness in a semilogarithmic plot remains the same. The effect of a changing diffusion constant is a vertical offset. The best fit for Mo samples is shown along with the measured data. The data for the other test layers cannot be fit by a single diffusion constant for the material, implying that the mechanisms of the hydrogen diffusion depends on film thickness. Thus, the hydrogenation rates of thin-films in the range of 3-12 nm cannot be predicted by a diffusion model using only a single diffusion constant. This is in line with a prior study of Pasturel et al. [25], where the measured hydrogen uptake by a $\mathrm{Mg}_{2} \mathrm{Ni}$ hydrogen sensitive layer did not depend in a straightforward way on the diffusivity in test metal layers. These results suggest that the diffusion constant of hydrogen through the test layers depends on layer structure and thickness, as discussed above. In addition, the solubility and film structure have a stronger influence on the hydrogen concentration gradient than included in our model.
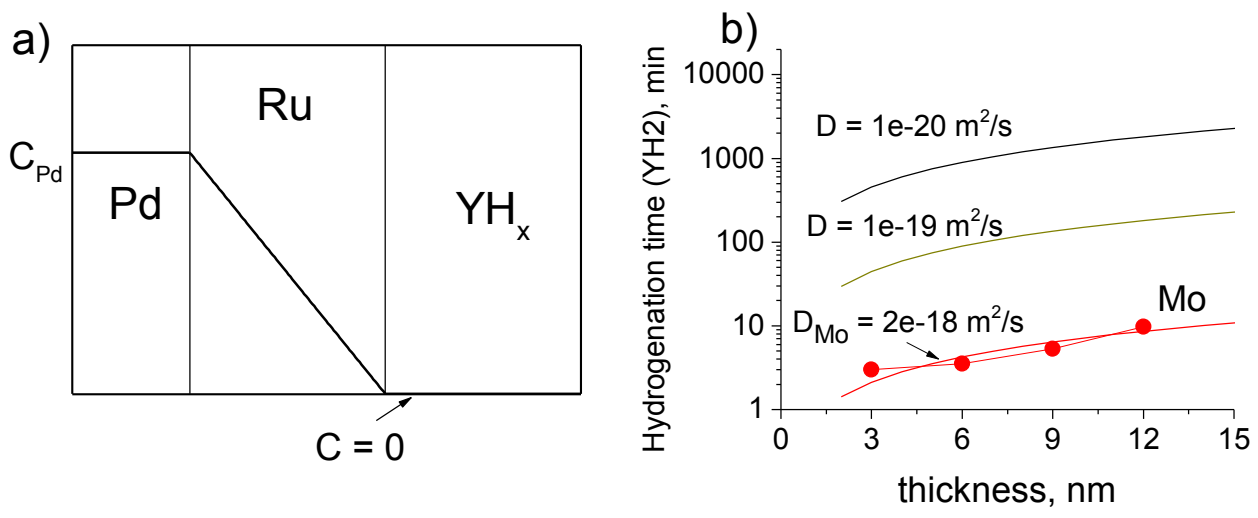

Figure 5.6. (a) A sketch of the hydrogen concentration profile assumed in the diffusion model. (b) Calculated hydrogenation times as a function of the layer thickness for three values of the diffusion coefficient of hydrogen in the test layer. The best fit for the Mo measured data is shown 
Table 5.2. Literature values of heat of solution $\Delta H_{S}$ and diffusion coefficient of hydrogen $D_{H}$ at room temperature (RT) for test materials and $P d$. Specimen type and method of measuring diffusion constant are indicated, including reference.

\begin{tabular}{|c|c|c|c|c|c|}
\hline $\begin{array}{c}\text { Mate- } \\
\text { rial }\end{array}$ & $\begin{array}{l}\text { Crystal } \\
\text { structure }\end{array}$ & $\begin{array}{c}\Delta \mathrm{H}_{\mathrm{S}}, \\
\mathrm{eV} / \mathrm{atom} \\
\text { from [26] }\end{array}$ & $\begin{array}{c}\text { Range of } D_{H} \\
\text { from this } \\
\text { study, } \mathrm{m}^{2} / \mathrm{s}\end{array}$ & $\begin{array}{c}D_{H} \text { at } \mathrm{RT} \\
\mathrm{m}^{2} / \mathrm{s}\end{array}$ & Reference \\
\hline \multirow{2}{*}{ Мo } & \multirow{2}{*}{ bcc } & \multirow{2}{*}{0.259} & \multirow{2}{*}{$\begin{array}{l}1.48 \times 10^{-18}- \\
2.63 \times 10^{-18}\end{array}$} & $1.9 \times 10^{-23}$ & $\begin{array}{l}7 \mathrm{~mm} \text { thick foil, elec- } \\
\text { tromigration [27] }\end{array}$ \\
\hline & & & & $2.1 \times 10^{-17}$ & $\begin{array}{c}\text { Tube, permeation } \\
\text { through tube walls [28] }\end{array}$ \\
\hline \multirow{2}{*}{$\mathrm{Cu}$} & \multirow{2}{*}{ fcc } & \multirow{2}{*}{0.476} & \multirow[t]{2}{*}{-} & $2.2 \times 10^{-13}$ & $\begin{array}{l}\text { Spherical single crystal, } \\
\text { thermal outgassing [29] }\end{array}$ \\
\hline & & & & $1.1 \times 10^{-14}$ & {$[30]$} \\
\hline $\mathrm{Ru}$ & hcp & 0.559 & $\begin{array}{l}5.7 \times 10^{-21}- \\
5.9 \times 10^{-19}\end{array}$ & $1.9 \times 10^{-19}$ & $\begin{array}{l}\text { nm-thick film, hydroge- } \\
\text { nography [13] }\end{array}$ \\
\hline \multirow{2}{*}{$\mathrm{Al}$} & \multirow{2}{*}{ fcc } & \multirow{2}{*}{0.621} & \multirow{2}{*}{$\begin{array}{l}1.4 \times 10^{-21}- \\
1.23 \times 10^{-18}\end{array}$} & $2.6 \times 10^{-11}$ & $\begin{array}{l}2 \mathrm{~mm} \text { thick wire, de- } \\
\text { sorption; [31] }\end{array}$ \\
\hline & & & & $5.2 \times 10^{-22}$ & $\begin{array}{c}10 \mathrm{~mm} \text { block, desorp- } \\
\text { tion [31] }\end{array}$ \\
\hline \multirow{2}{*}{$\mathrm{Ag}$} & \multirow{2}{*}{$\mathrm{fcc}$} & \multirow{2}{*}{0.652} & \multirow{2}{*}{$\begin{array}{c}3.9 \times 10^{-21}- \\
4.5 \times 10^{-19}\end{array}$} & $5.3 \times 10^{-12}$ & $\begin{array}{l}\mu \mathrm{m} \text {-thick thick mem- } \\
\text { brane, permeation [32] }\end{array}$ \\
\hline & & & & $1.9 \times 10^{-13}$ & {$[30]$} \\
\hline \multirow{2}{*}{$\mathrm{Si}$} & \multirow{2}{*}{$\mathrm{fcc}$} & \multirow{2}{*}{1.865} & \multirow{2}{*}{$\begin{array}{l}7.4 \times 10^{-22}- \\
1.31 \times 10^{-18}\end{array}$} & $1.1 \times 10^{-23}$ & $\begin{array}{l}\mu \mathrm{m} \text {-thick film of poly- } \\
\text { Si, SIMS [33] }\end{array}$ \\
\hline & & & & $2.2 \times 10^{-32}$ & $\begin{array}{c}\text { a-Si, H-D interdiffusion } \\
\text { [34] }\end{array}$ \\
\hline $\mathrm{Pd}$ & fcc & -0.103 & - & $1.9 \times 10^{-15}$ & $\begin{array}{l}\text { nm-thick films, electro- } \\
\text { chemical stripping tech- } \\
\text { nique [19] }\end{array}$ \\
\hline Y & hcp & -0.818 & - & $3 \times 10^{-14}$ & $\begin{array}{l}\text { nm-thick films, hy- } \\
\text { drogenography [22] }\end{array}$ \\
\hline
\end{tabular}


Using the described model, effective diffusion coefficients were calculated for each measurement point in Figure 5.4, (excluding $\mathrm{Cu}$ ). The ranges of the obtained diffusion coefficients are shown in Table 5.2.

When comparing the diffusion coefficients obtained in this work to the values from literature for materials used in this study (see Table 5.2), a few interesting observations can be made. The obtained coefficients for Ru samples agree with the value from the previous study, which used Ru films deposited in the same conditions as in this work. On the contrary, literature values for $\mathrm{H}$ diffusion in $\mathrm{Ag}$ are 6 orders of magnitude higher than the range of the calculated values, which is likely caused by the difference in sample microstructure.

Al presents an interesting case. Previous studies show a 13 order of magnitude spread in reported $\mathrm{H}$ diffusion constants, which is likely caused by different diffusion pathways (bulk, vacancies, or defects) dominating for samples investigated in different conditions [31]. According to Table 5.2, the largest reported diffusion constant for $\mathrm{Al}$ is higher than for $\mathrm{Pd}$ and $\mathrm{Y}$, meaning that the results for $\mathrm{Al}$ should be similar to those of $\mathrm{Cu}$. However, the calculated diffusion coefficient for $\mathrm{Al}$ in this work is in line with those of the smaller diffusion constants found in the literature (see Table 5.2). Our results add to the body of evidence that suggests that the effective diffusion rate in $\mathrm{Al}$ is extremely sensitive to experimental conditions, including film deposition parameters. The relatively low heat of solution predicts fast diffusion processes (see Figure 5.5), in agreement with larger diffusion constants. However, as discussed in [31], it is possible that a large density of defects or vacancies increases the measured hydrogenation time.

A wide spread of reported diffusion coefficients is also observed for Mo and $\mathrm{Si}$ (Table 5.2). This, combined with the (large) qualitative differences in hydrogen diffusion between our experiment and literature values of hydrogen diffusion, may be related to different methods used for probing diffusion, the different form of materials (thin films, powders or bulk materials), and, for thin-films, different deposition conditions, used for those studies. This stresses the importance that the measurement of diffusion constants or comparison of hydrogen diffusion properties should be performed with materials fabricated using similar methods, and identical methods for probing hydrogen diffusion should be used. 


\subsection{Summary and Conclusions}

In this work, we demonstrated a method for measuring hydrogen permeation through nanometer range thin films of $\mathrm{Si}, \mathrm{Al}, \mathrm{Ag}, \mathrm{Ru}, \mathrm{Mo}, \mathrm{Cu}, \mathrm{SiO}_{2}$ and $\mathrm{Al}_{2} \mathrm{O}_{3}$ deposited on top of a $\mathrm{Y}$ film that acts as sensor layer. Ellipsometry was used to monitor the transition of the $\mathrm{Y}$ film to $\mathrm{YH}_{2}$, in order to extract the relative rate of hydrogen diffusion through the test films as function of material and thickness. All samples had a protective Pd capping layer that ensures that all test materials were exposed to the same concentration of $\mathrm{H}$ dissolved in $\mathrm{Pd}$ at the Pd/test material interface.

No hydrogen diffusion through $\mathrm{SiO}_{2}$ and $\mathrm{Al}_{2} \mathrm{O}_{3}$ could be observed for the conditions and accessible time scales of this work. This indicates that oxides in general are better barriers for hydrogen diffusion compared to elemental materials, which is in agreement with prior studies using molecular hydrogen $[35,36]$. It was shown earlier in [37] that hydrogen diffusivity in oxides proceeds via hydrogen jumping between neighboring oxygen atoms and relies on dynamics of the host oxide atoms. Close packed oxides (like $\mathrm{Al}_{2} \mathrm{O}_{3}$ and $\mathrm{SiO}_{2}$ ) do not allow a high degree of $\mathrm{O}$-atom movement and, hence, act as an efficient hydrogen barrier.

We observed that for all metals, except $\mathrm{Cu}$, the hydrogenation rate of $\mathrm{Y}$ was limited by $\mathrm{H}$ diffusion through the test material. The hydrogenation time roughly scales with the heat of solution of $\mathrm{H}$ in the test material, indicating that heat of solution can serve as a first indicator for $\mathrm{H}$ diffusion speed through a material. The calculated diffusion constants are within the range of diffusion constant values reported in literature, with the exception of that of Ag. However, the range of values also indicates the importance of systematic effects due to differences in measurement methods and material preparation. This stresses the importance that $\mathrm{H}$ diffusion properties should be measured in a sample structure that is directly relevant for the application for which $\mathrm{H}$ diffusion properties are to be determined. Nevertheless, the proposed sensor is a valuable tool when the evaluation of the hydrogen diffusion is needed for test layers at hand.

\subsection{Acknowledgements}

The authors thank Mr. Theo van Oijen for depositing samples. This work is part of the research programme of the Netherlands Organization for Scientific Research (NWO), Domain Applied and Engineering Sciences (AES, previously Technology Foundation STW). The work is additionally supported by Carl Zeiss SMT GmbH. 
We also acknowledge the support of the Industrial Focus Group XUV Optics at the MESA+ Institute at the University of Twente, notably the industrial partners ASML, Carl Zeiss SMT GmbH, Malvern Panalytical, and the Province of Overijssel.

\subsection{References}

[1] R. Kirchheim and A. Pundt, "Hydrogen in Metals," in Physical Metallurgy, vol. 1, Elsevier, 2014, pp. 2597-2705.

[2] H. Horinouchi, M. Shinohara, T. Otsuka, K. Hashizume, and T. Tanabe, "Determination of hydrogen diffusion and permeation coefficients in pure copper at near room temperature by means of tritium tracer techniques," $J$. Alloys Compd., vol. 580, no. SUPPL1, pp. S73-S75, 2013.

[3] A. Mézin, J. Lepage, and P. B. Abel, "Hydrogen permeation properties of molybdenum coatings from absorption-desorption experiments," Thin Solid Films, vol. 272, no. 1, pp. 132-136, Jan. 1996.

[4] R. Gremaud et al., "Hydrogenography: An optical combinatorial method to find new light-weight hydrogen-storage materials," Adv. Mater., vol. 19, no. 19, pp. 2813-2817, Oct. 2007.

[5] V. Nemanič, "Hydrogen permeation barriers: Basic requirements, materials selection, deposition methods, and quality evaluation," Nuclear Materials and Energy, vol. 19. pp. 451-457, 2019.

[6] S. Graham, C. Steinhaus, M. Clift, and L. Klebanoff, "Radio-frequency discharge cleaning of silicon-capped Mo/Si multilayer extreme ultraviolet optics," J. Vac. Sci. Technol. B Microelectron. Nanom. Struct., vol. 20, no. 6, pp. 2393-2400, 2002.

[7] R. A. J. M. Van Den Bos, Hydrogen infuced blister formation in Mo/Si multilayer structures. Enschede, The Netherlands: University of Twente, 2018.

[8] S. K. Dwivedi and M. Vishwakarma, "Hydrogen embrittlement in different materials: A review," Int. J. Hydrogen Energy, vol. 43, no. 46, pp. 2160321616, 2018.

[9] R. A. J. M. Van Den Bos, C. J. Lee, J. P. H. Benschop, and F. Bijkerk, "Blister formation in $\mathrm{Mo} / \mathrm{Si}$ multilayered structures induced by hydrogen ions," J. Phys. D. Appl. Phys., vol. 50, no. 26, p. 265302, 2017.

[10] T. Hübert, L. Boon-Brett, G. Black, and U. Banach, "Hydrogen sensors - A review," Sensors Actuators, B Chem., vol. 157, no. 2, pp. 329-352, Oct. 2011. 
[11] O. Soroka, J. M. Sturm, R. W. E. van de Kruijs, C. J. Lee, and F. Bijkerk, "Control of YH 3 formation and stability via hydrogen surface adsorption and desorption," Appl. Surf. Sci., vol. 455, pp. 70-74, Oct. 2018.

[12] O. Soroka et al., "Hydrogenation dynamics of Ru capped Y thin films," $J$. Appl. Phys., vol. 126, no. 14, p. 145301, Oct. 2019.

[13] O. Soroka, J. M. Sturm, C. J. Lee, H. Schreuders, B. Dam, and F. Bijkerk, "Hydrogen diffusion through Ru thin films," Int. J. Hydrogen Energy, p. in press, doi: 10.1016/j.ijhydene.2020.03.201, 2020.

[14] F. J. A. Den Broeder et al., "Visualization of hydrogen migration in solids using switchable mirrors," Nature, vol. 394, no. 6694, pp. 656-658, Aug. 1998.

[15] A. Remhof, S. J. Van Der Molen, A. Antosik, A. Dobrowolska, N. J. Koeman, and R. Griessen, "Switchable mirrors for visualization and control of hydrogen diffusion in transition metals," Phys. Rev. B - Condens. Matter Mater. Phys., vol. 66, no. 2, pp. 1-4, 2002.

[16] F. Schweppe, M. Martin, and E. Fromm, "Model on hydride formation describing surface control, diffusion control and transition regions," J. Alloys Compd., vol. 261, no. 1-2, pp. 254-258, Sep. 1997.

[17] A. Borgschulte, R. J. Westerwaal, J. H. Rector, H. Schreuders, B. Dam, and R. Griessen, "Catalytic activity of noble metals promoting hydrogen uptake," J. Catal., vol. 239, no. 2, pp. 263-271, Apr. 2006.

[18] P. Ngene, T. Radeva, M. Slaman, R. J. Westerwaal, H. Schreuders, and B. Dam, "Seeing hydrogen in colors: Low-cost and highly sensitive eye readable hydrogen detectors," Adv. Funct. Mater., vol. 24, no. 16, pp. 2374 2382, Apr. 2014.

[19] Y. Li and Y. T. Cheng, "Hydrogen diffusion and solubility in palladium thin films," Int. J. Hydrogen Energy, vol. 21, no. 4, pp. 281-291, Apr. 1996.

[20] R. J. Westerwaal et al., "The hydrogen permeability of Pd-Cu based thin film membranes in relation to their structure: A combinatorial approach," Int. J. Hydrogen Energy, vol. 40, no. 10, pp. 3932-3943, 2015.

[21] A. Chandrasekaran, R. W. E. van de Kruijs, J. M. Sturm, A. A. Zameshin, and F. Bijkerk, "Nanoscale Transition Metal Thin Films: Growth Characteristics and Scaling Law for Interlayer Formation," ACS Appl. Mater. Interfaces, p. acsami.9b14414, Dec. 2019.

[22] A. Borgschulte et al., "Combinatorial method for the development of a catalyst promoting hydrogen uptake," J. Alloys Compd., vol. 404-406, no. SPEC. ISS., pp. 699-705, 2005. 
[23] A. Borgschulte, R. Gremaud, and R. Griessen, "Interplay of diffusion and dissociation mechanisms during hydrogen absorption in metals," Phys. Rev. B - Condens. Matter Mater. Phys., vol. 78, no. 9, p. 094106, Sep. 2008.

[24] F. J. J. Peeters, J. Zheng, I. M. P. Aarts, A. C. R. Pipino, W. M. M. Kessels, and M. C. M. van de Sanden, "Atomic hydrogen induced defect kinetics in amorphous silicon," J. Vac. Sci. Technol. A Vacuum, Surfaces, Film., vol. 35, no. 5, p. 05C307, 2017.

[25] M. Pasturel et al., "Influence of the chemical potential on the hydrogen sorption kinetics of $\mathrm{Mg} 2 \mathrm{Ni} / \mathrm{TM} / \mathrm{Pd}(\mathrm{TM}=$ transition metal) trilayers," Chem. Mater., vol. 19, no. 3, pp. 624-633, Feb. 2007.

[26] R. Griessen and T. Riesterer, "Heat of formation models," Hydrog. Intermet. Compd. Electron., pp. 219-284, 1988.

[27] R. Pietrzak and B. Rozenfeld, "The electromigration and diffusion of hydrogen in molybdenum," J. Less-Common Met., vol. 162, no. 1, pp. $23-$ 31, 1990.

[28] A. P. Zakharov, V. M. Sharapov, and E. I. Evko, "Hydrogen permeability of polycrystalline and monocrystalline molybdenum and tungsten," Sov. Mater. Sci., vol. 9, no. 2, pp. 149-153, 1975.

[29] L. Katz, M. Guinan, and R. J. Borg, "Diffusion of $\mathrm{H}_{2}, \mathrm{D}_{2}$, and $\mathrm{T}_{2}$ in singlecrystal Ni and Cu," Phys. Rev. B, vol. 4, no. 2, pp. 330-341, 1971.

[30] V. N. Verbetsky and S. V. Mitrokhin, "Copper- Silver- and GoldHydrogen," Solid State Phenom., vol. 73-75, pp. 503-0, Aug. 2000.

[31] G. A. Young and J. R. Scully, "The diffusion and trapping of hydrogen in high purity aluminum," Acta Mater., vol. 46, no. 18, pp. 6337-6349, Nov. 1998.

[32] H. Katsuta and R. B. McLellan, "Diffusivity of hydrogen in silver," Scr. Metall., vol. 13, no. 1, pp. 65-66, Jan. 1979.

[33] W. B. Jackson, N. M. Johnson, C. C. Tsai, I. W. Wu, A. Chiang, and D. Smith, "Hydrogen diffusion in polycrystalline silicon thin films," Appl. Phys. Lett., vol. 61, no. 14, pp. 1670-1672, Oct. 1992.

[34] D. E. Carlson and C. W. Magee, "A SIMS analysis of deuterium diffusion in hydrogenated amorphous silicon," Appl. Phys. Lett., vol. 33, no. 1, pp. 8183, Jul. 1978.

[35] L. G. Earwaker, D. K. Ross, J. P. G. Farr, and J. L. Cheetham, "The influence on hydrogen premeation through steel of surface oxide layers and their characterisation using nuclear reactions," IEEE Trans. Nucl. Sci., vol. 28, no. 2, pp. 1848-1850, 1981. 
[36] E. Fromm and H. Uchida, "Surface phenomena in hydrogen absorption kinetics of metals and intermetallic compounds," J. Less Common Met., vol. 131, no. 1-2, pp. 1-12, Mar. 1987.

[37] T. Norby, M. Widerøe, R. Glöckner, and Y. Larring, "Hydrogen in oxides," Dalt. Trans., no. 19, pp. 3012-3018, Oct. 2004. 



\section{Summary}

The ability of hydrogen to dissolve and diffuse in solid materials causes accelerated material wear and decreased robustness. In many applications hydrogen induced embrittlement determines the lifetime of hardware components that operate in direct contact with hydrogen gas. Examples of such applications are thermonuclear reactors, hydrogen storage and extreme ultraviolet lithography equipment. In addition, hydrogen induced embrittlement can also play a role in components exposed to hydrogen species generated by corrosion processes, like, for instance, in aircraft components. Hydrogen permeation into such components can be mitigated in several ways. For instance, metal alloying can be applied in order to reduce the hydrogen solubility. Alternatively, a protective film can be added that acts as a diffusion barrier between the component and the hydrogen environment. Such a barrier is beneficial when a component has a complex structure that is crucial for its functionality and, therefore, cannot be altered.

The choice of material for an optimal protective film will depend on the particular application. An easily accessible and preferably low cost technique for comparison of the hydrogen permeation in candidate barrier layers is needed to efficiently search for an effective material. Hydrogen permeation in materials strongly depends on its chemical interaction with hydrogen, its structure (which is defined by the material fabrication method), its geometrical form and any processing steps. Therefore, the availability of a technique to measure hydrogen transport across thin films of prospective barrier materials is very desirable.

In this work, an optical sensor for hydrogen diffusion in thin metal and non-metal films was proposed and the relevant physical processes regarding the fabrication and use of such a sensor were investigated. This knowledge was applied for measuring and comparing hydrogen diffusion through a range of potential barrier materials and reference materials. A Y thin film was used as the sensor layer, onto which a test layer, of which the diffusion properties are to be measured, was deposited. The dielectric function of the sensor film changes upon hydrogen absorption, which 
was monitored with spectroscopic ellipsometry or optical transmission. The design was optimized to enable comparison of hydrogen permeability in different materials. The work in this thesis resulted in, to our knowledge, the first quantitative measurements of the hydrogen diffusion constant in Ru. Furthermore, the knowledge was applied to design a layer stack that allows a reliable comparison of hydrogen diffusion kinetics in various barrier layers with low hydrogen diffusion constants.

First, an ellipsometric model was developed to quantify the ratio of the hydride phases $\mathrm{YH}_{2}$ and $\mathrm{YH}_{3}$ in a $\mathrm{Y}$ film, from which the absorbed amount of hydrogen can be determined. A ruthenium test layer was used for this case, since it allows stable $\mathrm{YH}_{2}$ and $\mathrm{YH}_{3}$ phases to form, even when the sample is exposed to atmosphere after hydrogen exposure. For calibration purposes, a study of structural changes in the $\mathrm{Y}$ film during hydrogenation was conducted with in situ and ex situ X-ray diffraction. The two consecutive transitions, $\mathrm{Y}$ to $\mathrm{YH}_{2}$ and $\mathrm{YH}_{2}$ to $\mathrm{YH}_{3}$, were fitted with two ellipsometric models. The transition from $\mathrm{Y}$ to $\mathrm{YH}_{2}$ could be accurately modelled with an effective medium approximation, while the transition from $\mathrm{YH}_{2}$ to $\mathrm{YH}_{3}$ could not be accurately fit with an ellipsometric model due to the presence of a plasmon resonance. The formation of the $\mathrm{YH}_{2}$ phase could be accurately determined from a peak in the ellipsometric angle $\Psi$ for a large range of wavelengths, which facilitates the use of ellipsometry for hydrogen diffusion measurements.

The uptake and diffusion of hydrogen in a sensor film covered by a test layer may be limited by diffusion processes in the thin films, or by surface or interface processes. In order to learn to what extent the test layer determines the hydrogen uptake and saturation level in the Y film, hydrogenation of samples was compared for several metal test layers (Ru, $\mathrm{Pd}, \mathrm{Ag}, \mathrm{Ta}$, and also a $\mathrm{Pd} / \mathrm{Ru}$ bilayer). Samples with different test layers that were hydrogenated with atomic hydrogen under the same conditions, showed the formation of different $\mathrm{Y}$ hydride phases $\left(\mathrm{YH}_{2}\right.$ or $\left.\mathrm{YH}_{3}\right)$, or even the absence of a measurable hydrogen uptake. The apparent stability or instability of $\mathrm{YH}_{3}$ is, in the case of thin films, governed by the desorption temperature of hydrogen from the capping layer surface. For measuring hydrogen transport through test layers, the influence of differences in absorption and desorption kinetics of hydrogen on the surface of the sensor sample should be mitigated. Therefore, all test layers were coated with a Pd capping layer, which has fast hydrogen uptake kinetics.

To check the feasibility of a Y-based hydrogen sensor for measurements of hydrogen transport in materials with low $\mathrm{H}$ permeability, hydrogen diffusion through $\mathrm{Ru}$ films was quantified using hydrogenography. With this technique, the optical transmittance of a $\mathrm{Pd} / \mathrm{Ru} / \mathrm{Y}$ multilayer stack (deposited on a transparent substrate) was 
monitored during exposure to hydrogen molecular gas. The combined effects of the promotion of $\mathrm{H}_{2}$ dissociation by a $\mathrm{Pd}$ cap and slow permeation of atomic $\mathrm{H}$ in the $\mathrm{Ru}$ layer, compared to $\mathrm{Pd}$ and $\mathrm{Y}$, enabled a direct measurement of the hydrogen diffusion rate through $\mathrm{Ru}$. From temperature dependent measurements, the activation energy of hydrogen diffusion was determined in the temperature range between room temperature and $100{ }^{\circ} \mathrm{C}$.

In addition, the $\mathrm{Y}$-based sensor was tested with a range of test materials, including metals ( $\mathrm{Ru}, \mathrm{Al}, \mathrm{Ag}, \mathrm{Mo}, \mathrm{Cu}), \mathrm{Si}$ and oxides $\left(\mathrm{SiO}_{2}\right.$ and $\left.\mathrm{Al}_{2} \mathrm{O}_{3}\right)$. Hydrogen diffusion kinetics were derived by exposing samples with different test layer thicknesses to atomic hydrogen, monitoring the time required for the $\mathrm{Y}$ to $\mathrm{YH}_{2}$ transition. When the hydrogenation time increased with layer thickness, it could be concluded that the observed hydrogenation kinetics is limited by diffusion through the test material. This provided means to exclude that the hydrogenation kinetics was limited by surface or interface processes, or diffusion through the $Y$ film or cap layer. The hydrogenation time (which is inversely proportional to the diffusion constant) roughly scaled with the heat of solution of $\mathrm{H}$ in the test material. The heat of solution denotes the heat released during hydrogen solution in a solid at infinite dilution. This scaling is indicating that the heat of solution can serve as a first indicator for the speed of hydrogen transport through a layer of a certain material. When comparing the hydrogen diffusion constants from this study to values reported in literature, it was found that the reported literature values scatter over orders of magnitudes for a single material, depending on the specimen form and the type of diffusion measurement. This stresses the importance of the sensing approach developed for this thesis, where different materials in the form of thin films can be investigated under identical conditions. 



\section{Samenvatting}

Waterstof kan gemakkelijk oplossen en diffunderen in veel vaste stoffen, wat versnelde degradatie en een verlaagde betrouwbaarheid van materialen tot gevolg kan hebben. Bij veel toepassingen waarbij materialen of componenten in direct contact met waterstofgas gebruikt worden, is waterstofgeïnduceerde verbrossing bepalend voor de levensduur. Voorbeelden van dit soort toepassingen zijn thermonucleaire reactoren, waterstofopslag en apparatuur voor extreem UV lithografie. Daarnaast kan waterstofgeïnduceerde verbrossing ook optreden bij componenten die blootgesteld worden aan waterstof dat gegenereerd wordt bij corrosieprocessen, wat bijvoorbeeld waargenomen is bij vliegtuigonderdelen. Er bestaan verscheidene methoden ter preventie van permeatie van waterstof in dergelijke componenten. Een metaal kan bijvoorbeeld vervangen worden door een legering met lagere oplosbaarheid voor waterstof. Een alternatief is het aanbrengen van een beschermende film die werkt als diffusiebarrière tussen de component en de waterstofomgeving. Een dergelijke barrière is met name gunstig wanneer een component een complexe structuur heeft die noodzakelijk is voor zijn functionaliteit en daarom niet kan worden veranderd.

De materiaalkeuze voor een optimaal beschermende film zal afhangen van de specifieke toepassing. Om verschillende kandidaat-barrièrematerialen te vergelijken, is het noodzakelijk eenvoudig toegang te hebben tot een techniek waarmee, bij voorkeur tegen lage kosten, de waterstofpermeabiliteit in materialen gemeten kan worden. De waterstofpermeabiliteit in materialen is sterk afhankelijk van de chemische interactie van een materiaal met waterstof, de structuur (die weer afhangt van de fabricagemethode), de geometrische vorm en eventuele behandelingen. Het is daarom gewenst om een techniek te hebben waarmee waterstoftransport door dunne films van kandidaat-barrièrematerialen kan worden gemeten.

Dit onderzoek richt zich op een optische sensor voor het meten van waterstofdiffusie in dunne films van metalen en niet-metalen. De relevante fysische processen voor het maken en gebruiken van een dergelijke sensor zijn onderzocht. Deze kennis is 
vervolgens gebruikt om de waterstofdiffusie in diverse kandidaat-barrièrematerialen en referentiematerialen te meten en vergelijken. Een dunne $\mathrm{Y}$ film is gebruikt als sensorlaag. Op deze laag is een testlaag, waarvan de waterstofdiffusie gemeten moest worden, gedeponeerd. De diëlektrische functie van de sensorlaag verandert bij absorptie van waterstof, wat gemeten kan worden met spectroscopische ellipsometrie of optische transmissie. Het ontwerp is geoptimaliseerd om de vergelijking van waterstofpermeabiliteit in verschillende materialen mogelijk te maken. Het onderzoek in dit proefschrift beschrijft, voor zover bekend, de eerste kwantitatieve metingen van de diffusieconstante voor waterstof in $\mathrm{Ru}$. De kennis over relevante fysische processen is gebruikt om een stapeling van lagen te ontwikkelen die het toestaat om op betrouwbare wijze de kinetica van waterstofdiffusie in diverse barrièrelagen met lage waterstofdiffusieconstanten te vergelijken.

Allereerst is een ellipsometriemodel ontwikkeld om de concentratie van de hydridefases $\mathrm{YH}_{2}$ en $\mathrm{YH}_{3}$ in een $\mathrm{Y}$ film te kwantificeren, zodat hieruit de hoeveelheid waterstof gemeten kan worden. Voor deze metingen is een $\mathrm{Ru}$ testlaag gebruikt, omdat hiermee stabiele $\mathrm{YH}_{2}$ en $\mathrm{YH}_{3}$ fases gevormd kunnen worden, zelfs wanneer een monster na blootstelling aan waterstof wordt blootgesteld aan atmosferische omstandigheden. Ter ijking van de ellipsometriemetingen, zijn de structurele veranderingen in de $\mathrm{Y}$ film tijdens en na waterstofabsorptie gemeten met in situ en ex situ röntgendiffractie. De twee opeenvolgende overgangen, $\mathrm{Y}$ naar $\mathrm{YH}_{2}$ en $\mathrm{YH}_{2}$ naar $\mathrm{YH}_{3}$ zijn gefit met twee ellipsometriemodellen. De overgang van $\mathrm{Y}$ naar $\mathrm{YH}_{2}$ kan nauwkeurig gemodelleerd worden met een effectief-mediumbenadering. De overgang van $\mathrm{YH}_{2}$ naar $\mathrm{YH}_{3}$ kan echter niet nauwkeurig gemodelleerd worden, vanwege plasmonresonanties. De vorming van de $\mathrm{YH}_{2}$-fase kan daarnaast nauwkeurig bepaald worden aan de hand een piek in ellipsometriehoek $\Psi$ voor een groot golflengtebereik, wat het eenvoudiger maakt ellipsometrie te gebruiken voor metingen van waterstofdiffusie.

De opname en diffusie van waterstof in een sensorfilm bedekt met een testlaag kan bepaald worden door diffusieprocessen in de dunne films, maar ook door processen aan oppervlakken of grenslagen. Om te leren in welke mate de testlaag bepalend is voor de opname en verzadiging van waterstof in de Y film, is de waterstofopname van monsters met verschillende testlagen ( $\mathrm{Ru}, \mathrm{Pd}, \mathrm{Ag}$, Ta en een $\mathrm{Pd} / \mathrm{Ru}$ bilaag) vergeleken. Deze monsters zijn blootgesteld aan atomair waterstof onder gelijke omstandigheden en vertoonden daarbij vorming van verschillende hydridefases $\left(\mathrm{YH}_{2}\right.$ of $\mathrm{YH}_{3}$ ) of zelfs de afwezigheid van meetbare waterstofabsorptie. Op deze wijze is aangetoond dat voor deze dunne films, de schijnbare stabiliteit of instabiliteit van $\mathrm{YH}_{3}$ bepaald wordt door de desorptietemperatuur van waterstof van het oppervlak 
van de toplaag. Voor het meten van waterstoftransport door een testlaag, is het van belang dat de invloed van verschillen in absorptie- en desorptiekinetiek van waterstof op het oppervlak van het monster zoveel mogelijk beperkt wordt. Daarom is er voor gekozen om alle testlagen te bedekken met een Pd toplaag, vanwege de snelle waterstofabsorptie in dit materiaal.

Om de mogelijkheid van een op Y gebaseerde sensor voor metingen van waterstoftransport in materialen met een lage waterstofpermeabiliteit te testen, is de waterstofdiffusie door Ru films gekwantificeerd met zgn. waterstofgrafie. Bij deze techniek wordt de optische transmissie van een $\mathrm{Pd} / \mathrm{Ru} / \mathrm{Y}$ trilaag (gedeponeerd op een transparant substraat) gemeten tijdens blootstelling aan moleculair waterstofgas. Aangezien de Pd toplaag de dissociatie en opname van $\mathrm{H}_{2}$ bevordert, en daarnaast de permeatie van $\mathrm{H}$ atomen door de $\mathrm{Ru}$ film langzaam is in vergelijking met diffusie in Pd en Y, kan op deze wijze de waterstofdiffusie door Ru direct afgeleid worden. Uit temperatuurafhankelijke metingen is de activeringsenergie voor waterstofdiffusie bepaald in het temperatuurbereik tussen kamertemperatuur en $100{ }^{\circ} \mathrm{C}$.

De op $\mathrm{Y}$ gebaseerde sensor is verder gebruikt met testlagen van diverse metalen ( $\mathrm{Ru}, \mathrm{Al}, \mathrm{Ag}, \mathrm{Mo}, \mathrm{Cu})$, $\mathrm{Si}$ en oxides $\left(\mathrm{SiO}_{2}\right.$ en $\left.\mathrm{Al}_{2} \mathrm{O}_{3}\right)$. De diffusiekinetica van waterstof is afgeleid door monsters met testlagen van verschillende dikte bloot te stellen aan atomaire waterstof en daarbij de tijd van de overgang van $\mathrm{Y}$ naar $\mathrm{YH}_{2}$ te meten. Wanneer deze tijd toeneemt met toenemende laagdikte, kan hieruit geconcludeerd worden dat de waterstofdiffusie door de testlaag de beperkende factor is voor algehele diffusiekinetica. Op deze wijze kan uitgesloten worden dat de gemeten diffusietijd bepaald wordt door oppervlakte- of grenslaagprocessen, of diffusie door de Y film of toplaag. De benodigde tijd voor waterstofopname (die omgekeerd evenredig is met de diffusieconstante) schaalt ruwweg met de oplossingsenthalpie van waterstof in het testmateriaal. Hierbij staat de oplossingsenthalpie voor de warmte die vrijkomt bij het oplossen van een waterstofatoom in een materiaal bij oneindige verdunning. Deze schaling duidt aan dat de oplossingsenthalpie een eerste indicator kan zijn om de snelheid van waterstoftransport door een materiaal te schatten. Bij het vergelijken van de in dit onderzoek gemeten waterstofdiffusieconstanten met literatuurwaardes, is vastgesteld dat literatuurwaardes voor waterstofdiffusie in hetzelfde materiaal een spreiding vertonen tot vele ordes van grootte, afhankelijk van de vorm van het gemeten monster en de methode van de diffusiemeting. Dit benadrukt het belang van de methodologie die in dit onderzoek ontwikkeld is, waarbij verschillende materialen in de vorm van dunne films onder identieke condities vergeleken kunnen worden. 



\section{Acknowledgements}

Completion of this dissertation took a lot of perseverance and would not have been possible without help of many people. First of all, I want to thank my promotor Fred Bijkerk for giving the opportunity to conduct the $\mathrm{PhD}$ research as a member of his group. Thank you for motivating me throughout the years of my study.

During my PhD study, I was fortunate to have two daily supervisors. I would like to express gratitude to Marko Sturm for being my supervisor for the last two years of my study. Thank you for your full support with arranging experiments, doing measurements, for helping to find the way forward in, what it seemed to me, deadend situations.

My deep appreciation goes to my initial daily supervisor Chris Lee. Thank you for valuable discussions and brilliant ideas, which always kept me motivated. This thesis would not see the world without your guidance and insights.

I would also like to thank all members of our group's staff for their support, especially Robbert, for fruitful discussions and support with XRD measurements, and Igor, for making possible our measurements in ESRF and his support during the beamtime. Many thanks go to Sergey Yakunin for his help and support at the beamline. I want to thank our technical staff, especially Theo, for his help with preparation of my numerous samples, and Koen, for his support with setup issues. I am thankful to Carin and Jacqueline for their support with all administration issues.

I am very grateful to Wim van der Zande for his support at ASML and Edgar Osorio for useful discussions and his help with experimental setup. Especially I want to thank John de Kuster, Goran Milinkovic and Luc Stevens for their technical support. Without you, I would not have been able to keep my setup functional.

I would like to thank Bernard Dam for the opportunity to conduct the experiment in his lab. At TU Delft, I am especially grateful to Herman Schreuders, a master of the 
hydrogenography setup. Thank you for your help with measurements and data analysis. Also, my thanks go to Steffen, Joost and Lars for interesting discussions.

I am very lucky to have worked in a friendly and supportive team of PhD students. I thank Małgorzata and Baibhav for all the fun we had, as well as my other colleagues Rogier, Feng, Sasha, and Maria.

The coffee break chat is a very important part of a workflow. I would like to thank all my colleagues whom I have chatted with over a cup of coffee, especially Ani, Parikshit, Cristiane and Igor.

Many thanks go to Daria Sharykina for making the cover design of this thesis.

I am fortunate to have Nadiia and Gabriele as my dearest friends. These $\mathrm{PhD}$ years would not have been the same without our visits in Leuven and Dresden.

My full appreciation goes to all my friends in Ukraine, especially to Victoria and Yulia.

My deepest gratitude goes to my husband Pavlo for his constant support during these $\mathrm{PhD}$ years. Thank you for your patience while I was working late hours in the lab and going to business trips.

I would also like to thank my family. Дорогі мої мама i брат, дякую за вашу підтримку і віру в мене, особливо у скрутні моменти на моєму життєвому шляху!

Separately I would like to acknowledge my grandmother, who lived not long enough to see my graduation. She always encouraged me to follow my curiosity and supported my enthusiasm in all things. At the same time, she taught me perseverance for completing my tasks even when enthusiasm left me. Thank you for everything!

Olena Soroka

Eindhoven

October 2020 


\section{About the author}

Olena Soroka was born on 30th of June 1989 in Chernihiv, Ukrainian SSR, Soviet Union. She moved to Kyiv in 2006 to start her study at faculty of Radiophysics of Taras Shevchenko National University. During her Bachelor study, she joined the department of cryogenic and microelectronics, which was reorganized into the department of nanophysics and nanoelectronics in 2011. She obtained her Bachelor degree in Applied Physics in 2010 and pursued the Master degree in 2012 in the same department. During her Master study, she went on an exchange program at University of Konstanz, Germany and worked with dynamic light scattering by colloidal suspensions at the Soft Matter Physics Group. From 2012 until 2015, she worked as a postgraduate researcher at the department of Polariton Optoelectronics of V.E. Lashkaryov Institute of Semiconductor Physics NAS of Ukraine. In 2015, she started her PhD study in Industrial Focus Group XUV Optics of University of Twente and worked in close collaboration with ASML Research. The PhD project was a part of an NWO research program supported by Carl Zeiss SMT GmbH. While finalizing her thesis, she started a job at ASML as a design engineer in 2020. 